\title{
Antioxidant and antiapoptotic properties of oat bran protein hydrolysates in AAPH-induced oxidative stress hepatocarcinoma HepG2
}

By

\author{
Ramak Esfandi
}

A thesis submitted to the Faculty of Graduate and Postdoctoral Affairs in partial fulfillment of the requirements for the degree of

Masters of Science

In

Chemistry

(Specialization in Food Science and Nutrition)

Carleton University

Ottawa, Ontario, Canada

(C) 2017

Ramak Esfandi 


\section{Abstract}

The onset of many chronic diseases such as cancer, carcinogenesis, cardiovascular disease, and several other health problems, involves oxidative stress damage to biomolecules such as DNA, lipid, and proteins. There have been many preventative and therapeutic methods proposed to increase cellular defense mechanisms against oxidative damage such as using bioactive peptide with antioxidant activities from food sources. This study found that AAPH-induced oxidative stress in human hepatocarcinoma HepG2 cells caused changes in cellular morphological features and functionalities such as cell viability, activity of antioxidative enzymes (catalase (CAT), glutathione peroxidase (GPx), and superoxide dismutase (SOD)), production of reactive oxygen species (ROS), and rate of apoptosis. The use of oat bran protein hydrolysates restored some of the properties to normal values (i.e., control cells). In this work, oat brans were treated with two carbohydrases (Cellulase ${ }^{\circledR}$ (Cell) and viscozyme ${ }^{\circledR} \mathrm{L}$ (Visc) which cleave cell wall polysaccharides and produce oat bran protein isolates (OBPIs) with protein contents. OBPI was subsequently treated with proteases Alcalase (Alca), Flavourzyme ${ }^{\circledR}$ (Flav), Papain (Papa) and Protamex (Prot) to produce four oat bran protein hydrolysates (OBPHs) from each of oat bran protein isolate (OBPIs). Antioxidative effects of both the two OBPI and four OBPH samples were studied in chemistry and HepG2 cell cultures assays. In the chemistry assays the antioxidative activities were determined using oxygen radical absorbance capacity (ORAC), 2,2'-azino-bis (3ethylbenzothiazoline-6-sulphonic acid) or $\mathrm{ABTS}^{\bullet+}$, radical, hydroxyl $\left({ }^{\bullet} \mathrm{OH}\right)$, and superoxide anion $\left(\mathrm{O}_{2}{ }^{\bullet-}\right)$ radical scavenging assays. Data from oxygen radical absorbance capacity (ORAC) and 2,2'azino-bis (3-ethylbenzothiazoline-6-sulphonic acid) (ABTS ${ }^{\bullet+}$ ) assays were expressed as Trolox (a water-soluble vitamin $E$ analogue) equivalent per gram (TE/g) of the sample followed the same pattern. The highest ORAC activities were observed in Cell/Papa (417.0 $\pm 5.1 \mathrm{TE} / \mathrm{g}$ ), Visc/Flav $(406.0 \pm 8.8 \mathrm{TE} / \mathrm{g})$ and Visc/Papa $(397.0 \pm 13.9 \mathrm{TE} / \mathrm{g})$ while in the $\mathrm{ABTS}{ }^{\bullet+}$, highest scavenging samples were Visc/Flav and Visc/Papa (863.80 \pm 20.3 and $814.8 \pm 17.2$ TE/g respectively). In the hydroxyl radical scavenging assay, Cellulase and Viscozyme OBPIs significantly prevented the formation of ${ }^{\circ} \mathrm{OH}$, radicals $38.5 \pm 0.8$ and $36.0 \pm 0.4 \%$, respectively compared to all hydrolysates. 
Superoxide anion radical scavenging activity was the highest in samples Visc/Alca and Cell/Prot both at $37.3 \pm 0.9 \%$. SDS-PAGE results indicated that globulin ( $58 \mathrm{kDa}$ ) was the main protein in OPBIs and those hydrolysates did not contain protein or fragments above $15 \mathrm{kDa}$. Cytotoxicity of OBPIs and OBPHs, their ability to reduce intracellular reactive oxygen species (ROS), and regulate the activity of three main antioxidant enzymes were evaluated in the AAPH-induced oxidative stress of HepG2 cells. Cytotoxic effect OBPH was evaluated using Visc/Flav ND at 50 $400 \mu \mathrm{g} / \mathrm{mL}$. No cytotoxicity was observed in MTT (3-(4,5-Dimethylthiazol-2-yl)-2,5Diphenyltetrazolium Bromide) assay. In the cytoprotection assay, Viscozyme and all its OBPHs derivatives were able to increase cell viability significantly compared to stressed control HepG2 cells. However, Cellulase OBPI and its OBPHs derivatives enhanced cell HepG2 cell death, except for Cell/Flav OBPH which had no effect. OBPHs from Viscozyme treated brans and Cell/Flav OBPH were then chosen for investigation of their effects on antioxidant enzymes. In the Catalase (CAT) assay, all samples increased enzyme activity $(p<0.05)$ in AAPH-stressed cells, with Visc/Papa being the highest at $352.0 \%$. In superoxide dismutase (SOD), all samples increased activity level above positive control (POS) with Visc/Flav performing significantly better than the other samples. Visc/Flav not only restored glutathione peroxidase (GPx) activity to that of negative control (NEG) (i.e., unstressed cells), it also reduced the most intracellular reactive oxygen species (ROS). Total glutathione (GSH) increased up to 6-fold in the presence of OBPH in stressed HepG2 cells. In the Caspase-3 assay for anti-apoptosis properties, samples reduced caspase-3 significantly compared to AAPH-induced oxidative stress in HepG2 cells. OBPH protected HepG2 cells from oxidative stress due to a combination of factors including radical scavenging activity, upregulation of antioxidant enzymes, and inhibition of the activity of the apoptotic enzyme caspase-3. 


\section{DEDICATION}

I would like to dedicate this work to my family for their constant support and encouragements. 


\section{ACKNOWLEDGEMENTS}

I would like to sincerely acknowledge my supervisor Dr. Apollinaire Tsopmo for his direction, motivation, patience, and mentorship throughout this project.

I would like to thank Dr. William Willmore for co-supervising this work and his insight and valuable field experience.

A special recognition to my friends Mallory, Nikki, Rowida, and Shana for all the technical and non-technical support.

I'd like to thank all members of the Food Science and Nutrition and Biology labs, especially Dr. Hosseinian for their teachings and guidance throughout my graduate studies.

A special thanks to Chantelle Gravelle for her guidance, advice, and administrative assistance.

I lastly want to thank my friends and family for supporting and encouraging me to chase my dream. Without them, I would not be able to do this and will be forever grateful to them. 


\section{Contents}

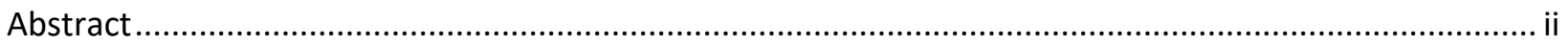

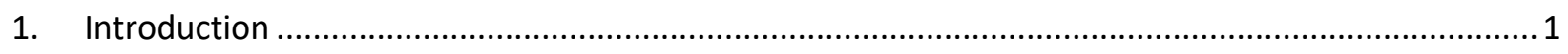

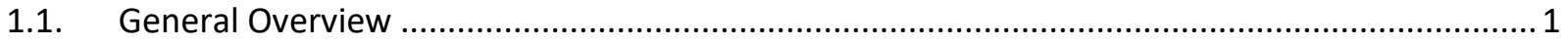

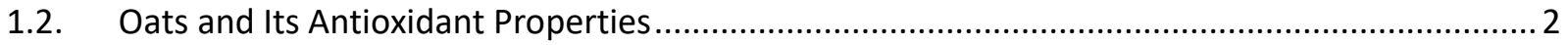

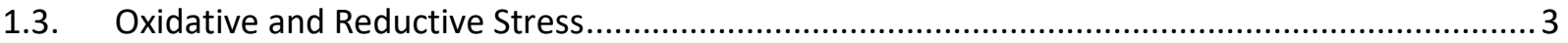

1.4. Oxidants and Free Radicals in Biological Systems .............................................................. 5

1.5. Oxidant and Free Radical Damage to Biomolecule ..................................................................... 7

1.6. Antioxidants and Defense Mechanisms against Oxidation.....................................................11

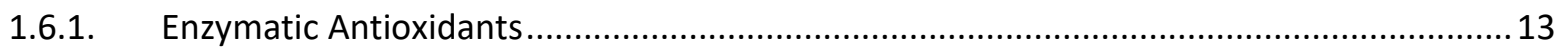

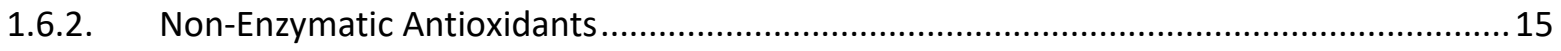

1.6.3. Food Derived Protein Hydrolysates and Bioactive Peptides as Antioxidants ....................18

1.7. Liver HepG2 and Oxidative Stress and the Antioxidants ...................................................... 21

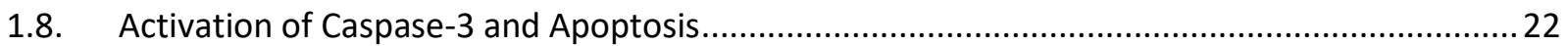

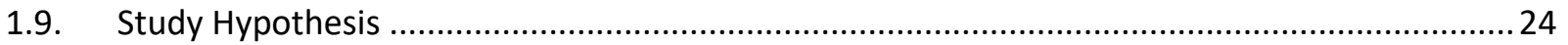

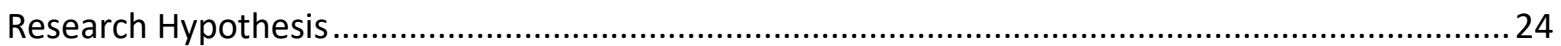

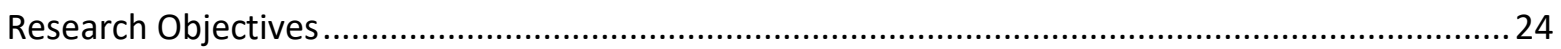

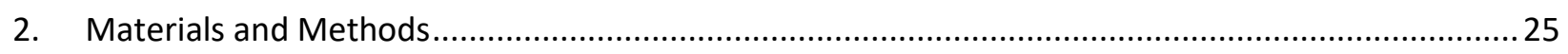

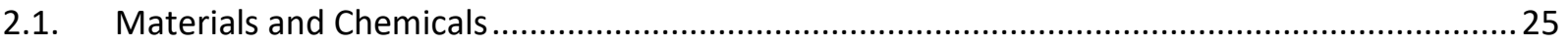

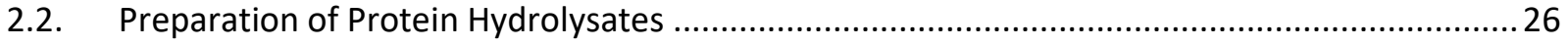

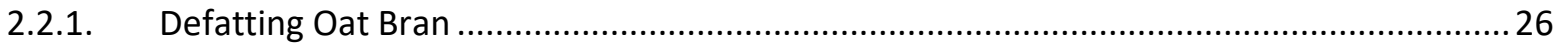

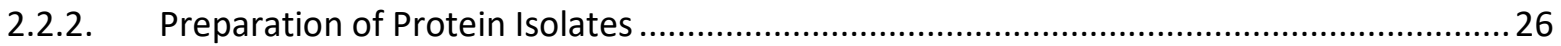

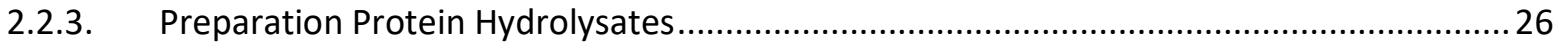

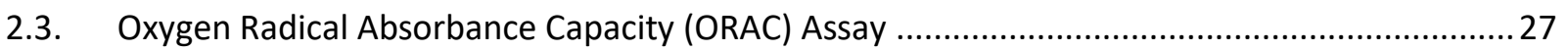

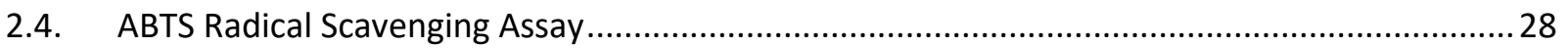

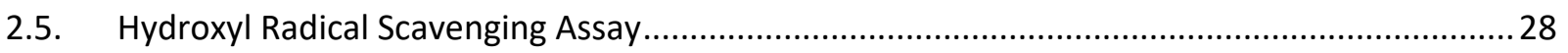

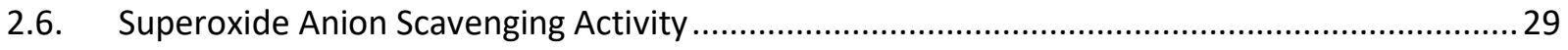

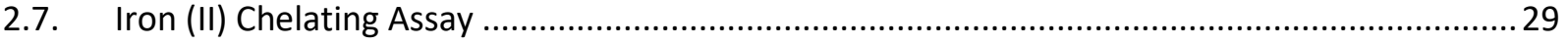

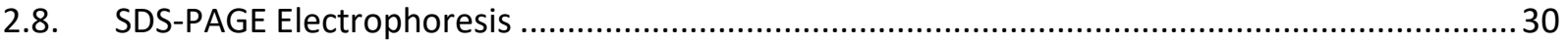

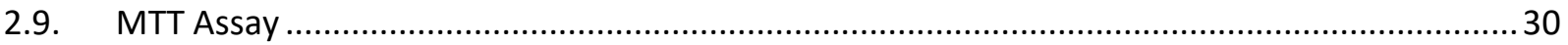

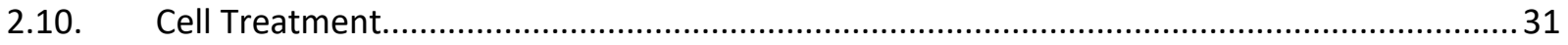

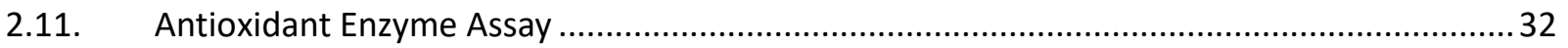

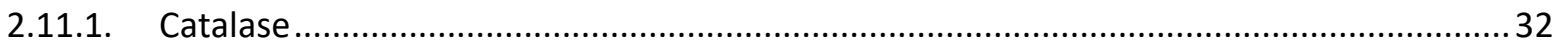




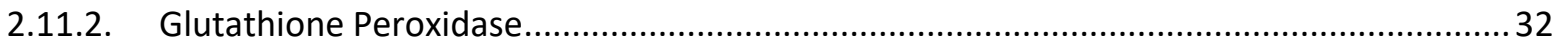

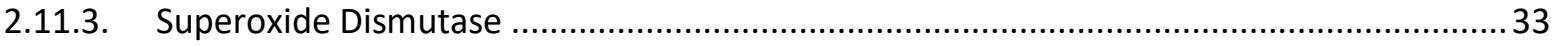

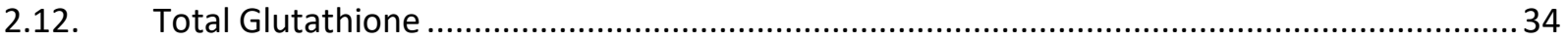

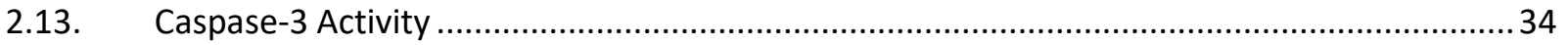

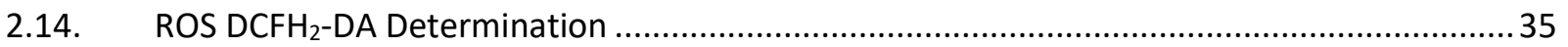

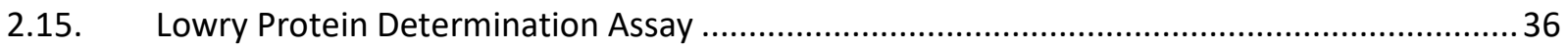

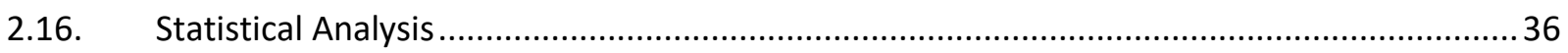

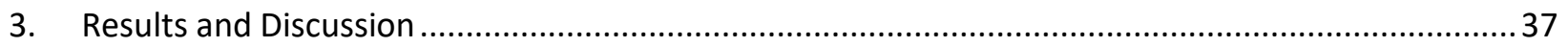

3.1. Hydrolysis of Proteins and Characterization of Protein Isolates and Hydrolysates....................37

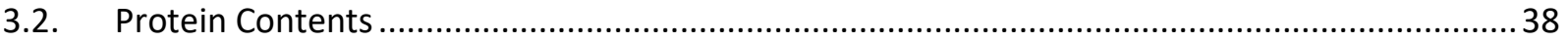

3.3. Molecular Weight Determination by SDS-PAGE Gel Electrophoresis...................................... 40

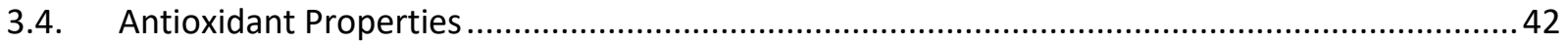

3.4.1. Oxygen Radical Absorbance Capacity (ORAC) ............................................................... 42

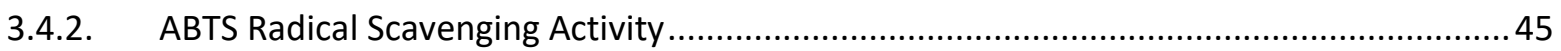

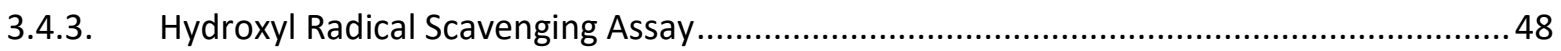

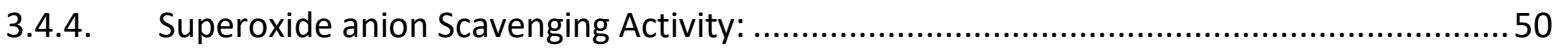

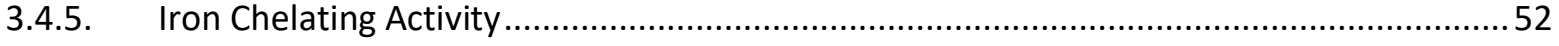

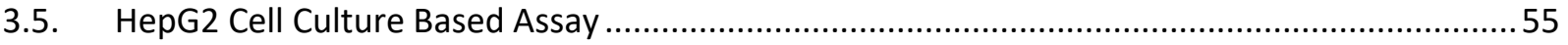

3.5.1. MTT Cytotoxicity and Cytoprotective Activity of OBPI and OBPH ................................55

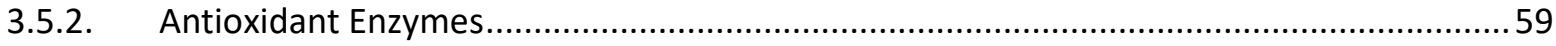

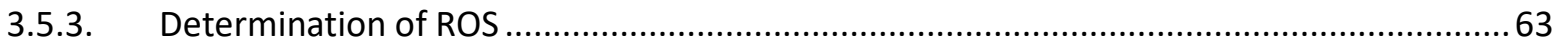

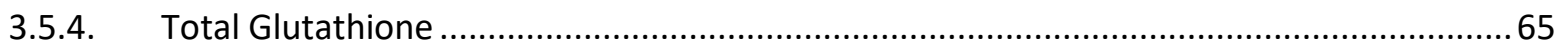

3.5.5. Caspase-3 Determination and Cell Apoptosis..............................................................68

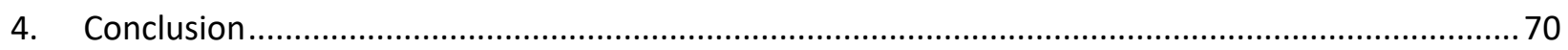

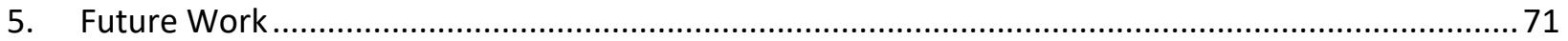




\section{LIST OF FIGURES:}

Figure 1. Origin of free radicals and oxidants ......................................................................... 7

Figure 2. Oxidative stress stages induced in lipid biomolecule ............................................... 8

Figure 3. Oxidative stress induced in protein backbone ....................................................... 9

Figure 4. Oxidation of guanine and transversion of GC to either TA or CG........................... 11

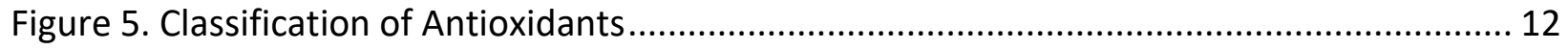

Figure 6. Intracellular antioxidant enzyme system.......................................................... 13

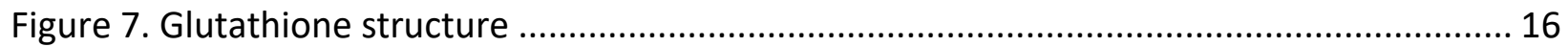

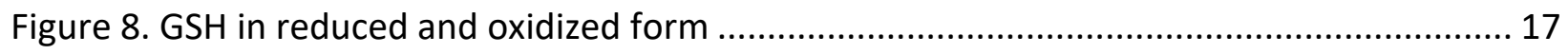

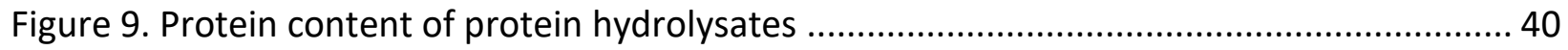

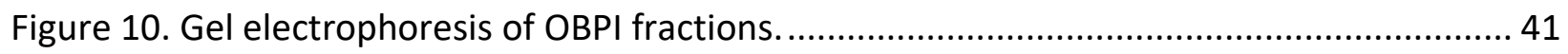

Figure 11. Oxygen radical absorbance capacity (ORAC) .................................................... 43

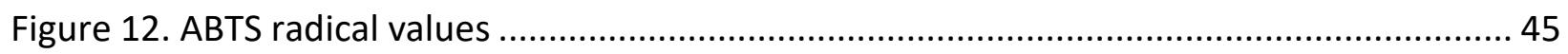

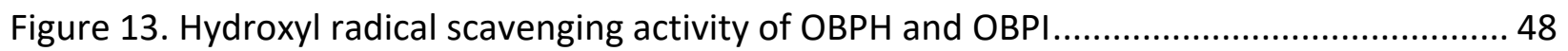

Figure 14. Superoxide radical scavenging activity of OBPH and OBPI................................... 51

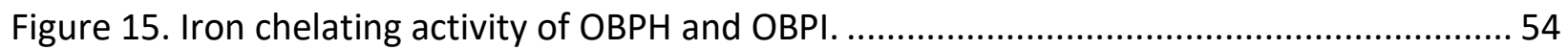

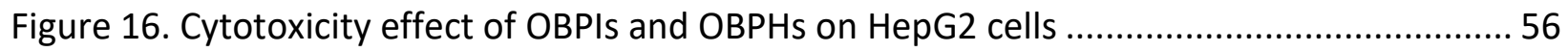

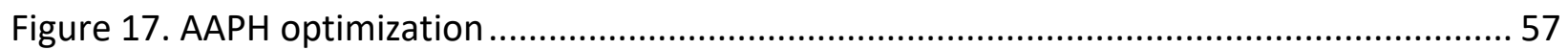

Figure 18. Cytoprotective effect of OBPIs and OBPHs on HepG2 cells .................................. 58

Figure 19. Changes in antioxidant enzyme activity in selected OBPHs ................................... 61

Figure 20. AAPH optimization to evaluate maximum ROS production .................................... 63

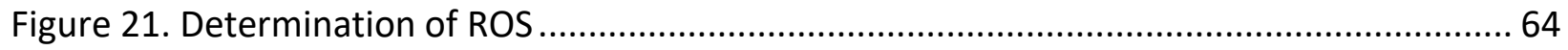

Figure 22. Total Glutathione change responses due to AAPH-induced oxidative stress in HepG2

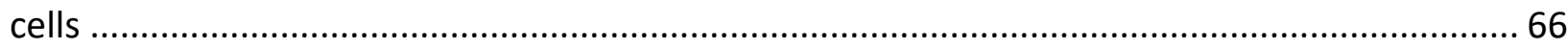

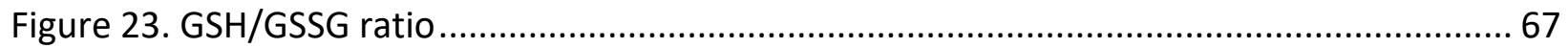

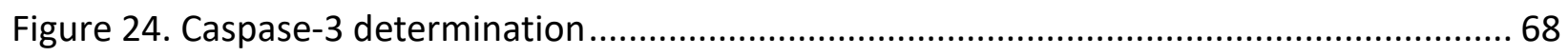




\section{LIST OF TABLES:}

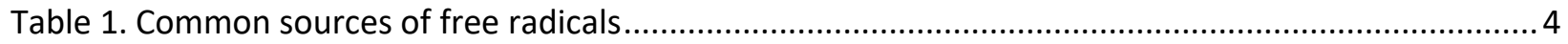

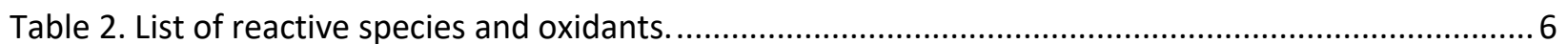

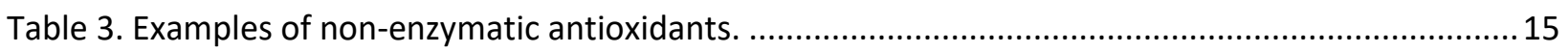

Table 4. List of proteases with condition used for each enzyme.........................................................27 


\section{LIST OF ABBREVIATION}

\begin{tabular}{|c|c|}
\hline AAPH & 2,2'-Azobis-2-methyl-propanimidamide dihydrochloride \\
\hline ABTS & 2,2'-Azinobis (3-ethylbenzothiazoline-6- sulphonic acid) \\
\hline $\operatorname{Arg}$ & Arginine \\
\hline Asp & Aspartic acid \\
\hline AUC & Area under the curve \\
\hline CAT & Catalase \\
\hline Cys & Cysteine \\
\hline $\mathrm{D}$ & Dialyzed \\
\hline DCFH-DA & $2^{\prime}, 7^{\prime}$-Dichlorofluorescin diacetate \\
\hline DNA & Deoxyribonucleic acid \\
\hline ET & Electron transfer \\
\hline GSH & Reduced glutathione \\
\hline GPx & Glutathione peroxidase \\
\hline Gln & Glutamine \\
\hline Glu & Glutamic acid \\
\hline Gly & Glycine \\
\hline GSSG & Oxidized glutathione \\
\hline HAT & Hydrogen atom transfer \\
\hline HEK-293 & Human embryonic kidney 293 \\
\hline HepG2 & Human hepatocarcinoma \\
\hline His & Histidine \\
\hline$\cdot \mathrm{OH}$ & Hydroxyl radical \\
\hline $\mathrm{H}_{2} \mathrm{O}_{2}$ & Hydrogen peroxide \\
\hline Ile & Isoleucine \\
\hline Leu & Leucine \\
\hline LMW & Low molecular weight \\
\hline Lys & Lysine \\
\hline
\end{tabular}




\begin{tabular}{ll} 
Met & Methionine \\
MTT & 3-(4,5-Dimethylthiazol-2-yl)-2,5-diphenyltetrazolium bromide \\
NO & Non-dialyzed \\
OBPH & Nitric oxide \\
OBPI & Oat bran protein hydrolysate \\
ORAC & Oat bran protein isolates \\
PCD & Oxygen radical absorbance capacity assay \\
Phe & Programmed cell death \\
Pro & Phenylalanine \\
RNA & Proline \\
ROO & Ribonucleic acid \\
ROS & Peroxyl radical \\
RP-HPLC & Reactive oxygen species \\
Ser & Reverse phase-high performance liquid chromatography \\
SOD & Throonine \\
O ${ }^{\bullet-}$ & Serine \\
TE(AC) & Superoxide dismutase \\
Thr & Superoxide radical \\
Trp & Trolox equivalent antioxidant capacity \\
\hline al & Throsine \\
\hline
\end{tabular}




\section{Introduction}

\subsection{General Overview}

The term "oxygen paradox" is used to explain the fact that although aerobic organisms need oxygen for their survival, the very same molecule can be oxidized to a free radical that is toxic when it is produced in excess (i.e. oxidative stress) [1]. A living organism is equipped with defense mechanisms to neutralize free radicals, but there are circumstances where the natural antioxidant defense system is not enough to eliminate excess radicals, hence cause damage to biomolecules [2],[3]. Recent data have shown protein isolates that have been broken down into fragments can serve as a dietary source of antioxidants and other bioactive functions [4].

Proteins are a group of macronutrients critical for normal human body functions such as growth, repair, and maintenance; however, there has been numerous studies showing multiple activities/functionalities of proteins in addition to their basic role as nutrients in the human body and in physiological systems [5]. Proteins and their small building blocks (peptides and amino acids) possess characteristics such as gelling, emulsifying, foaming properties, etc.[6], which make them suitable for diverse applications in different industries. Some of the functions of proteins that have been studied in recent years include their role as antioxidants [7], antiinflammatory [8], anti-diabetic [9], or antihypertensive compounds [10]. Proteins, and often their hydrolysates, work in many cases by scavenging radicals or by regulating many enzymes involve maintaining the redox balance in biological systems. Protein hydrolysates can then serve as natural and economical sources of antioxidants [11]. Even though in normal cell conditions an optimum amount of free radicals are produced as the result of normal cell functions, under certain oxidative stress conditions there are more oxidants produced, which are also known as Reactive Oxygen or Nitrogen Species (ROS or RNS) [12]. In cells, there are different defense mechanisms that can control and neutralize free radicals, but when the production of free radicals increases beyond the ability of the physiological system to neutralize them, they become harmful and disrupt normal cell functions [13]. To protect biological systems, an excess reservoir of natural and dietary antioxidants is helpful to quench free radicals and reduce their destructive effect. Protein hydrolysates and small molecule peptides are proven to possess antioxidant effects and it is possible to isolate them from wide range of sources, e.g. dairy, egg, plant, marine, 
and meat sources [14]. Among these sources, plant based proteins have been attracting many researchers' attention as valuable and safe sources of protein hydrolysates and bioactive peptides to be used as a dietary antioxidants [15]. Among plant-based protein, cereals are the most important source of protein hydrolysates [16]. Oat (Avena sativa) have received substantial attention for their high content of dietary components such as proteins, fibers, phytochemicals and antioxidants [17]. These characteristics make oats and their isolated proteins a potential subject of antioxidant studies.

\subsection{Oats and Its Antioxidant Properties}

Oat is a cereal grain cultivated and consumed worldwide among other major grains such as wheat, rice, maize, barley, sorghum, millet and rye. In Canada and United states, oat is a widely planted crop after the five major grains which are wheat, barley, rapeseed/canola, maize. [18]. Consumption of whole grains is linked to increased health benefits and reduced risks of chronic diseases such as cardiovascular disease, type 2 diabetes, some cancers, and lowering blood cholesterol [19].

Oats primarily are grown to be used as animal feeds, however, due to its nutritional value - high value protein, $\beta$-glucan, antioxidants and polyphenol - it has also find its way in for human consumption over years [20]. Fibers ( $\beta$-glucan), phytochemical, antioxidants are compounds known to have bioactivity properties inside living organism [20]. Oat antioxidants includes a variety of components such as tocols (tocopherols and tocotrienols), avenanthramides, pcoumaric acid; ferulic acid, caffeic acid, vanillin, etc. [21]. Phytochemicals, antioxidants and fibers are not nutritionally essential for humans, but their presence can enhance the health state of the biological system, by preventing for example DNA oxidative damage through various mechanisms [19].

According to the different studies, antioxidants and phytochemicals are mostly located in the grain bran and the concentration of these chemicals can be affected by the environmental and growing conditions [19],[22],[23]. Some of the antioxidant compounds - e.g. phenolic acids - are attached to insoluble fibers, which make them inaccessible when they're consumed. It is possible to enhance their bioavailability by different treatments such as yeast, fermentation, or enzymatic 
hydrolysis. For a component to be bioavailable, it must be absorbed through digestive system and pass through the blood stream and finally the liver system, to exert its effect in a target organ or other tissues. This important concept is required for any bioactive food factor to have any health benefits. Bioavailability depends on many factors such as the concentration, presence in bound or free form, water or fat solubility, absorbability, delivery to the target site or tissues, degree of food processing, etc.[24],[25],[26].

Oats are often consumed as whole grains because bran is not always clearly separated from the seed and, therefore, stays with the germ during dehulling and processing. This makes oats more nutritious compared to other grains[21],[27]. Studies have shown that oats possess a wide variety of bioactive micronutrients such as vitamins, minerals, essential fatty acids, fibers, and phytochemicals such as phenolic acids and avenanthramides [28]. These bioactive compounds can prevent oxidation, cell proliferation, or inflammation, thereby improving health status and reducing the risk of many diseases [29],[30],[31],[32].

Valuable components such as phytochemicals and antioxidants concentrated in oats, particularly those in the outer bran layer may not be readily available for digestion due to bounding of these chemicals to insoluble fibers. Many strategies including enzymatic hydrolysis have been used to separate them and fully evaluate their biological function [33],[34]. However, there is challenges in finding consistent and reliable methods. It, also, is important to elucidate if these compound are capable of being absorbed in the human intestine, and if they can reach the target organ or tissue [35]. Normally, small peptides such as di-or tri-peptides may absorbed intact through intestinal tract, whereas, larger peptides with MW higher than 3000 Da may only be absorbed in certain cases when a proper cellular carrier is present [36].

\subsection{Oxidative and Reductive Stress}

Even though oxygen is a necessity for survival of an aerobic living organism, it can be toxic to the cellular components of the same organism due to production of free radicals [37],[38],[39],[40]. Excessive generation of free radicals and inability of the organism's biological system to neutralize them result in "oxidative stress". Free radicals are chemical atoms or molecules with one or more unpaired electrons in the outer valence shell [2],[41],[42]. In normal state, a 
molecule without unpaired electrons has lower energy and less tendency to react with another molecule. However, under some situations molecules lose electrons and become very unstable with higher energy state, which in turn tend to react with other compounds to gain or lose electrons to reach stability and return to a lower energy state. Free radical formation in biological systems is the result of common cellular activity in response to either endogenous or exogenous stimulant. Common sources of stimulants are listed in Table 1 [43],[44]:

Table 1. Common sources of free radicals

\begin{tabular}{|c|c|}
\hline Exogenous sources & Endogenous sources \\
\hline $\begin{array}{l}\text { - Radiation } \\
\text { - } \text { Air pollutants } \\
\text { - Smoking tobacco } \\
\text { - Heavy and transition metals } \\
\text { - Industrial and household chemicals and } \\
\text { - } \text { solvents } \\
\text { - Pesticides } \\
\text { - } \text { Alcohol } \\
\text { - Nanoparticles } \\
\text { - Vigorous exercising }\end{array}$ & $\begin{array}{l}\text { - Mitochondrial respiration } \\
\text { - } \text { Peroxisomes } \\
\text { - Enzymatic reactions } \\
\text { O Lipoxygenases } \\
\text { O NADPH oxidase } \\
\text { - Respiratory burst } \\
\quad \text { O Infections } \\
\text { - Metal ions } \\
\text { - Cellular level redox reactions } \\
\text { - Peroxisome } \\
\text { - Endoplasmic reticulum } \\
\text { O Cytochrome P450 }\end{array}$ \\
\hline
\end{tabular}

Cells are evolved in a way that can allow them to neutralize these free radicals through enzymatic and non-enzymatic system, and maintain cellular redox balance [45]. Conversely, if the cell fails to neutralize the free radicals an oxidative stress can occur, and cause damage to other cell chemical components in cell such as lipids, proteins and DNA/RNA [44]. Free radicals are proven to be involved in the onset of many diseases in different organs of human body. Some of the oxidative stress related diseases in different human body organ are: asthma and chronic bronchitis in lungs; arthritis rheumatoid in body joints; Alzheimer's, Parkinson's, stroke, depression in brain; cataract and retinal diseases in eyes; arteriosclerosis, cardiomyopathy, hypertension, ischemia, and heart stroke in heart; inflammation, aging, infection, cancers, diabetes and other diseases in different body organs all are associated with oxidative stress in human body [46],[47],[48],[49],[50],[51],[52],[53]. 
In normal and healthy biological systems, there is a balance between production of free radicals and the defense mechanisms and maintain proper homeostasis. Depending on generated free radicals condition and the antioxidant defensive mechanisms, the state of cellular functions can be determined. In other words, free radicals act as regulatory mediator of signaling processes in biological systems [44],[2],[54]. They play important physiological roles as secondary messengers and in maintaining the immune system. Stimulation of cytokines, interleukins, transcription factor NF-kB or, growth factors, tumor necrosis factor- $\alpha$, transforming growth factor $\beta 1$, angiotensin II, platelet-derived growth factors, nerve growth factor, redox-responsive transcription factors, and fibroblast growth factors cause oxidative bursts [2],[54]. The oxidative bursts generate a low to moderate concentration of free radicals responsible for the regulation of cellular processes, such as cell growth and proliferation, signal transduction, redox balance $[2],[54],[55]$. Free radicals can also activate protein kinases to regulate gene functions. In the case of immunity, when there is an infection or inflammation in tissues, there is an oxidative burst and higher concentration of free radicals produced by immune cells to destroy inflamed tissue and kill invading organisms [56]. In this process, cells that are involved in immune system, such as white blood cells and phagocytes, consume a large amount of oxygen and generate free radicals such as superoxide or hydrogen peroxide. Myeloperoxidase, secreted largely in neutrophils, produce hypochlorous acid which is toxic to foreign microorganism in the presence of hydrogen peroxide and chloride. Hypochlorous acid, even though not a free radical, has a very short lifespan and can contribute to oxidative burst, oxidative stress, and initiation of many signaling pathways involved in aging, disease and cell death [44],[57]. Some of these free radicals and oxidants are discussed in the following section.

\subsection{Oxidants and Free Radicals in Biological Systems}

Many types of oxidants exist because they are part of normal metabolism and thereby, also perform various cellular functions. They are often classified as Reactive Oxygen Species (ROS) and Reactive Nitrogen Species (RNS) but other species exist [58],[59]. Oxidants are present in the form free radicals and non-radicals and will contribute to the oxidative stress upon excess production [60]. Chemical structures of some of these reactive species are shown in Table 1. 
Table 2. List of reactive species and oxidants.

\begin{tabular}{|l|l|}
\hline Free Radicals & Nonradicals \\
\hline Superoxide anion $\left(\mathrm{O}_{2}^{-\bullet}\right)$ & \multicolumn{1}{|c|}{ Oxygen containing species } \\
Hydroxyl radical $\left({ }^{\circ} \mathrm{OH}\right)$ & Singlet oxygen $\left({ }^{1} \mathrm{O}_{2}\right)$ \\
Hydroperoxyl radical $\left(\mathrm{HO}_{2}{ }^{\cdot}\right)$ & Ozone $\left(\mathrm{O}_{3}\right)$ \\
Peroxyl radical $\left(\mathrm{RO}_{2}{ }^{\circ}\right)$ & Hydrogen peroxide $\left(\mathrm{H}_{2} \mathrm{O}_{2}\right)$ \\
Lipid peroxides $(\mathrm{LOOH})$ & Hypochlorous acid $(\mathrm{HOCl})$ \\
\hline & Hydroperoxide $(\mathrm{ROOH})$ \\
\hline Nitric oxide $(\mathrm{NO} \bullet)$ & Nitrogen containing species \\
\hline Nitrogen dioxide $\left(\mathrm{NO}_{2}{ }^{-}\right)$ & Nitrite $\left(\mathrm{NO}_{2}^{-}\right)$ \\
& Nitroxyl anion $\left(\mathrm{NO}^{-}\right)$ \\
& Nitrosyl cation $\left(\mathrm{NO}^{+}\right)$ \\
& Peroxynitrite $\left(\mathrm{ONOO}^{-}\right)$ \\
& Dinitrogen tetroxide $\left(\mathrm{N}_{2} \mathrm{O}_{4}\right)$ \\
& Nitrous acid, $\left(\mathrm{HNO}_{2}\right)$ \\
\hline
\end{tabular}

There are other reactive species such as chlorine/bromine, sulfur, carbonyl and reactive selenium species which all are capable of damaging cell components [60],[61].

The mitochondria are one of the sources of production of free radicals. In aerobic systems, such as human cells, oxygen is involved in a series of chemical reactions during mitochondrial respiration to generate ATP in a series of reactions known as the electron transport chain (ETC). During this process, oxygen acts as an electron acceptor and is reduced to water [2],[62],[63]. However, sometimes this process isn't complete, and oxygen can leak out prematurely and become partially reduce to superoxide anion free radicals $\left(\mathrm{O}_{2}^{-\bullet}\right)$. This species in high concentrations can cause damage, especially to macromolecules and to mitochondria itself, resulting in mitochondrial dysfunction [64],[65]. Some reactions that may happen in the cell and result in the production of ROS are summarized in figure 1. 


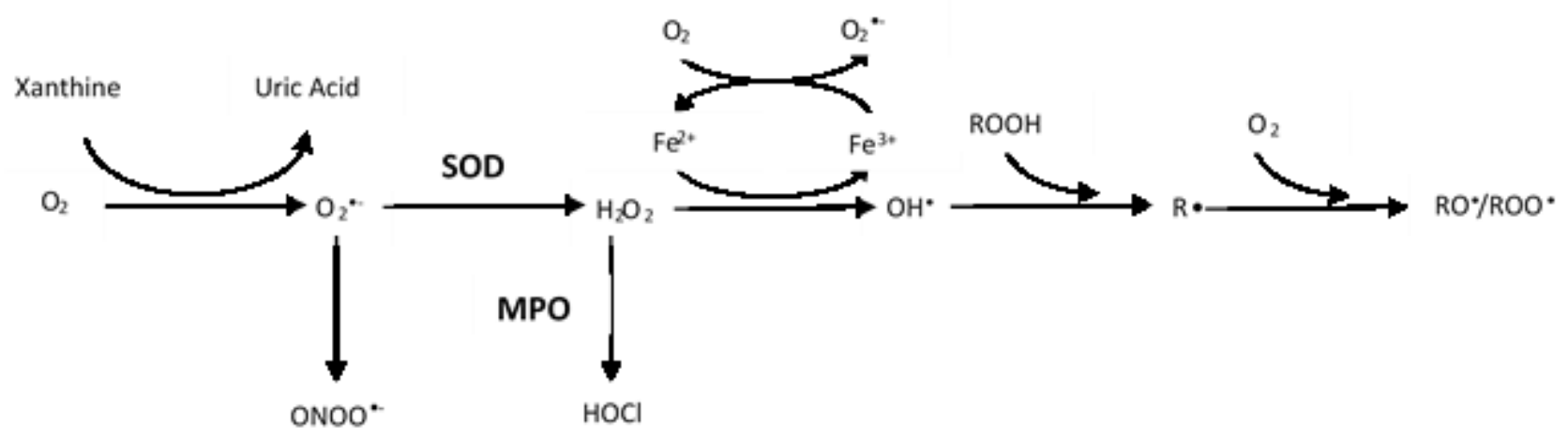

Figure 1. Origin of free radicals and oxidants through complicated redox reactions.

One of the primary enzymes effective in the formation of superoxide anion radicals is NAD(P)H oxidase. Once generated, $\mathrm{O}_{2}^{-\bullet}$ can subsequently be converted to hydrogen peroxide $\left(\mathrm{H}_{2} \mathrm{O}_{2}\right)$, hypochlorous acid ( $\mathrm{HOCl}$ utilizing the enzyme myeloperoxidase) or peroxynitrite $\left(\mathrm{ONOO}^{-}\right)$ through interaction with nitric oxide $\left(\mathrm{NO}^{\circ}\right)$. Nitric oxide $\left(\mathrm{NO}^{\circ}\right)$ is formed by the activity of nitric oxide synthase (NOS), a group of enzymes catalyzing its production using the amino acid Larginine as substrate [66].

Transition metals are also responsible for the formation of highly reactive compounds. Among them, iron (Fe) and copper ( $\mathrm{Cu}$ ) are the most abundant and can promote the generation of free radicals such as hydroxyl radicals. The production $\mathrm{HO}$ is via the Fenton reaction (equation 1 ) between $\mathrm{H}_{2} \mathrm{O}_{2}$ can and $\mathrm{Fe}^{2+}$. Superoxide, also, can reduce the oxidized metal released during the Fenton reaction (equation 2), and the combination of the two equations results in a net reaction called Haber-Weiss (equation 3) [67],[68].

(1) $\mathrm{Fe}^{2+}+\mathrm{H}_{2} \mathrm{O}_{2} \rightarrow \mathrm{Fe}^{3+}+\mathrm{OH}^{-}+\mathrm{OH}^{\bullet}$

(Fenton Reaction)

(2) $\mathrm{Fe}^{3+}+\mathrm{O}_{2}^{-\bullet} \rightarrow \mathrm{Fe}^{2+}+\mathrm{O}_{2}$

(3) $\mathrm{O}_{2}^{-\bullet}+\mathrm{H}_{2} \mathrm{O}_{2} \rightarrow \mathrm{OH}^{-}+{ }^{\bullet} \mathrm{OH}+\mathrm{O}_{2} \quad$ (Haber-Weiss Reaction)

\subsection{Oxidant and Free Radical Damage to Biomolecule}

Due to the high reactivity of free radicals and oxidants during oxidative stress, they can react with and damage any biomolecule such as proteins, carbohydrate, nucleic acids (DNA), and lipids lipids are typically the main target. Lipids are abundant in cell phospholipid bilayer and it is critical 
to the cell integrity. The damage to the cell membrane can alter its functionality, fluidity, and permeability. Oxidative stress can induce a series of chain reactions known as initiation, propagation, and termination. Oxidants and free radicals such as hydroxyl radical, hydroperoxyl, and peroxynitrite initiate lipid peroxidation reactions by taking hydrogen atom $\left(\mathrm{H}^{+}\right)$from lipids and producing lipid radicals. The next step is the formation of a lipid peroxyl radical (LOO ${ }^{\circ}$ ) by the addition of oxygen to the molecule, and due to the instability of lipid peroxyl, it obtains a hydrogen atom from nearby unsaturated fatty acids to gain stability. The new compound is lipid hydroperoxide ( $\mathrm{LOOH}$ ) and can go through a series of reconfiguration and isomerization to form a lipid alkoxyl radical ( $\left.\mathrm{LO}^{\circ}\right)$ which is also unstable. The formation of lipid radicals in propagation stage can continue endlessly and cause damage not only to lipids, but also to proteins, DNA, and phospholipids. Termination happens when the radicals react with each other and form nonradical molecules [69],[70],[71]. There are also enzymes such as cyclooxygenase and lipoxygenase are responsible for lipid oxidations [71],[70]. Figure 2. summarizes different stages of oxidative stress in lipids:

a) Initiation Reaction (Radical Formation):

$$
*^{\bullet}+\mathrm{LH} \rightarrow \mathrm{L}^{\bullet}+\mathrm{RH}
$$

b) Propagation (Peroxyl/Hydroperoxide Formation):

$$
\begin{aligned}
& \mathrm{L}^{\bullet}+\mathrm{O}_{2} \rightarrow \mathrm{LOO}^{\bullet} \\
& \mathrm{LOO}^{\bullet}+\mathrm{LH} \rightarrow \mathrm{LOOH}+\mathrm{L}^{\bullet} \\
& \mathrm{LOOH} \rightarrow \mathrm{LO}^{\bullet}+\mathrm{LOO}^{\bullet}
\end{aligned}
$$

c) Termination Reactions:

$$
\begin{aligned}
& 2 \mathrm{~L}^{\bullet} \rightarrow \mathrm{L}-\mathrm{L} \\
& 2 \mathrm{LO}^{\bullet} \rightarrow \mathrm{L}-\mathrm{OO}-\mathrm{L} \\
& 2 \mathrm{LOO}^{\bullet} \rightarrow \mathrm{LOOL}+\mathrm{O}_{2}
\end{aligned}
$$

Figure 2. Oxidative stress stages induced in lipid biomolecule. ${ }^{*} R^{\circ}: R O S / F r e e ~ R a d i c a l s / F e^{2+}$ or $\mathrm{Cu}^{2+}$.

Proteins and their building blocks, amino acids, are also susceptible to oxidative stress and the damage from free radicals. Hydroxyl radical, which is the most reactive species, along with other 
RNS and ROS react with protein and amino acids and cause damage to these biomolecules. Peptide backbone, amino acid side chains, and protein functional groups are the target sites for ROS and RNS attack. Typically, reactive species can remove a hydrogen atom and leave protein in a radical state itself. A series of conversion and reactions can then produce active compounds such as peroxyl radicals and alkyl peroxide. The susceptible amino acids in these kinds of reactions are cysteine and methionine since they contain sulfur centres [72]. Oxidization of proteins results in generating a variety of derivatives including carbonyl, amide derivatives and oxidized amino acids [73]. Reaction pathways involved are shown in Figure 3.

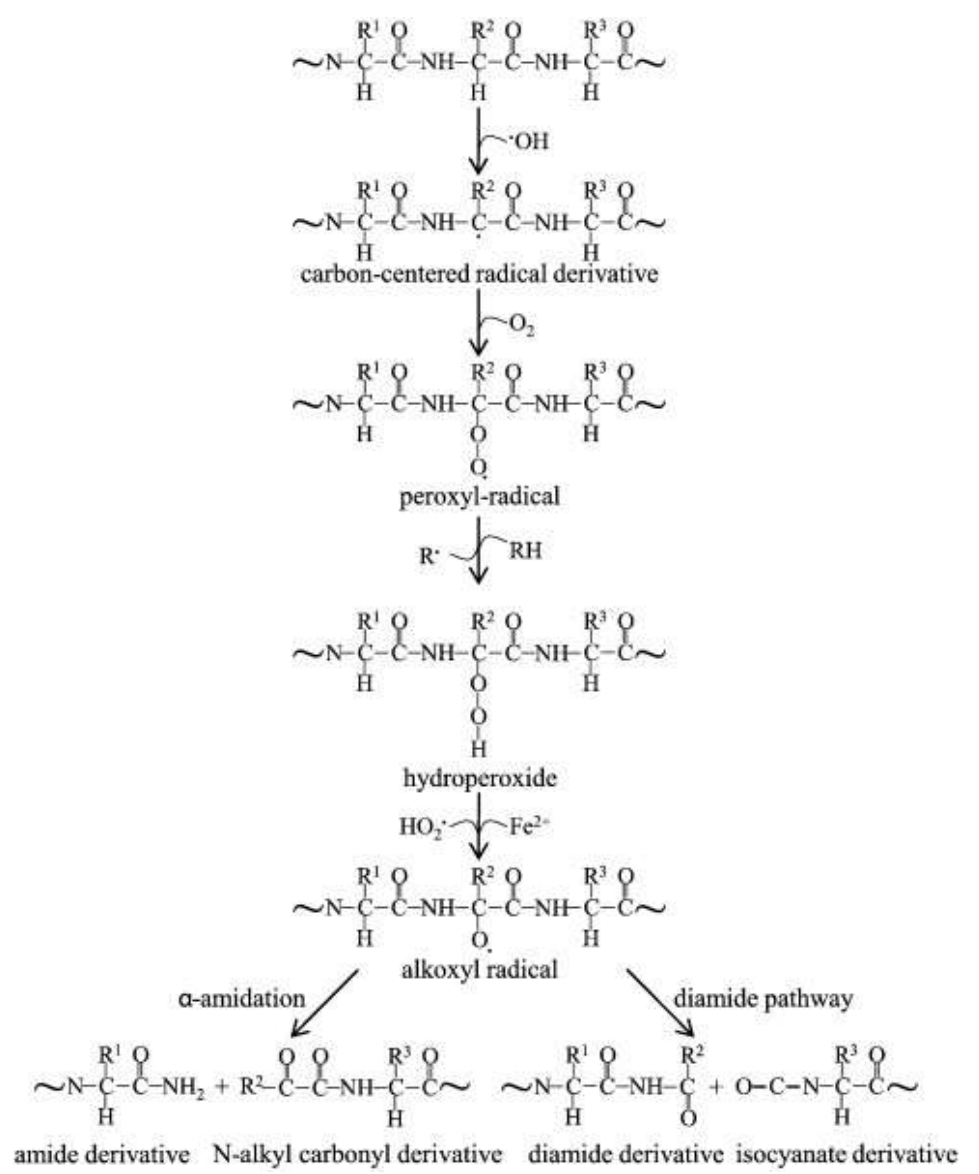

Figure 3. Oxidative stress induced in protein backbone (Taken from Reference [73]).

A primary source of superoxide generation is the electron transfer chain (ETC) in the mitochondrial membrane. Superoxide can go through dismutation to form hydrogen peroxide $\left(\mathrm{H}_{2} \mathrm{O}_{2}\right)$, result in the formation of the hydroxyl radical $\left(\mathrm{HO}{ }^{\circ}\right)$. Therefore, mitochondrial DNA is more susceptible to oxidative stress due to its proximity to the generation site. Prolonged 
oxidative stress can cause damage to mitochondrial components and induce degradation processes such as aging processes. Oxidative stress induces apoptosis by degradation of mitochondrial polynucleotides in DNA and RNA by mitochondrial nuclease and causes activation of enzymes such as caspase which is involved in apoptosis [74]. Frequently, damage to DNA by oxidative stress can affect replication and transcription, leading to mutations in tissue cells. These mutations can change a normal cell growth pattern into a malignant tumor, and eventually cause cell death [75],[76]. ROS and RNS can cause DNA oxidation which in turn can cause changes including nucleotide base modification, abasic (apurinic-apyrimidinic) site formation, DNA single and even double strand breaks [77]. DNA and RNA are composed of five nucleotides - uracil, thymine, cytosine, adenine, and guanine - out of which guanine is the most vulnerable to oxidation damage. Hydroxyl radical $\left(\mathrm{HO}^{\circ}\right)$ interaction with carbon of imidazole ring of guanine (C8) results in the formation of 8-oxo-7,8-dihydroxyguanine (8-oxodG) which is a biomarker of DNA damage. The presence of 8-oxodG in DNA synthesis cause a mismatch pair with adenine instead of cytosine, result in GC $\rightarrow$ TA or $\mathrm{GC} \rightarrow \mathrm{CG}$ transversion inducing mutagenesis or carcinogenesis [78]. A possible mechanism of mismatch pairing is shown in Figure 4: 


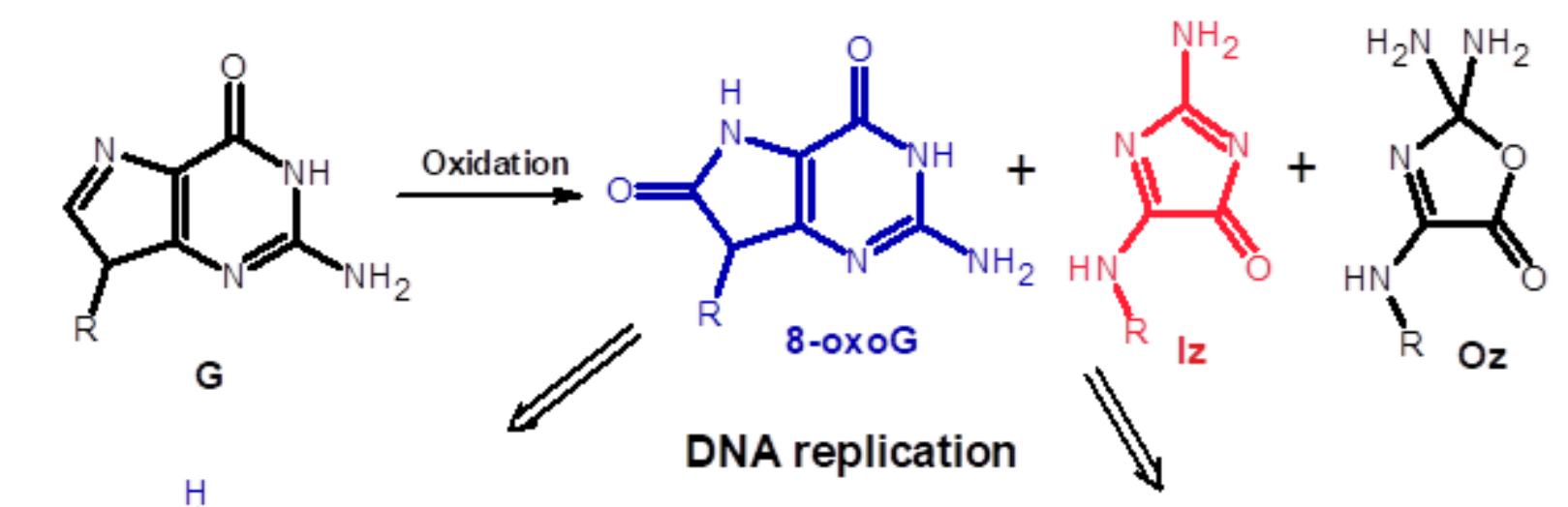

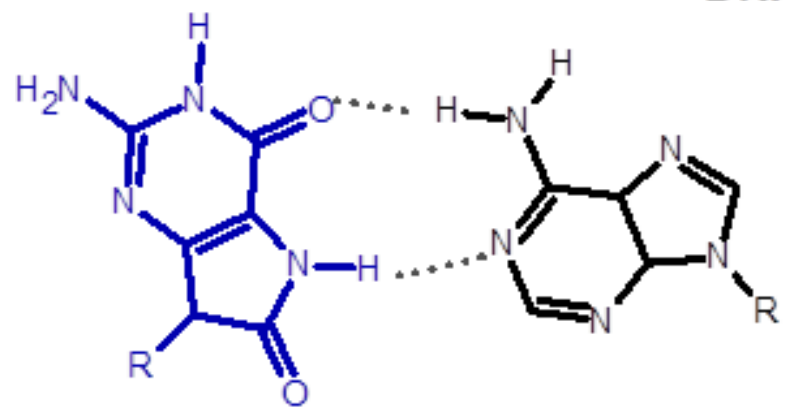

8-oxoG: A<smiles>C=[12CH]</smiles>

$\mathrm{G}: \mathrm{C} \longrightarrow \mathrm{T}: \mathrm{A}$ transversion

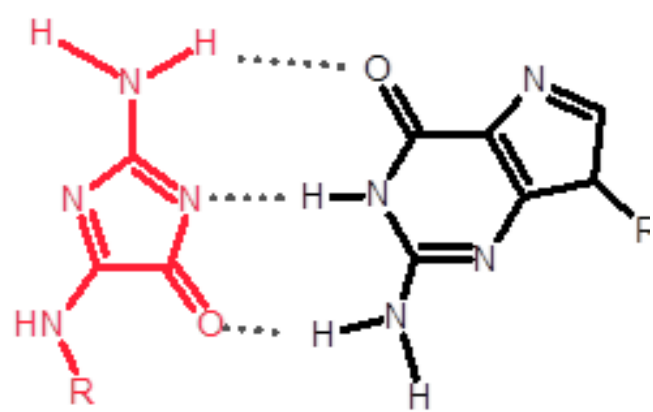

Iz: G

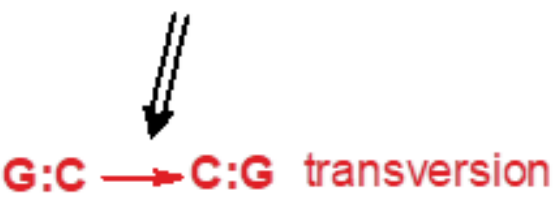

Figure 4. Oxidation of guanine and transversion of GC to either TA or CG ( Taken from Reference [78]).

In order to counteract the destructive effects of free radicals on biomolecule and cell components, biological systems are equipped with antioxidative and defense mechanism for protection purpose, and will be discussed briefly in the following section.

\subsection{Antioxidants and Defense Mechanisms against Oxidation}

Antioxidants are classified into two main groups: enzymatic and non-enzymatic[45]. Here, the non-enzymatic antioxidant can be endogenous or exogenous, whereas, enzymatic antioxidants are endogenous exclusively (Figure 5). 


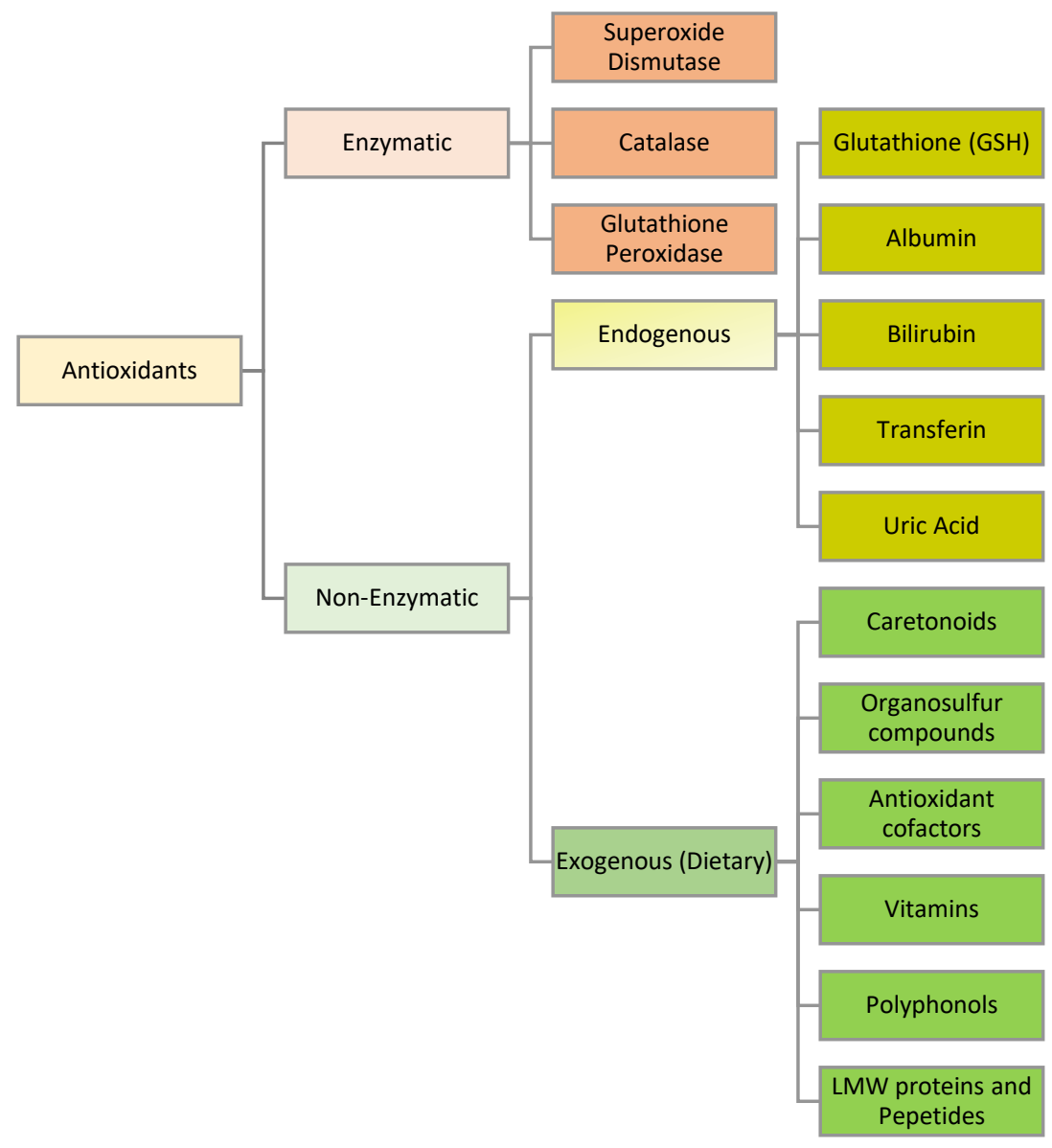

Figure 5. Classification of Antioxidants (Adopted from Reference [45]).

Antioxidants are a group of compounds that can neutralize the excess free radicals to limit the damaging effects of ROS/RNS. Antioxidants are said to have the ability to delay or prevent oxidation in biomolecules when it is presented in the environment at low concentrations [79]. In a biological system, antioxidants are originated from exogenous related sources (diet) or endogenous sources. Antioxidants provided through diet such as vitamins, flavonoids, carotenoids, are either water- or lipid-soluble in nature. Endogenous antioxidants exist within the biological system and they include antioxidant enzymes, metal binding proteins, and chainbreaking compounds. Critical endogenous-enzymatic antioxidants are catalase (CAT), glutathione peroxidase (GPx), and superoxide dismutase (SOD) [80]. Some biomolecules are also important antioxidants - known as chain breaking antioxidants - and have the ability to interfere with the chain reaction induced by free radicals. Examples of these compounds are uric acid, glutathione (GSH), ascorbate, $\alpha$-tocopherol [81]. From different sources of antioxidants, diet- 
provided ones are the most abundant, while endogenous enzymatic antioxidants are the most efficient [3]. Antioxidants exert their antioxidant mechanism through three mechanisms: by preventing the formation of RON/RNS, efficiently scavenging already formed reactive species and by repairing existed ROS/RNS-induced damaged molecules [82].

\subsubsection{Enzymatic Antioxidants}

There are three primary enzymatic antioxidants include catalase (CAT), glutathione peroxidase (GPX) and superoxide dismutase (SOD). These are the primary line of defense mechanism and most efficient enzymes in counteracting deleterious effects of free radicals and oxidants. Antioxidant interactions with oxidants are summarized in Figure 6.

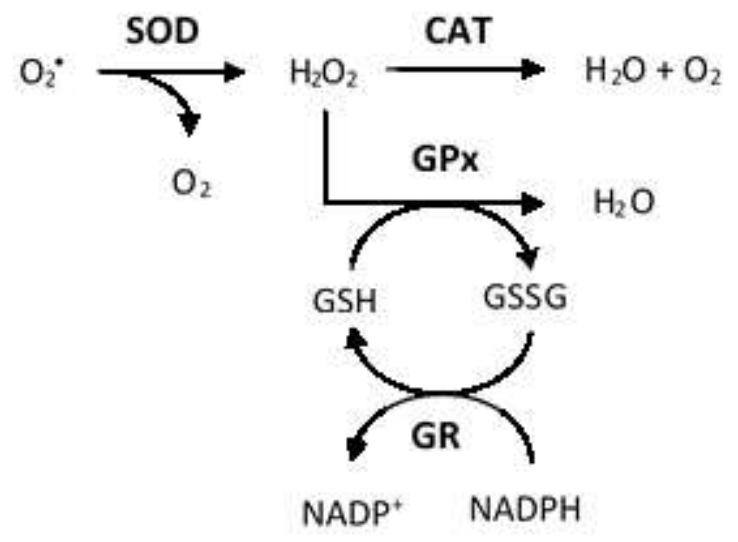

Figure 6. Intracellular antioxidant enzyme system.

\subsubsection{Catalase}

Catalase (CAT) contains iron in its structure as a cofactor and depending on the shape of the enzyme, provides two to three channels for the substrate to access its active site. CAT is a peroxisomal enzyme that mediates the decomposition of hydrogen peroxide to molecular oxygen and water.:

$2 \mathrm{H}_{2} \mathrm{O}_{2} \rightarrow 2 \mathrm{H}_{2} \mathrm{O}+\mathrm{O}_{2}$

The decay of catalase happens in two stages: it begins with one $\mathrm{H}_{2} \mathrm{O}_{2}$ oxidizing heme in catalase and forming intermediate cation radicals, and in the second stage $\mathrm{H}_{2} \mathrm{O}_{2}$ reduces the compounds from the first stage to water and oxygen [83]. Catalase is not the only enzyme responsible for eliminating of $\mathrm{H}_{2} \mathrm{O}_{2}$. In this case, glutathione peroxidase is also responsible [84]. During 
oxidative stress, CAT increased activity provides a defense mechanism against destructive effect of hydrogen peroxide in the cells. The upregulation of CAT expression in cells provides resistance to disruption of cell entity by increasing the catalase enzyme level and by preventing oxidation of cell lipid peroxidation [85].

\subsubsection{Glutathione Peroxidase}

Glutathione peroxidases (GPx) are a group of six isoforms of which four selenium dependent enzymes that have the ability to reduce peroxides. As mentioned above, GPx can reduce hydrogen peroxide to water; this enzyme can also react against the destructive activity of peroxides and superoxide anion. The reaction catalyzed by GPx is as follow:

$2 \mathrm{GSH}+\mathrm{H}_{2} \mathrm{O}_{2} \rightarrow \mathrm{GS}-\mathrm{SG}+2 \mathrm{H}_{2} \mathrm{O}$

In this reaction, two molecules of glutathione (GSH) are oxidized and donate their hydrogen atoms to reduce one molecule of hydrogen peroxide to two molecules of water. In this process, GSH which is oxidized to glutathione disulfide (GSSG) can be reduced back to GSH using NADPH as hydrogen atom donor and the activity of glutathione reductase enzyme (GR) [86] as shown in Figure 6. GPx, also, tend to react with hydroperoxides ( $\mathrm{ROOH})$ as substrate [87]. In the catalyzed reaction by GPx, hydrogen peroxide and peroxides are reduced to water and corresponding alcohols (ROH). Usually, the change in the level of an antioxidant enzyme is a biomarker of oxidative stress [88].

\subsubsection{Superoxide Dismutase}

Superoxide dismutase $(\mathrm{SOD})$ catalyze the dismutation of highly reactive superoxide anion $\left(\mathrm{O}_{2}{ }^{\bullet-}\right)$ to hydrogen peroxide and less reactive molecular oxygen with lower energy content through the following reaction:

$2 \mathrm{O}_{2}^{\bullet-}+2 \mathrm{H}^{+} \rightarrow \mathrm{H}_{2} \mathrm{O}_{2}+\mathrm{O}_{2}$

There are three isoforms of superoxide dismutase: SOD1 or copper and zinc dependent SOD (CuZn-SOD), SOD2 or manganese superoxide dismutase (Mn-SOD), and SOD3 another zinc and copper dependent superoxide dismutase (EC-SOD). SOD1 has a dimeric structure, whereas SOD2 
and SOD3 have tetrameric structures. SOD1 (CuZn-SOD) is found in cell cytosol, SOD2 (Mn-SOD) in mitochondria, and SOD3 (EC-SOD)exists in extracellular tissues [89]. During oxidative stress, the activity of SOD can be altered drastically and based on the tissue, the activity could be increased or decreased. This change in the level of SOD activity can alter cell functionality [90]. It is important for biological systems to be able to restore the activity of antioxidants to a natural level based on the nature of tissue or cells. In cells, expression of SOD increased by the presence of superoxide radical and this enzyme has a critical role in eliminating of this reactive species from the biological system. SOD1, however, is inducible by hydrogen peroxide as well [91]. In addition to the primary enzymes - CAT, GPx, and SOD - there are secondary antioxidant enzymes that participate in antioxidative reactions, including glutathione reductase, glucose-6-phosphate dehydrogenase, and glutathione-S-transferase. These groups of enzymes work together with primary enzymes to exert their antioxidant effect. For example, glucose-6-phosphatase dehydrogenase is responsible for catalyzing NADPH from NADP' to sustain a source of NADPH for the activity of glutathione reductase for the normal function of primary enzymes [49],[69].

\subsubsection{Non-Enzymatic Antioxidants}

Even though enzymatic antioxidants are the most important enzymes in defense against oxidative stress, the human body is equipped with non-enzymatic antioxidant mechanisms as well. These groups of non-enzymatic can be endogenous and exogenous and some examples are shown in Table 3:

Table 3. Examples of non-enzymatic antioxidants.

\begin{tabular}{|l|l|}
\hline Endogenous & Exogenous \\
\hline Glutathione & Vitamin E \\
L-arginine & Vitamin C \\
Coenzyme Q10 & Carotenoids \\
Melatonin & Trace metals (selenium, manganese, zinc) \\
Uric acid & Flavonoids \\
Bilirubin & Omega-3 and omega-6 fatty acids \\
Metal-chelating proteins & \\
Transferrin & \\
Lipoid & \\
\hline
\end{tabular}


The combinations of these antioxidants help to maintain a proper cell redox state [3]. Among all these antioxidants, the role of GSH is highly significant, and is explained in the following section.

\subsubsection{Glutathione as Endogenous Non-Enzymatic Antioxidant}

Glutathione (GSH) is an intracellular antioxidant molecule composed of three amino acids: glycine, glutamic acid, and cysteine, as it is shown in Figure 7[92].

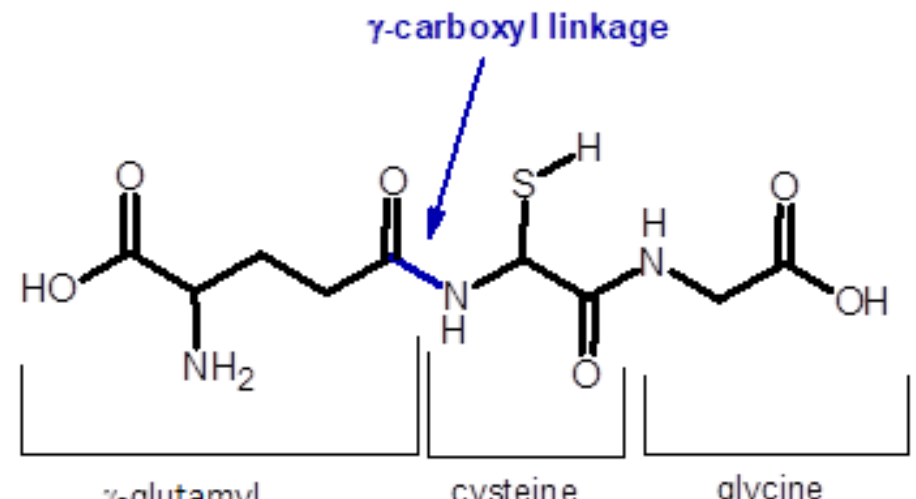

Figure 7. Glutathione structure

GSH in the cells could exist in both reduced and oxidized forms and its reduced form act as an antioxidant by either reacting with free radicals or by donating an electron. The following equations explain how GSH can react with free radical:

$\mathrm{GSH}+\mathrm{R}^{\bullet} \rightarrow \mathrm{GS}^{\bullet}+\mathrm{RH}$

$\mathrm{GS}^{\bullet}+\mathrm{GS}^{\bullet} \rightarrow \mathrm{GSSG}$

Glutathione disulfide (GSSG) is the oxidized form of GSH and is unreactive due to the pairing of the two electrons on each GS compounds. GSSG can, however, be easily reduced to form by the glutathione reductase (GR). The conversion mechanism is shown in Figure 8: 


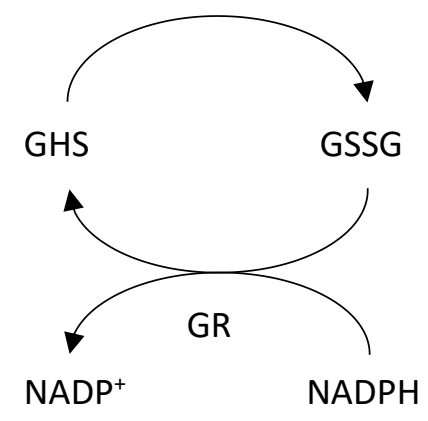

Figure 8. GSH in reduced and oxidized form

GSH an important biological antioxidant, has a protective role against oxidative stress through different mechanisms such as conjugation, reduction, and interaction with non-enzymatic antioxidants such as vitamin C and vitamin E [93]. Generally, during oxidative stress, the amount of intracellular reduced glutathione is increased; however, the increase depends on the availability of cysteine. In other words, cysteine is a rate-limiting amino acid in the synthesis of glutathione. Changes in intracellular GSH/GSSH is a key determinant of redox state inside the cell. In cancerous cells, the ratio of GSH/GSSG stays constant despite elevated levels of ROS/RNS which might be due to GSSG depletion [94]. Reduced glutathione is responsible for scavenging free radicals, reacting with different xenobiotics, and bounding to formaldehyde to efficiently remove it from the system [69].

\subsubsection{Exogenous, Diet-Based Non-Enzymatic Antioxidants}

Studies have shown that antioxidant-rich diets can improve the overall state of health. Compounds such as vitamin E and C, carotenoids, polyphenols, flavonoids, stilbenes, phenolic acid, and lignans are the most efficient exogenous antioxidants. Consistent consumption of antioxidant-rich foods can enhance health by providing more protection against cancers, cardiovascular diseases, diabetes, osteoporosis, brain and neurological disorders [95], [96], [97].

Recently another group of compounds has been the focus of research as a possible source of antioxidants. Originating from a wide range of food and plant sources, these compounds contain biologically active peptides and can be produced and isolated using different hydrolysis methods [98]. These bioactive peptides and their derivatization methods described in more detail in the following section. 


\subsubsection{Food Derived Protein Hydrolysates and Bioactive Peptides as Antioxidants}

Different food sources such as plants an animal are good sources of various nutrients including lipids, carbohydrates, minerals, and proteins. There have been various studies showing many food proteins and peptides derived from these foods possess certain bioactivities in addition to their conventional nutritional value. These biologically active peptides exhibit health-promoting effects in biological systems [4],[35].

Food bioactive peptides - also known as protein hydrolysates - are made of a short chain of amino acids ranging from 2 - 30 amino acids, produced using fermentation, acid, alkaline, or enzymatic hydrolysis of different food sources. The resulted product contains a wide variety of different fragmented protein or peptides, with lower molecular weight and more stability in various conditions, making them easily absorbed and more available for biological reactions [99],[100].

In general, when food is consumed, gastric enzymes digest food proteins, which releases different protein fragments with specific peptide sequences that can exert an antioxidant effect. Depending on their amino acid profile, protein hydrolysates can alter physiological pathways and activities. Antioxidant properties of protein hydrolysates are affected and defined by amino acid sequence, composition, structure, hydrophobicity, peptide linkage and configuration (L/D), also by production methods/conditions, types of enzymes and proteases used, peptide source and final employed concentration [4],[101]. In term of production condition, it is important to consider the effect of other compounds such as carbohydrates and possibly Maillard reaction products in the processing environment.

Studies have shown the use of hydrolysates can improve and attenuate adverse effects of raised blood pressure, inhibit microbial growth, enhance mineral bonding, act as antioxidants and immunomodulatory compounds, and lower blood cholesterol [102],[103]. Even though many studies have shown the antioxidant influence of protein hydrolysates, the underlying mechanisms still need to be elucidated. All studies, however, showed protein hydrolysates are capable of donating protons, scavenging radicals [104], and chelating metal ions such as copper and iron [105]. It is also observed that food-derived peptide also can induce gene expression to 
code for proteins with oxidation inhibitory properties. Erdmann and colleague (2006), have found that methionine-tyrosine, a dipeptide isolated from fish, can increase protein expression of heme-oxygenase-1 and ferritin by raising mRNA level. This in turn results in the production of antioxidant compounds such as bilirubin [106].

\subsubsection{Protein Hydrolysate Production by Enzymatic Hydrolysis}

Due to increasing demand for proteins that is economical and safe-for-human-consumption in recent years, many researches have been conducted on methods to produce plant derived protein and peptides. There have been many studies focussed on plant-derived protein hydrolysates with biological activities from a variety of sources including buckwheat, corn, chickpeas, rice, soybean, wheat, and vegetables such as broccoli [14],[107]. There are different methods to produce protein hydrolysates, and they are enzymatic, acid and alkali methods. Enzymatic methods are more common to produce protein hydrolysates due to milder processing conditions, and peptides produced to maintain the amino acid configuration and integrity with high specificity [15]. Common enzymes used in production and release of protein hydrolysates are alcalase, chymotrypsin, Flavourzyme ${ }^{\circledR}$, papain, protamex, trypsin, and many more [15],[103],[108]. These enzymes can be used on their own in one step or utilized in a combination of the different enzymes in more than one step to enhance production of protein hydrolysates. In this research, a combination of enzymes was employed to facilitate the extraction of protein hydrolysates by proteases in the second step. Two enzymes used in the first phase are Cellulase and Viscozyme. Cellulase is an enzyme, from a fungal source, produced by Trichoderma reesei and catalyzes the degradation of cellulose into cellobiose and glucose. This enzyme is widely used in food industries such as in fruit and vegetable industries in carotenoid extraction, brewery and wine industries [109]. It facilitates the breakdown of plant cell walls to release cell components and increase the protein substrate for second stage proteolysis. Cellulase affects glycosidic bonds such as $\beta$-D-glucan and 1,6- $\beta$-glycosidic bonds [110]. Viscozyme ${ }^{\circledR}{ }^{\circledR}$ a complex of carbohydrases - including arabinase, cellulase, $\beta$-glucanase, hemicellulase, and xylanase produced by Aspergillus sp., which catalyzes cell wall degradation. This enzyme works best at $\mathrm{pH}$ range of $4-9$, and the effective enzyme is endo-1,3- $\beta$-glucanase [111]. Proteases used in this study were alcalase, papain, protamex and Flavorzyme $L^{\circledR}$ - of Novozymes. Flavourzyme $L^{\circledR}$ is a 
mixture of enzymes produced by a strain of fungal origin called Aspergillus oryzae with mostly endopeptidase and carbohydrase activity. It is composed of aminopeptidases, dipeptidyl peptidases, endopeptidases, and $\alpha$-amylase. This combination of enzymes gives Flavourzyme a broad range of activity [112]. Flavourzyme is known to produce very small peptide even amino acids due its exo/endopeptidase activity [113],[114]. Alcalase, also known as subtilisin, belong to serine endopeptidase enzymes and have a nucleophilic serine residue at the active site. It can catalyze a wide-range of protein substrates and can hydrolyze most peptide bonds [115]. This enzyme is produced by Bacillus licheniformis and it has a broad range of application in many industries [116]. Alcalase, normally, cleaves proteins where there is a hydrophobic (aromatic or aliphatic) aminon acid residue such as Tyr, Leu and Trp [117], as well as sulfur containing residues such as Met [118]. Papain - a plant based enzyme - belongs to hydrolases enzymes and is responsible for hydrolytic cleavage of C-N bonds [119]. Eventhough it has a broad range of activity, papain tends to cleave amino acid Phe in a poly peptide chain at the second position of the substrate [120]. In the food industry, papain is used as a meat tenderizer. Protamex is a hydrolase/peptidase enzyme isolated from bacteria Bacillus $s p$. It is a serine protease with endopeptidase activity as well which is capable of releasing hydrophobic and aromatic amino acid residue from proteins [121].

\subsubsection{Mechanism of Antioxidant Activity of Protein Hydrolysates}

The activity of proteases on protein molecule of different components results in producing average and low molecular weight (LMW) peptide and amino acids that have shown to have bioactivities such as free radical scavenging and metal-ion chelating activities, yet the underlying mechanism needs to be elucidated [102],[103].

It seems that the influencing factors on antioxidant capacities of protein hydrolysates are: amino acid composition, hydrophobicity and amino acid sequence [122]. Amino acid N-or C-terminus positioning and their type significantly affect antioxidant activity of protein hydrolysates. For example, aromatic amino acids, such as tyrosine, phenylalanine, tryptophan and histidine, are capable of donating electron and quenching free radicals. Also, sulfur containing amino acid cysteine is a good free radical scavenger, and therefore, can act as an antioxidant. Acidic and 
basic amino acids are involved in transition metal chelating activity, again serving as antioxidants [101].

There are many obstacles to evaluate the characteristics of protein hydrolysates, however, there are difficulties in isolation, fractionation, and purification; also, maintaining their structure, peptide linkage, and composition during processing. However, there have been many methods developed to measure the antioxidative activity of protein hydrolysates. Some of these methods are: scavenging activity of $\mathrm{ABTS}^{\circ+}, \mathrm{DPPH}^{\bullet}, \mathrm{HO}^{-}$, and $\mathrm{O}_{2}{ }^{\bullet-}$ radicals, as well as iron and copper chelating activity of protein hydrolysates [123]. Cell culture models are also suitable methods to evaluate antioxidant activity of protein hydrolysates.

\subsection{Liver HepG2 and Oxidative Stress and the Antioxidants}

The liver is an organ responsible for detoxification and composed mainly of hepatocytes. Under oxidative stress, the amount of ROS and RNS increases considerably and the liver - as an organ responsible for detoxification of these species - is required to neutralize more than average amount of RNS and ROS. Although under normal cell conditions the amount of liver cell antioxidants is sufficient, it may not be enough to neutralize free radicals during oxidative stress. Therefore, the liver cells become the target of oxidative damage, and the liver cell chemical components, such as DNA, proteins, lipids, can be injured [124]. For these reasons, hepatocytes are often chosen as the cell line to study the effects of antioxidants on oxidative stress.

Human HepG2, a well-differentiated cell line from a hepatic origin, is a suitable study model used for biochemical studies where many compounds and conditions can be assayed with minor variations. There are different hepatocytes available for research purposes and, usually, the choice of cell culture depends on the function and the type of enzyme that the specific cell line produces [88]. One of the reason makes HepG2 an appropriate model to study oxidative stress in liver cells is that HepG2 cell line has an excellent array of enzymes produced during oxidative stress, e.g., phase I and II enzymes. Also, HepG2 cells can resemble the metabolism of free radicals in human body [125]. A good study model in oxidative stress research should have appropriate characteristics such as proper viability in response to induced oxidative stress, abundant production of measurable enzymatic and non-enzymatic antioxidant defense 
compounds, also the presence of oxidative damage biomarkers [126],[127]. The compounds commonly used to induce oxidative stress in cells are hydrogen peroxide $\left(\mathrm{H}_{2} \mathrm{O}_{2}\right), 2,2$ '-Azobis(2amidinopropane) dihydrochloride (AAPH), and tertbutyl hydroperoxide (t-BOOH) [128],[129]. Normally, it is suggested to use biologically relevant free radicals to study oxidative damage to the biological systems or cells [130]. AAPH is known to be capable of producing peroxyl radical $\left(\mathrm{ROO}^{\circ}\right)$ mimicking like $\mathrm{t}-\mathrm{BOOH}$ those from cellular lipid oxidation [131]. The standard methods to evaluate antioxidant enzymes activity and antioxidant compounds in HepG2 cells are very well established and been used have been used in many similar studies. General primary antioxidant enzyme activities measured in oxidative stress are catalase (CAT), glutathione peroxidase, and superoxide dismutase (SOD); also, total GSH to GSSG ratio is another aspect to consider in oxidative stress.

\subsection{Activation of Caspase-3 and Apoptosis}

Programmed cell death (PCD) or apoptosis is a genetically controlled and highly regulated process essential for biological entity's developmental stages, crucial for appropriate responses to environmental factors, and necessary for living organism survival [132],[133],[134]. Cellular ROS/RNS level fluctuations, due to exogenous or endogenous stimuli, such as oxidative stress, can trigger a series of signaling cascades inside cells including apoptosis by activation a series of proteases known as caspases [135]. Apoptosis can help cells and biological system to function properly by eliminating malfunctioning cells [136]. Apoptosis is initiated through either intrinsic or extrinsic pathways. Both pathways cause changes in cell morphology and characteristics such as cell wall blebbing, DNA fragmentation, protein cleavage, and chromosomal DNA degradation. These changes cause the cell to shrink and become more available to be engulfed by macrophages or neighboring cells [137]. Oxidative stress triggers apoptosis by the generation of an excessive amount of ROS such as superoxide anion $\left(\mathrm{O}_{2}{ }^{--}\right)$, hydroxyl $\left(\mathrm{HO}{ }^{\bullet}\right)$, peroxyl $\left(\mathrm{RO}_{2}{ }^{\bullet}\right)$, and alkoxyl $\left(\mathrm{RO}^{\circ}\right)$ radicals, and hydrogen peroxide $\left(\mathrm{H}_{2} \mathrm{O}_{2}\right)$ with the latter compound having the prominent role [136].

One important role of caspase in apoptotic process is to accommodate programmed cell death. The release of caspases can be triggered through different pathways: free radicals all can trigger both intrinsic and extrinsic pathways, directly or indirectly. Intrinsic or mitochondrial pathways, 
Bcl-2 superfamily integral membrane protein inhibition ability is suppressed by proapoptotic protein group (Bax, Bak, etc.) released from mitochondria, changes membrane permeability and produces distinct pores in mitochondrial membrane [138]. This increases the permeability of the membranes which allows compounds such as cytochrome $\mathrm{C}$ and other intermembrane proteins to be released into cytoplasm [139]. Released cytochrome C binds to the protein Apaf-1 (apoptotic protease activating factor-1) and forms a complex. This complex aggregate to form apoptosome which acts as cytosolic signaling platform, eventually activating caspase-9 [140]. Caspase-9 (an apoptosis initiator compound) belongs to a family of cysteine-proteases that targets and cleave peptide bonds of protein after an aspartic amino acid residue (ㅡysteine, Aspartic acid, Protease $=$ Caspase) [141]. The initiation of caspase-9 triggers activation of other caspases, eventually caspase-3 activation. Upon increasing concentration of caspase enzymes, a series of protein cleavage due to increased proteolytic activity occurs, which results in degradation of cytoplasmic proteins, DNA and other cellular components [142].

Extrinsic pathways are triggered by extracellular initiator ligands such as tumor necrosis factor (TNF) family and Fas-ligands, usually following an extracellular ligand binding to the death receptors on the surface of the cell $[136],[143]$. These ligands bind to extracellular transmembrane receptors and result in the formation of death-inducing signaling complex (DISC), which in turn induce activation of caspase-8. This eventually leads to the formation of caspase-3 a definite sign of PCD and apoptosis [144].

Bcl-2 membrane proteins have the ability to act as an antioxidants blocking oxidative stress caused by hydroxyl radicals [145]. However, depending on the system target for study, it is important to keep the apoptosis at a controlled and healthy rate to maintain the proper function of organ or tissue. For example, it has been observed that increased proliferative rate of cancerous cells have been reduced using antioxidative protein hydrolysates, whereas apoptosis rate been elevated eliminating tumor cells [146],[147],[148] There are also have been many studies showing the protective effect of protein hydrolysates against oxidative stress produced free radicals and induced apoptosis in cell culture models.[149],[150],[151],[152]. 


\subsection{Study Hypothesis}

The liver is considered a detoxification site for different chemical compounds, especially free radicals such as ROS and RNS. Normally, liver cells neutralize these free radicals through enzymatic and non-enzymatic mechanisms. However, due to endogenous or exogenous factors, the level of free radicals may rise, and the cell defense mechanism may not be able to neutralize them. Therefore, the use of exogenous antioxidants may help the cells to survive the toxicity of ROS and RNS. These antioxidants can be provided through diet. Recently it has been observed that some crop derived hydrolyzed proteins and peptides have demonstrated some antioxidant effects in various models. Oat bran is considered a by-product of oat processing and was used as a source of proteins for this thesis project. Hydrolyzed oat bran proteins possess antioxidant activities in various chemical based assays, but their properties in a cellular model are still lacking.

\section{Research Hypothesis}

Hydrolyzed oat bran proteins with radical scavenging and metal chelating properties will reduce oxidative stress in a hepatic cell culture model.

\section{Research Objectives}

The objectives of this study were to:

1. Extract proteins from oat brans and hydrolyze them with two carbohydrases and four proteases to generate hydrolysates containing peptides of different size and amino acid sequences

2. Determine the antioxidant capacity of oat bran protein isolates (OBPI) and hydrolysates (OBPH) using different chemistry based assays such as $\mathrm{ABTS}^{\circ+}$, hydroxyl radical ( $\left.\mathrm{HO}{ }^{*}\right)$, superoxide $\left(\mathrm{O}_{2}{ }^{*}\right)$ radicals scavenging assays, and oxygen radical absorbance capacity (ORAC).

3. Evaluate the cytotoxicity and cytoprotection effect of OBPI and OBPH in hepatic HepG2 cells.

4. Determine the potential of hydrolysates to regulate the activity of primary antioxidant enzymes, or to decrease the production of intracellular reactive oxygen species.

5. Investigate the effect of OBPI and OBPH on Caspase-3 activity in hepatic HepG2 cells. 


\section{Materials and Methods}

\subsection{Materials and Chemicals}

Medium oat bran with particle size percentage distribution of $2.00 \mathrm{~mm}(0.8 \%), 0.841 \mathrm{~mm}(61.5 \%)$, $0.595 \mathrm{~mm}$ (32.1\%), $0.420 \mathrm{~mm}$ (5.0\%), Pan and (0.6\%) was obtained from Richardson International, Manitoba, Canada. Cellulase from Trichoderma reesei, Viscozyme ${ }^{\circledR}$ L from Aspergillus sp., Alcalase or Protease from Bacillus licheniformis, Flavourzyme ${ }^{\circledR}$ or Protease from Aspergillus oryzae, Protamex ${ }^{\circledR}$ or Protease from Bacillus sp., Papain from papaya latex, bovine serum albumin (BSA) 2,2'-Azobis(2-amidinopropane) dihydrochloride (AAPH), (6-hydroxy2,5,7,8-tetramethylchromane-2-carboxylic acid (Trolox), 1,10-phenanthroline, iron(II) sulfate heptahydrate $(\mathrm{FeSO} 4 \cdot 7 \mathrm{H} 2 \mathrm{O})$, hydrogen peroxide $\left(\mathrm{H}_{2} \mathrm{O}_{2}\right)$, Tris(hydroxymethyl)aminomethane hydrochloride (Tris-HCl), pyrogallol, ethylenediaminetetraacetic acid disodium (EDTA), 2,29azinobis(3-ethylbenzothiazoline-6-sulfonic acid) diammonium salt (ABTS), di-potassium peroxdisulfate, ferrous chloride $\left(\mathrm{FeCl}_{2}\right)$, 3-(2-Pyridyl)-5,6-diphenyl-1,2,4-triazine-p, $\mathrm{p}^{\prime}$-disulfonic acid monosodium salt hydrate (ferrozine), 3-(4,5-dimethylthiazol-2-yl)-2,5-diphenyltetrazolium bromide (MTT), 96-well and 60-mm tissue culture plates, dimethylsulfoxide $\geq 95 \%$ (DMSO), sodium azide (NaN3), reduced glutathione (GSH), oxidized glutathione (GSSG), glutathione reductase (GR), nicotinamide adenine dinucleotide phosphate (NADPH), hydrogen peroxide, Catalase, bathocuproinedisulfonic acid disodium salt (BCS), nitroblue tetrazolium chloride (NBT) diethylenetriaminepentaacetic acid (DETAPAC), xanthine, xanthine oxidase, 5,5-dithiobis-(2nitrobenzoic acid) (DTNB), dihydrochlorofluorescein diacetate (DCF-DA) were obtained from Sigma Aldrich (Oakville, ON, Canada). Fluorescein, mono- and dibasic potassium phosphates, Antibiotic-Antimycotic (100X) (Catalog number: 15240062) were obtained from Fisher Scientific Canada (Ottawa, Ontario)

HepG2 (ATCC ${ }^{\circledR}$ HB-8065 ${ }^{\mathrm{TM}}$ ) human hepatocellular carcinoma cells were obtained from the American Type Culture Collection (ATCC). They were grown in Dulbecco's Modified Eagle Media (DMEM) with $10 \%$ fetal bovine serum (FBS), passaged every 3-4 days and maintained in a humidified incubator at $37{ }^{\circ} \mathrm{C}$ supplemented with $5 \% \mathrm{CO}_{2}-95 \%$ air. Dulbecco's Modified Eagle's Medium (DMEM) and Fetal Bovine Serum (FBS) were purchased from Wisent Bioproducts (ST- 
BRUNO, CA). Caspase-3/CPP32 Colorimetric Assay Kit (\# K106-100) was purchased from Biovision (Mountain View, CA, USA).

\subsection{Preparation of Protein Hydrolysates}

\subsubsection{Defatting Oat Bran}

Medium oat bran was defatted by mixing with hexane $(1: 3 \mathrm{w} / \mathrm{v}$ ratio) and stirred for one hour at room temperature on a magnetic stirring plate. It was then filtered on cheesecloth and left to dry overnight in a fume hood. Dried and defatted brans were used for protein extraction in two stages. First protein isolates were obtained using carbohydrases, and the protein isolates were further digested with proteases to obtain protein hydrolysates.

\subsubsection{Preparation of Protein Isolates}

Five $\mathrm{g}$ of dried and defatted oat bran was mixed with $50 \mathrm{~mL}$ deionized water $(1: 10 \mathrm{w} / \mathrm{v})$, and blended to obtain a homogeneous slurry. The pH of slurry adjusted to 4.5 or 5.5 using either $0.1 \mathrm{M} / 1 \mathrm{M}$ of $\mathrm{NaOH}$ or $\mathrm{HCl}$. Either Viscozyme ${ }^{\circledR} \mathrm{L}$ at $3 \mathrm{FBG} / \mathrm{g}$ or Cellulase at $20 \mathrm{EGU} / \mathrm{g}$ of defatted oat bran were added to the slurries. Then the slurries were incubated in Thermo Fisher Model $\mathrm{MaxQ}^{\mathrm{TM}} 8000$ shaker incubator at $45^{\circ} \mathrm{C}, 150 \mathrm{rpm}$ for 1.5 hours. Then each solution $\mathrm{pH}$ was adjusted to 9.5 with $1 \mathrm{M} \mathrm{NaOH}$ and incubated further at the same parameters. Samples were cooled, centrifuged at $2500 \times \mathrm{xg}, 4^{\circ} \mathrm{C}$, for 20 minutes, and the supernatant was collected to be more processed. Supernatant's pHs were adjusted to 4.0 and centrifuged at $10,000 \times$ g for 40 minutes at $4^{\circ} \mathrm{C}$ after which liquids were discarded Precipitates which are protein isolates were dissolved in water ( $\mathrm{pH} 7.0)$, frozen and freeze dried.

\subsubsection{Preparation Protein Hydrolysates}

To $0.3 \mathrm{~g}$ of the freeze-dried protein isolates, $20 \mathrm{~mL}$ of deionized water was added, and the $\mathrm{pH}$ was adjusted to optimum $\mathrm{pH}$ of proteases with either $1 \mathrm{M} \mathrm{NaOH}$ or $1 \mathrm{M} \mathrm{HCl}$ ash showed in Table 2. Proteases were added to samples at $2 \%$ enzyme/substrate ratio and incubated for 3 hours. Optimum temperature for alcalase $(\mathrm{pH} 8.0)$ was $60^{\circ} \mathrm{C}$, for Flavourzyme ${ }^{\circledR} \mathrm{L}\left(\mathrm{pH} \mathrm{7.0)}\right.$ was $50^{\circ} \mathrm{C}$, for papain ( $\mathrm{pH} 7.0$ ) was $65^{\circ} \mathrm{C}$, and for Protamex $\left(\mathrm{pH} \mathrm{7.5)}\right.$ was $50^{\circ} \mathrm{C}$. Each sample were incubated in Thermo Fisher MaxQ 4450 Incubated Orbital Shakers at 150 rpm for optimum time and temperature. After incubation period, the enzymes were inactivated by heating in hot water bath at $85-90{ }^{\circ} \mathrm{C}$ for $5 \mathrm{~min}$. Samples were cooled to room temperature and centrifugated at 
$8000 x g$ for 15 minutes at $4^{\circ} \mathrm{C}$. Then supernatant was collected and stored at $-20^{\circ} \mathrm{C}$. Freeze dried samples (protein hydrolysates) were used for further evaluation.

Table 4. List of proteases with condition used for each enzyme

Enzyme Name

Enzyme/Substrate

Incubation

Incubation Time

pH

Ratio (\%)

Temperature $\left({ }^{\circ} \mathrm{C}\right)$

(h)

$(w / w)$

\begin{tabular}{|c|c|c|c|c|}
\hline Alcalase & 2 & 60.0 & 3.0 & 8.0 \\
\hline Flavourzyme ${ }^{\circledR}$ & 2 & 50.0 & 3.0 & 7.0 \\
\hline Papain & 2 & 60.0 & 3.0 & 7.0 \\
\hline Protamex & 2 & 50.0 & 3.0 & 7.5 \\
\hline
\end{tabular}

\subsection{Oxygen Radical Absorbance Capacity (ORAC) Assay}

Oxygen radical absorbance capacity (ORAC) was determined according to the procedure by Li, et al., 2009 [153]. A potassium phosphate buffer $(75 \mathrm{mM}, \mathrm{pH}$ 7.4) was prepared to dissolve all reagents, standards, samples, and the control. A set of five Trolox (a water-soluble vitamin E analogue) concentrations ranging from 6.25 to $100 \mu \mathrm{M}$ were used to construct a calibration curve. Solutions of fluorescein $(0.082 \mu \mathrm{M})$ and AAPH $(153 \mathrm{mM})$ were prepared immediately before use. Two concentrations of glutathione $(0.1$ and $0.2 \mathrm{mg} / \mathrm{mL})$ were used as antioxidant control. Also, two concentrations of samples $(0.1$ and $0.2 \mathrm{mg} / \mathrm{mL})$ were prepared and assayed in triplicates. All reagents, standards and samples were transferred to a black 96-well microplate tray in the following order: $120 \mu \mathrm{L}$ fluorescein to all the wells, and $20 \mu \mathrm{L}$ of potassium phosphate buffer as blank, $20 \mu \mathrm{L}$ of glutathione controls, $20 \mu \mathrm{L}$ of all Trolox standards, $20 \mu \mathrm{L}$ of samples. A microplate fluorescence reader model FLx800 (Bio-Tek Instruments, Inc., Winooski, VT) with fluorescence filters (excitation wavelength $485 \mathrm{~nm}$, emission wavelength $528 \mathrm{~nm}$ ) was used to incubate the tray at $37^{\circ} \mathrm{C}$ in the built-in incubator for 20 minutes. After the initial incubation time, $60 \mu \mathrm{L}$ of $153 \mathrm{mM} \mathrm{AAPH}$ were added to all wells containing blank, control, standards and samples, and immediately plate was placed in the microplate reader and data were collected over 1 hour period in a kinetic assay. ORAC values were expressed as Trolox equivalents (TE) using constructed standard curve. 


\subsection{ABTS Radical Scavenging Assay}

ABTS radical cation decolorization activity was measured by the method described by Re et al. (1999) [154]. A stock solution of $\mathrm{ABTS}^{\bullet+}$ in deionized water $(7 \mathrm{mM})$ was prepared by reacting ABTS [2,2'-azino-bis (3-ethylbenzothiazoline-6-sulphonic acid)] stock solution with potassium persulfate $(2.45 \mathrm{mM})$ with ratio of $1: 1(\mathrm{~V} / \mathrm{V})$ and allowing the mixture to develop in the dark at room temperature for $16 \mathrm{~h}$. Fresh $\mathrm{ABTS}^{\bullet+}$ was prepared for each assay and diluted 50-60 times with PBS ( $\mathrm{pH} 7.4)$ to obtain an absorbance of $0.706 \pm 0.02$ units at $734 \mathrm{~nm}$ using a spectrophotometer BioTek ${ }^{\circledR}$ Epoch $^{\mathrm{TM}}$ UV-Vis (Fisher Scientific, Nepean, ON, Canada). Samples $(0.2$ and $0.4 \mathrm{mg} / \mathrm{mL})$ and five Trolox standards $(1.875-30 \mu \mathrm{M})$ were prepared in PBS. The samples and standards $(50 \mu \mathrm{L})$ were transferred into 96-well microplate reader and $\mathrm{ABTS}^{\bullet+}(200 \mu \mathrm{L})$ were added to samples and standards then the absorbance readings were measured between 1 to 6 min after addition of $\mathrm{ABTS}^{\bullet+}$. The assay was done in triplicates. The absorbance readings were calculated and reported based on $\mu \mathrm{M}$ Trolox equivalent(TE)/g of peptide.

\subsection{Hydroxyl Radical Scavenging Assay}

The hydroxyl radical $\left({ }^{\circ} \mathrm{OH}\right)$ scavenging assay was modified on the basis of a method described by Vanvi and Tsopmo, 2016 [155]. Briefly, potassium phosphate buffer (0.75 mM, pH 7.4) was prepared and used to make $3 \mathrm{mM}$ of 1,10-phenanthroline, and two concentrations of peptide (1.0 and $0.5 \mathrm{mg} / \mathrm{mL})$. Also, a solution of $\mathrm{FeSO}_{4} \cdot 7 \mathrm{H}_{2} \mathrm{O}(3 \mathrm{mM})$ and a solution of $0.03 \% \mathrm{H}_{2} \mathrm{O}_{2}$ in water were prepared. Then blank, control and samples were transferred into a clear 96-well plate as follow: $50 \mu \mathrm{L}$ of either buffer for blank and control, or $50 \mu \mathrm{L}$ of each concentration for samples. Next $50 \mu \mathrm{L}$ of phenanthroline was added to the wells containing blank, control, and samples. Then $50 \mu \mathrm{L}$ of $\mathrm{H}_{2} \mathrm{O}_{2}$ was added to control and samples, and instead of $\mathrm{H}_{2} \mathrm{O}_{2}$, only water was added to blank. The assay performed in triplicates. The plate was sealed with plastic film and incubated in a shaker incubator for one hour at $37^{\circ} \mathrm{C}$ and $150 \mathrm{rpm}$. After the incubation period, the absorbance was measured at $536 \mathrm{~nm}$ using a BioTek ${ }^{\circledR}$ Epoch $^{\text {TM }}$ UV-Vis (Fisher Scientific, Nepean, ON, Canada). The hydroxyl radical scavenging activity then calculated using the following equation:

HO• Activity $(\%)=\left[\left(A_{s}-A_{c t l}\right) /\left(A_{b l k}-A_{c t l}\right)\right] \times 100$ 
Where $A_{s}$ is sample absorbance, $A_{b l k}$ is blank absorbance and $A_{c t l}$ is control absorbance

\subsection{Superoxide Anion Scavenging Activity}

The superoxide scavenging activity was measured according to a method described by Pownall, et al., 2011 with modifications. Peptide samples and glutathione (GSH) were dissolved in in 50 $\mathrm{mM}$ Tris- $\mathrm{HCl}$ buffer containing $1 \mathrm{mM}$ EDTA ( $\mathrm{pH} \mathrm{8.3)} \mathrm{in} \mathrm{two} \mathrm{concentrations} \mathrm{(0.5} \mathrm{and} 1.0 \mathrm{mg} / \mathrm{mL})$. Then peptide samples $(80 \mu \mathrm{L})$ were mixed with $80 \mu \mathrm{L}$ of $50 \mathrm{mM}$ Tris- $\mathrm{HCl}$ buffer directly into a clear round bottom 96-well microplate in triplicate. This was done in the dark to prevent light interference. Then, $70 \mu \mathrm{L}$ pyrogallol $(1.5 \mathrm{mM})$ dissolved in $10 \mathrm{mM} \mathrm{HCl}$ was added to each well. Control was prepared using Tris-buffer instead of samples with pyrogallol. Blank also prepared using Tris-buffer instead of samples and $70 \mu \mathrm{L}$ of $10 \mathrm{mM} \mathrm{HCl}$. Absorbance was measured at 420 $\mathrm{nm}$ every 20 seconds for $4 \mathrm{~min}$ at room temperature using BioTek ${ }^{\circledR}$ Epoch $^{\mathrm{TM}}$ UV-Vis (Fisher Scientific, Nepean, ON, Canada). The reaction rates were used to calculate the superoxide radical scavenging activity per the following equation:

Superoxide Scavenging Activity $(\%)=\{[(\Delta \mathrm{A} / \mathrm{min})$ Control $-(\Delta \mathrm{A} / \mathrm{min})$ Sample $] /[(\Delta \mathrm{A} / \mathrm{min})$ Control $]\}$ $\times 100$

\subsection{Iron (II) Chelating Assay}

Iron (II) chelating assay were performed based on a method described by Laetitia et al., 2015 [156] with modifications. Ferrous chloride $\left(\mathrm{FeCl}_{2}: 50 \mu \mathrm{L}, 0.66 \mathrm{mM}\right)$ was added to $1 \mathrm{~mL}$ of protein extract (8 different concentrations from 0.0078 to $2.0 \mathrm{mg} / \mathrm{mL}$ dissolved in water). Samples, at this point, were incubated for 15 minutes in a shaker incubator at $35^{\circ} \mathrm{C}$ and $200 \mathrm{rpm}$. The reaction was initiated by the addition of $200 \mu \mathrm{L}$ of $1.66 \mathrm{mM}$ of ferrozine solution. The mixture was vortexed and again left to stand in the incubator for 10 minutes. After the second incubation period, samples were centrifuged at 35,000 xg for 5 minutes, and the supernatant was used for absorbance reading. The samples were transferred into a 96-well plate $(200 \mu \mathrm{L})$ and the absorbance of solution was measured at $562 \mathrm{~nm}$ with a spectrophotometer BioTek ${ }^{\circledR}$ Epoch $^{\text {TM }}$ UVVis (Fisher Scientific, Nepean, ON, Canada). Control was prepared using water only instead of samples (water $+\mathrm{FeCl}_{2}+$ ferrozine) and a blank absorbance reading was measured using water 
only. All assays were repeated in triplicates. The following formula was used to calculate iron II chelating activity:

$\mathrm{Fe}^{2+}$ chelating effect $(\%)=\left[1-\left(\mathrm{A}_{\mathrm{S}} / \mathrm{A}_{C}\right)\right] * 100$

In this equation, $A_{S}$ is the sample absorbance and $A_{C}$ is the absorbance of the control.

\subsection{SDS-PAGE Electrophoresis}

Sodium dodecyl sulphate polyacrylamide gel electrophoresis (SDS-PAGE) was conducted by the method (first described by Laemmli, 1970) reported by Lee, 2005 [157]. Protein samples (1 mg/ $\mathrm{mL}$ ) were mixed 1:1 (v/v) with 5X sample buffer (loading buffer) consisting of $0.2 \mathrm{M}$ Tris (pH 6.8), $20 \%$ glycerol (v/v), 10\% SDS, $0.05 \%$ bromophenol blue and $10 \mathrm{mM} \beta$-mercaptoethanol. Then the samples were denatured in boiling water $\left(100^{\circ} \mathrm{C}\right)$ for 5 minutes. The gel system, contained $12 \%$ polyacrylamide gel with $40 \%$ polyacrylamide resolving gel $(\mathrm{pH} 8.8)$ and a $6 \%$ stacking gel (pH 6.8). Samples (30 $\mathrm{LL} /$ well) were loaded in the gel and system run at 140 volts for one hour. Protein bands were stained by immersion of the gels in a $0.1 \%$ Coomassie brilliant blue G-250 solution, in $40 \%$ methanol and $10 \%$ acetic acid solution. Bio-Rad 7-protein Kaleidescope Prestained Broad Range (MW 7,600-216,000) were used as molecular markers for SDS-PAGE electrophoresis

\subsection{MTT Assay}

The cytotoxicity and cytoprotection effects of protein hydrolysates were evaluated using a modified MTT assay described by Nair and Liu, 2010 [158]. Briefly, cells were plated in 96-well flat-bottomed microplates at a density of $2 \times 10^{4}$ cells/mL (200 $\mu \mathrm{L} /$ well), in DMEM containing $10 \%$ FBS and left in incubator for 24 hours for cells to adhere to the bottom of the wells. Media used to treat cells at all stages was supplemented with $1 \%$ antibiotic to prevent contamination. A negative control (NEG) was prepared using untreated cells and a positive control (POS) with AAPH only treated cells were used. After 24 hours, media was removed and cells were washed with $200 \mu \mathrm{L}$ phosphate buffer saline solution (PBS), pH 7.4 once and removed to add media containing protein hydrolysates. Different concentrations $(50 \mu \mathrm{g} / \mathrm{mL}$ and $100 \mu \mathrm{g} / \mathrm{mL})$ of the protein hydrolysates were prepared in media, then added to the cultures and incubated for 24 hours. In the case of protein hydrolysates cytotoxicity, the media was removed and cells were washed 
once with PBS and MTT assay was performed. However, in the case of protein hydrolysates cytoprotection, a media containing AAPH (10 mM) was added to HepG2 cells and incubated for another 24 hours. Again, before MTT assay to evaluate cytoprotection, media was removed and cells were washed with PBS once.

One hundred $\mu \mathrm{L}$ of media followed by $10 \mu \mathrm{L}$ of filtered MTT $(5 \mathrm{mg} / \mathrm{mL}$ in PBS) were added to all wells. Plates were incubated for 1 hour at $37^{\circ} \mathrm{C}$ and after the incubation period, MTT solution was removed and $50 \mu \mathrm{L}$ of dimethyl sulfoxide (DMSO) was added to the wells. Absorbance was measured at $570 \mathrm{~nm}$ with $630 \mathrm{~nm}$ background subtraction using a microplate reader (Epoch, Biotek Instruments Inc.).

\subsection{Cell Treatment}

The following cell treatment procedure was followed for all enzymatic assays, total glutathione and Caspase- 3 assay. Briefly, HepG2 cells were seeded at $5 \times 10^{5}$ cell/mL (4 mL/plate) in $60 \mathrm{~mm}$ tissue culture plates and incubated at 24 hours for cells to adhere. After 24 hours, media was discarded and plates were washed twice with $4 \mathrm{~mL}$ PBS ( $\mathrm{pH} 7.4)$. Protein hydrolysate samples were dissolved in media for two concentrations of 50 and $100 \mu \mathrm{g} / \mathrm{mL}$ and added to the plates (4 $\mathrm{mL} / \mathrm{plate}$ ) and incubated for 24 hours. After treating cells with protein hydrolysates, media was removed and cells were washed with $4 \mathrm{~mL}$ PBS twice. Then the cells were treated with $10 \mathrm{mM}$ AAPH ( $4 \mathrm{~mL} /$ Plate) for 24 hours. Cells were treated using $0.5 \mathrm{~mL}(0.25 \%)$ trypsin, incubated at $37^{\circ} \mathrm{C}$ for five minutes, and then $1 \mathrm{~mL}$ culture media was added to each plate to inhibit trypsin activity. Plates were kept on ice to be harvested. Cells were collected in Eppendorf tubes and cell pellets were obtained by centrifuging at 1,000xg for 5 minutes. Then supernatant was removed and cells were re-suspended in ice-cold PBS $(500 \mu \mathrm{L})$. Additional centrifugation may be required to remove media until no pink color is observed. Depending on the assay, the cell pellet was resuspended in $800 \mu \mathrm{L}$ of ice-cold PBS for catalase, glutathione peroxidase and superoxide dismutase. For total glutathione and caspase-3, cell lysis buffer was added, which was explained in the related experimental method. Then the cells were lysed by sonication on ice for 1 minute using a probe-type sonicator (Vibra-Cell, Sonics \& Materials Inc.) pulsing at 15 seconds on, 10 seconds off cycles at 50\% power. For Caspase-3, pulsing was adjusted to 10 second on and 10 
second off cycle. To separate cell components, cell lysates were centrifuged at 13,000xg for 5 minutes, and supernatant were collected and used for enzymatic assays, total glutathione and Caspase-3, as well as to measure protein content (Lowry). Negative (NEG) controls were prepared using cells treated only with media and Positive (POS) controls were treated only with $\mathrm{AAPH}$, no peptide was used for controls. All sample media was prepared containing Gibco 100X Antibiotic-Antimycotic dissolved and diluted 100 times.

\subsection{Antioxidant Enzyme Assay}

\subsubsection{Catalase}

Catalase activity was evaluated using a method originally described by Beers and Sizer, 1952 [159]. A $50 \mathrm{mM}, \mathrm{pH}$ 7.0, potassium phosphate buffer was prepared and 1,790 $\mu \mathrm{L}$ of the buffer mixed with $200 \mu \mathrm{L}$ cell lysate in a quartz cuvette. To this mixture, $10 \mu \mathrm{L} \mathrm{H}_{2} \mathrm{O}_{2}$ (30\%) was added, and immediately the removal of $\mathrm{H}_{2} \mathrm{O}_{2}$ by catalase was measured using a spectrophotometer (Cary 50 Bio UV-Vis, Varian Inc.). Wavelength was set at $240 \mathrm{~nm}$. Unit of catalase can be calculated using the following formula:

Unit Catalase $=($ Absorbance change rate at $240 \mathrm{~nm} / \mathrm{min} \times 1,000) / 39.4 \mathrm{~mol}^{-1} \mathrm{~cm}^{-1}$

(Where $39.4 \mathrm{~mol}^{-1} \mathrm{~cm}^{-1}$ is, the hydrogen peroxide molar extinction coefficient.)

To report catalase activity per milligram protein, protein content was determined using Lowry method of protein evaluation. Catalase activity was expressed as percentage relative to control.

\subsubsection{Glutathione Peroxidase}

Glutathione peroxidase was determined using a method described by Lawrence and Burk, 1974 and modified to be performed in 96-well microplate [160]. A $50 \mathrm{mM}$ potassium phosphate stock buffer (pH 7.0) containing 1.1 mM EDTA and $1.1 \mathrm{mM} \mathrm{NaN}_{3}$ was prepared. On the day of the experiment, a working buffer was prepared using stock buffer containing 1 Unit/mL GSSGreductase (GR), and $1 \mathrm{mM}$ GSH. Also, a $4.0 \mathrm{mM} \mathrm{NADPH}$ solution in stock buffer was prepared on the day of the assay and kept on ice. A $2.5 \mathrm{mM} \mathrm{H}_{2} \mathrm{O}_{2}$ was prepared fresh before assay and the absorbance was controlled at $240 \mathrm{~nm}$ wavelength and diluted to obtain an absorbance reading of 0.099 . For the assay, $187.5 \mu \mathrm{L}$ of working buffer was transferred to each well in 96 -well plate 
microplate and $12.5 \mu \mathrm{L}$ of $4.0 \mathrm{mM}$ NADPH solution were added to all the wells, followed by addition of $25 \mu \mathrm{L}$ of samples or GPx standards and stock buffer (used for blank). The reaction initiated by addition of $25 \mu \mathrm{L}$ of $\mathrm{H}_{2} \mathrm{O}_{2}$ and incubated at $30^{\circ} \mathrm{C}$ for 5 minutes. The change in absorbance were measured at $340 \mathrm{nM}$ for 5 minutes using BioTek ${ }^{\circledR}$ Epoch $^{\text {TM }}$ UV-Vis (Fisher Scientific, Nepean, ON, Canada) spectrophotometer. GPx activity was calculated using the following equation and reported based on protein content (evaluated by Lowry method):

UGPx $/ \mathrm{mg}$ Protein $=\left\{\left[\left(\right.\right.\right.$ Abssample - Abs $\left._{\text {Blank }}\right) /$ minute $\left.] / 6.22 * 2\right\} /($ Protein $/ \mathrm{mL})$

Where 6.22 is NADPH extinction coefficient of $\mathrm{NADPH}$, and 2 is conversion factor for converting GSSG to 2 GSH. One unit of GPX activity is calculated as the amount of protein that can oxidize 1 $\mu \mathrm{M}$ NADPH per min. Protein content was evaluated using Lowry method of protein determination.

\subsubsection{Superoxide Dismutase}

Superoxide dismutase (SOD) enzyme activity was measured using the BCS-NBT assay described by Spitz and Oberley (1989) [161] and the method was modified to be conducted in 96-well microplate. An assay solution was prepared using BSA-DETAPAC buffer (50 mM phosphate buffer - pH 7.8, 1.0 mM DETAPAC, and 0.202 mg/mL BSA), $40 \mathrm{U} / \mathrm{mL}$ Catalase, $2.24 \mathrm{mM} \mathrm{NBT,} 1.18 \mathrm{mM}$ xanthine, and $0.01 \mathrm{M}$ BCS. A $0.06 \mathrm{Unit} / \mathrm{mL}$ xanthine oxidase solution was prepared and concentrations were adjusted so the absorbance rate was measured between 0.016 to 0.025 ideally at 0.020 - per minute. To conduct the assay, $25 \mu \mathrm{L}$ of sample, standard, or buffer (blank) was mixed with $200 \mu \mathrm{L}$ of assay solution, and to initiate the reaction $25 \mu \mathrm{L}$ of xanthine oxidase solution was added to the mixture. The change in absorbance was measured at $560 \mathrm{~nm}$ using a microplate spectrophotometer BioTek ${ }^{\circledR}$ Epoch $^{\text {TM }}$ UV-Vis (Fisher Scientific, Nepean, ON, Canada). Percent inhibition was calculated using the following equation:

Percent inhibition $=[($ blank rate - sample rate $) /$ blank rate $] \times 100 \%$

Results were reported as the amount of protein (evaluated by Lowry) that inhibited NBT reduction by $50 \%$. The assay was conducted in triplicate. 


\subsection{Total Glutathione}

Total glutathione was measured using the enzymatic recycling method as described by Rahman et al., 2007, for use in a 96-well microplates [162]. Cells were cultured as per the method explained in section 2.10. Just prior to sonication a cell lysis buffer was made using $0.1 \mathrm{M}$ potassium phosphate buffer with $5 \mathrm{mM}$ EDTA (pH 7.5), $0.1 \%$ Triton- $\mathrm{X}$, and $0.6 \%$ sulfosalicylic acid. One milliliter of cell lysis buffer was used to re-suspend cell pallet and sonication procedure was followed as previously mentioned. For the assay a serial dilution of GHS and GSSG was prepared ranging from $0.103-26.4 \mathrm{nM} / \mathrm{mL}$ ) to construct the standard curve. A solution of 2-vinylpyridine was prepared by diluting in potassium phosphate buffer at ratio of 1:10 (v/v) and kept on ice. Triethanolamine was diluted 1:6 with buffer. Two milligrams of DNTB and $2 \mathrm{mg}$ of $\beta$-NADPH were dissolved in $3 \mathrm{~mL}$ of the buffer, protected from light and kept on ice. Glutathione reductase (40 $\mu \mathrm{L}, 250$ units $/ \mathrm{mL}$ ) was mixed with $3 \mathrm{~mL}$ buffer and kept on ice. To measure total glutathione, 20 $\mu \mathrm{L}$ of samples, standards and buffer (blank) were added to the wells. Then an equal amount of DTNB and GR solution were mixed together and $120 \mu \mathrm{L}$ of this mixture was added to the wells. After 30 seconds, $60 \mu \mathrm{L}$ of $\beta$-NADPH was added to the wells and absorbance was measured immediately at $412 \mathrm{~nm}$ applying kinetic reading for 2 minutes at 30 second intervals using BioTek

${ }^{\circledR}$ Epoch $^{\mathrm{TM}}$ UV-Vis (Fisher Scientific, Nepean, ON, Canada) spectrophotometer. Total GSH was calculated using GSH standard curve and results reported based on glutathione content per mg protein content evaluated using Lowry assay. To measure reduced glutathione (GSSG), $100 \mu \mathrm{L}$ of cell lysate were mixed with $2 \mu \mathrm{L}$ of 2 -vinlylpyridine and the mixture was let to stand at room temperature in a fume hood. Then, $6 \mu \mathrm{L}$ of triethanolamine was added to the mixture and incubated for 10 minutes at room temperature. The procedure to measure total GSH was repeated and measurements were recorded at $412 \mathrm{~nm}$. Results were interpreted using GSSG standard curve and expressed based on protein content. The samples, standards, and blank were prepared in triplicates.

\subsection{Caspase-3 Activity}

Caspase-3/CPP32 Colorimetric Assay Kit (Biovision, Catalog \#K 106-100) was used to determine the apoptosis induced by AAPH with minor modifications. Cell treated as explained in the section 2.10. Cell Treatment section and the procedure was followed. Cells were harvested, and pelleted 
at $1-5 \times 10^{6}$, and lysed in the lysis buffer provided in the kit. Lowry assay was conducted to determine protein content prior to the assay. Fifty $\mu \mathrm{g}$ cell lysate protein was diluted in $50 \mu \mathrm{L}$ cell lysis buffer for each sample and $50 \mu \mathrm{L}$ of $2 \times$ Reaction Buffer (containing $10 \mathrm{mM} \mathrm{DTT}$ ) was added to each sample. Five $\mu \mathrm{L}$ of $4 \mathrm{mM}$ DEVD-pNA substrate (200 $\mu \mathrm{M}$ final concentration) was added and then the tube was incubated at $37{ }^{\circ} \mathrm{C}$ for 1-2 h. Absorbance changes of samples were measured at $405 \mathrm{~nm}$ in a microplate reader BioTek ${ }^{\circledR}$ Epoch $^{\text {TM }}$ UV-Vis (Fisher Scientific, Nepean, ON, Canada) spectrophotometer. Absorbance values were quantified in triplicates. A blank was also prepared using cell lysis buffer only.

\subsection{ROS DCFH2-DA Determination}

Reactive oxygen species were determined using a modified method described by Wolfe and Liu,

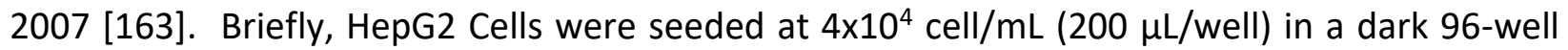
plate view tissue culture plates and incubated at $37^{\circ} \mathrm{C}, 5 \% \mathrm{CO}_{2}$ for 24 hours prior to assay. After 24 hours, culture medium was aspirated and cells were washed with $200 \mu \mathrm{L}$ PBS (pH 7.4) twice. Then media with or without samples (50 and $100 \mu \mathrm{g} / \mathrm{mL}$ ) were added to the wells. Cells were incubated for 4 hours. After initial incubation period, media was removed and cells were washed with $200 \mu \mathrm{L}$ PBS twice, and replaced with medial containing $1.5 \mathrm{mM} \mathrm{AAPH}(200 \mu \mathrm{L} /$ well $)$. The cells were incubated again for 45 minutes. After AAPH treatment, media was aspirated and replaced with $200 \mu \mathrm{L}$ of treatment media composed of $40 \mathrm{mM}$ dihydrochlorofluoresceindiacetate (DCFH 2 -DA) and $10 \mathrm{mM}$ HEPES. Fluorescent intensity was read immediately and measurement was carried out at 5 minute intervals for one hour, using FLUOstar-OPTIMA (BMGLABTECH, Germany) at an excitation wavelength at $485 \mathrm{~nm}$ and emission at $530 \mathrm{~nm}$. Untreated cells were used as negative control (NEG), whereas positive control (POS) consists of cells treated with AAPH only. Change in fluorescent intensity was calculated using the following equation:

Percent increase in fluorescent $=[($ final reading-initial reading $) /$ initial reading $] \times 100$

Results were normalized as per mg protein content evaluated by Lowry assay and percent change in fluorescent was reported based on \%NEG. 


\subsection{Lowry Protein Determination Assay}

The protein content of samples and cell cultures was determined based on the method described by Markwell et al.1978, using bovine serum albumin as the standard [164]. Reagent A stock solution was made containing $2.0 \%$ sodium carbonate $\left(\mathrm{Na}_{2} \mathrm{CO}_{3}\right), 0.4 \%$ sodium hydroxide $(\mathrm{NaOH})$, $0.16 \%$ sodium tartrate, and $0.5 \%$ SDS in deionized water. Reagent B was prepared containing $4 \%$ cupric sulfate pentahydrate $\left(\mathrm{CuSO}_{4} \cdot 5 \mathrm{H}_{2} \mathrm{O}\right)$. Reagent $\mathrm{C}$ was composed of mixing reagent $\mathrm{A}$ and $\mathrm{B}$ $(100: 1 \mathrm{v} / \mathrm{v})$ on the day of assay. Also, a 1:1 dilution of $2.0 \mathrm{~N}$ Folin-Ciocalteu phenol reagent was prepared fresh right before the assay. A standard curve was generated using a serial dilution (0$200 \mu \mathrm{g} / \mathrm{mL}$ ) made from bovine serum albumin (BSA) and used to calculate the protein content of samples or cell lysates. To measure protein content, in an Eppendorf tube, $200 \mu \mathrm{L}$ of reagent C was mixed with either $66.7 \mu \mathrm{L}$ protein hydrolysate sample ( 80 and $120 \mu \mathrm{g} / \mathrm{mL}$ ), or $66.7 \mu \mathrm{L}$ of cell lysate (up to $5 \mathrm{X}$ dilution was required for cell lysates). The resulting mixture was incubated at room temperature for 25 minutes. After initial incubation, $20 \mu \mathrm{L}$ of diluted and fresh FolinCiocalteu phenol reagent was added and incubated again at room temperature for 45 minutes.

The assay was done in triplicates and the absorbance of all samples and BSA standards were measured at 660nm using a microplate reader BioTek ${ }^{\circledR}$ Epoch $^{\text {TM }}$ UV-Vis (Fisher Scientific, Nepean, ON, Canada). BSA standard curve constructed and protein content of samples and cell lysates were calculated using BSA standard curve.

\subsection{Statistical Analysis}

All experiments were performed in triplicate $(n=3)$, and one-way analysis of variance (ANOVA) tests (SAS ${ }^{\circledR}$ Software, SAS OnDemand, 9.4, 2017) were used to compare the mean values of each treatment. Significant differences between the means of values were evaluated using Duncan's multiple range test $(p<0.05)$. 


\section{Results and Discussion}

\subsection{Hydrolysis of Proteins and Characterization of Protein Isolates and Hydrolysates}

Cereals are rich in polysaccharides that can make protein extraction difficult. To increase protein extraction efficiency, carbohydrases can be used to decrease the viscosity of slurries or release proteins bound to polysaccharides [165]. In this work, cellulase, an endocellulase that hydrolyze $\beta$-1,4-glycosidic linkages [166], and Viscozyme, a multi-carbohydrase complex were used to increase the efficiency of extracting proteins from oat brans as previously reported [167].

Cellulose is a complex network of $\beta-1,4-$ glycosidic linkages that is resistant to hydrolysis, however, cellulase can catalyze its hydrolysis into glucose components. Using cellulase for enzymatic digestion is an effective method to release internal components such as proteins. The cellulase used in this study was isolated from the fungi Trichoderma reesei, and normally is composed of three distinct enzymes known as cellobiase or $\beta$-glucosidase (effective on glycosidic bonds), endocellulase (cleave internal glycosidic bonds), and exocellulase (cleaving and producing disaccharides) [168]'[169]. Viscozyme on the other hand is a cell wall degrading enzymes complex from Aspergillus sp. with a broad range of carbohydrases, including arabanase, cellulase, $\beta$-glucanase, hemicellulase, and xylanase [170]. It is has been used for hydrolysis of fruit and vegetable pectin, an abundant component of plant cell wall [171].

To release peptides from OBPIs, four proteases were used to produce eight hydrolysates. These proteases were Alcalase, Flavourzyme, Papain, and Protamex. Alcalase, also known as subtilisin, is a serine endopeptidase that breaks the peptide bond through a serine (SER or S) residue, and at its active site acting as nucleophile, donating electron to the carbon of the protein on Cterminus site to cleave peptide bond [172]. Flavourzyme is an enzyme with both endo- and exopeptidase activities and cleaves proteins by hydrolysis of peptide bonds [173]. The use of Flavourzyme enhances the solubility of protein hydrolysates and produces smaller size peptides [174]. However, activity of Flavourzyme depends on the substrate used, can be either efficient [175] or inefficient [176]. Flavourzyme and Alcalase similary increase methionine and aromatic amino acids in protein hydrolysates [177]. Protamex, is a protease complex produced by Bacillus $s p$. It affects disulfide linkages[178],[179]. Papain, from papaya latex, catalyzes the hydrolysis of 
peptide bonds with tendency towards cleavage of amino acid containing a large hydrophobic side

chain [180]. Papain belongs to cysteine proteases group with catalytic unit formed by $\mathrm{Cys}_{25}-\mathrm{His}_{159}$ and cleaves preferentially at aromatic, basic and nonpolar residues (e.g. phenylalanine) in the substrates [181]. For this study, these proteases were selected to produce hydrolsates with various lengths and sequences, hence maximizing the potential to discover one with excellent biological properties.

Since there is salt in hydrolysates and to determine the effect of activity one sample - Visc/Flav $\mathrm{OPBH}$ - was picked and dialyzed (100 Da MWCO) to reduce impurities such as LMW compounds and salt. Its activity was compared to the of the non-dialyzed sample. All OBPI and OBPH samples were characterized based on protein contents and average molecular weights.

\subsection{Protein Contents}

Amounts of proteins in OBPIs and OBPHs were quantified and used as a way to assess the extraction efficiency. Values are show in Figure 9. The protein content of OBPI was $54.2 \%$ in Cellulase treated and was $43.9 \%$ in Viscozyme treated oat bran. In OBPH, Viscozyme-derived peptides samples ranged from 43.1 - 69.9\%, and Cellulase-derived OBPH ranged from 50.9 87.0\%. In Viscozyme-derived OBPH, an increase in protein content was observed in Visc/Alca, Visc/Papa and Visc/Flav D, indicating the protein content of the hydrolysate samples was higher than the OBPI treated with Viscozyme only sample. The increase in calculated protein content of OBPH is attributed to an increase in solubility of smaller peptides [182]. In Cellulase-derived $\mathrm{OPBH}$, no significant increase was observed compared to Cellulase treated OPBI, except for Cell/Papa treated OBPH.

In a previous study done by Jodayree et al. (2012), amount of protein from Cellulase treated oat bran was calculated to be at $53 \%$ which is close to calculated protein content of OBPI in this work. However, for Viscozyme used in this assay, the amount of proteins in OBPI is lower by about $25 \%$ [167]. The low protein contents of the samples may be due to the presence of interfering compounds such as salts, reducing sugars, and buffer components [183],[184]. Apart from the effect of interfering compounds, it is possible for protein isolates to aggregate and therefore, their solubility is reduced. Such decrease in solubility were observed in plant protein isolates or 
hydrolysates, and it is suggested that increased cleavage and release of hydrophobic amino acids may be the driving force for aggregation of these compounds [185],[186],[117]. This may also explain possible low value of Visc/Alca (56\%), and Cell/Alca (48\%), compared to the previous study at $68 \%$ and $53 \%$, respectively. Among the OBPH, both samples that were treated with papain - Cell/Papa (87\%) and Visc/Papa (69\%) - showed higher protein content. Early work on the activity of papain showed that this enzyme had specific preference for substrate containing amino acid phenylalanine (aromatic and non-polar residue) followed by a hydrophobic or basic residues such as alanine e.g. Phe-Ala sequence [120]. It is possible that cleavage at this site increases concentration of hydrophobic peptides. However, it is mentioned in different studies that papain has a broad selectivity range for preferred peptide linkage and therefore, using papain may result in increased protein content measurable by Lowry assay [187],[188]. The calculated protein content of OBPI and OBPH was slightly higher than the ones isolated from rice [189], however, it was slightly lower than the protein isolated from pea protein using Alcalase and Flavourzyme, with the exception of papain treated samples which was in the same range [190].

It is important to assess the correlation of the protein content of OBPI and OBPH in antioxidant activity assay with their ability to scavenge free radicals. 


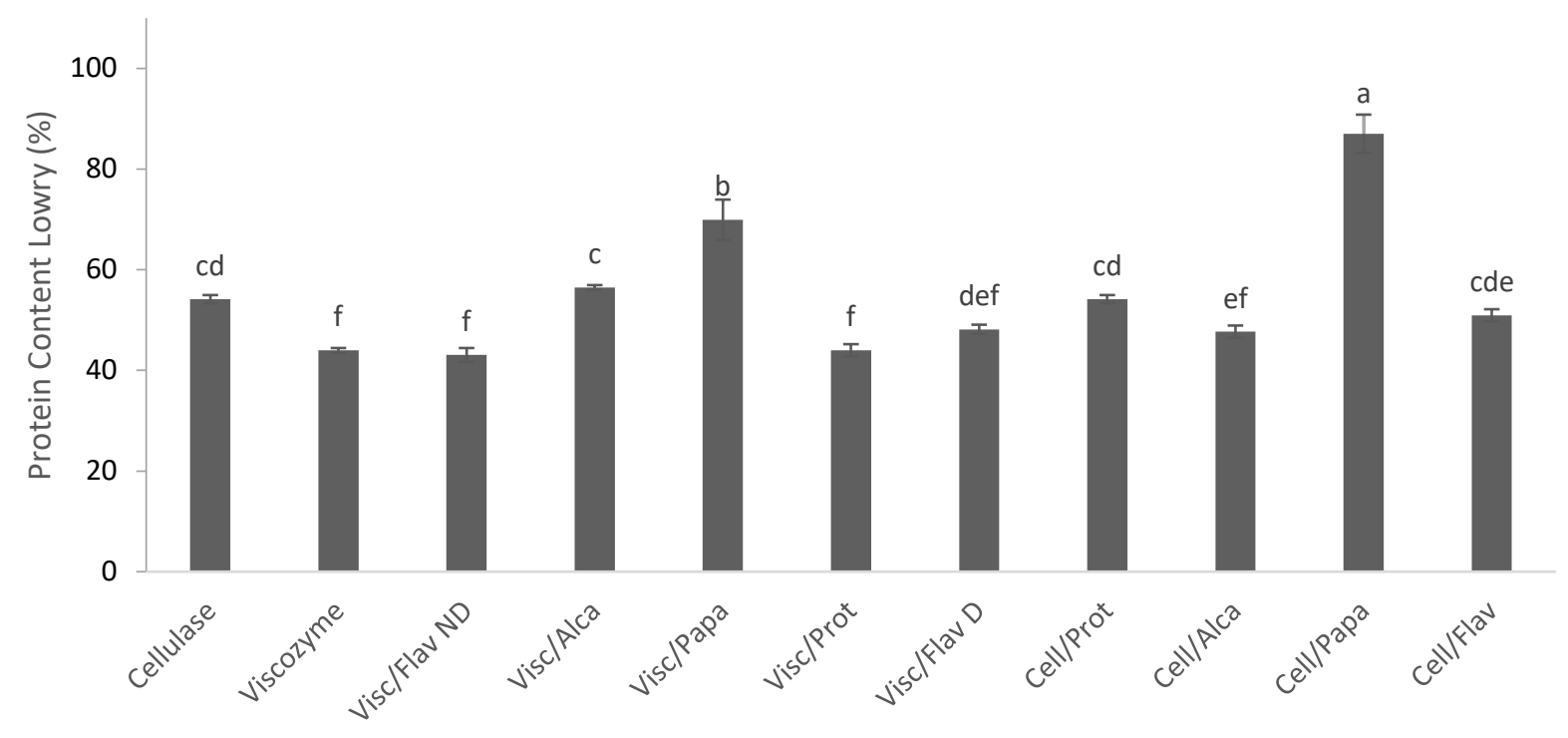

Figure 9. Protein content of protein hydrolysates. Cellulase (cell) and Viscozyme (Visc) were the primary carbohydrases used, and proteases were used as the second stage digestion enzymes. Alca: Alcalase, Flav: Flavourzyme, Papa: Papain, and Prot: Protamex. Different letters show significant difference between group means $(P<0.05)$. Data showed as means $\pm \operatorname{SEM}(n=3)$

\subsection{Molecular Weight Determination by SDS-PAGE Gel Electrophoresis}

Oat proteins are unique qualitatively and quantitively compared to other cereals. The major storage proteins in oats are globulins and prolamins. Major fractions in oat globulins are 3, 7, and $12 \mathrm{~S}$ globulins. $12 \mathrm{~S}$ globulin consists of two major subunits $A$ and $B$ with molecular weight of around 32 and $22 \mathrm{kDa}$. 7S has a molecular weight of $55 \mathrm{kDa}$, and $3 \mathrm{~S}$ has two fractions with molecular weight of 15 and $21 \mathrm{kDa}$ [191].

SDS-PAGE gel electrophoresis (Figure 10) showed that Viscozyme treated OBPI had intense protein bands around 55, 32 and $7.6 \mathrm{kDa}$. These corresponds to 7S globulin and $12 \mathrm{~S}$ globulin. Cellulase treated OBPI showed two bands around 50 and $20 \mathrm{kDa}$ and one band with less than 7.6 kDa. Molecular weights of proteins in each carbohydrase treated bran are different. Both enzymes had released major proteins in oat bran, however, smaller fractions with less than 7.6 $\mathrm{kDa}$ were also released, which possibly due to presence of small protein resulted of partially hydrolyzed proteins by the activity of the carbohydrases. In Viscozyme treated OBPI, 7S with molecular weight of between 75 and $43 \mathrm{kDa}$, was visibly formed. The $7 \mathrm{~S}$ globulin fraction is a great substrate for the activity of papain and papain-like enzymes [188]. The activity of papain like enzyme results in converting insoluble protein to water-soluble $43 \mathrm{kDa}$ fractions, consisting 
of 30 and $10 \mathrm{kDa}$ peptides [192]. Protein fractions released by the activity of enzymes possess different properties. For example, they can be water soluble, soluble in alcohol or dilute salt, acid or alkaline solutions with acidic or basic properties. The enzymatic activity of carbohydrase/protease produced an array of proteins and peptide fractions with wide range of chemical properties, that make them effective as antioxidants in hydrophilic or hydrophobic environment.

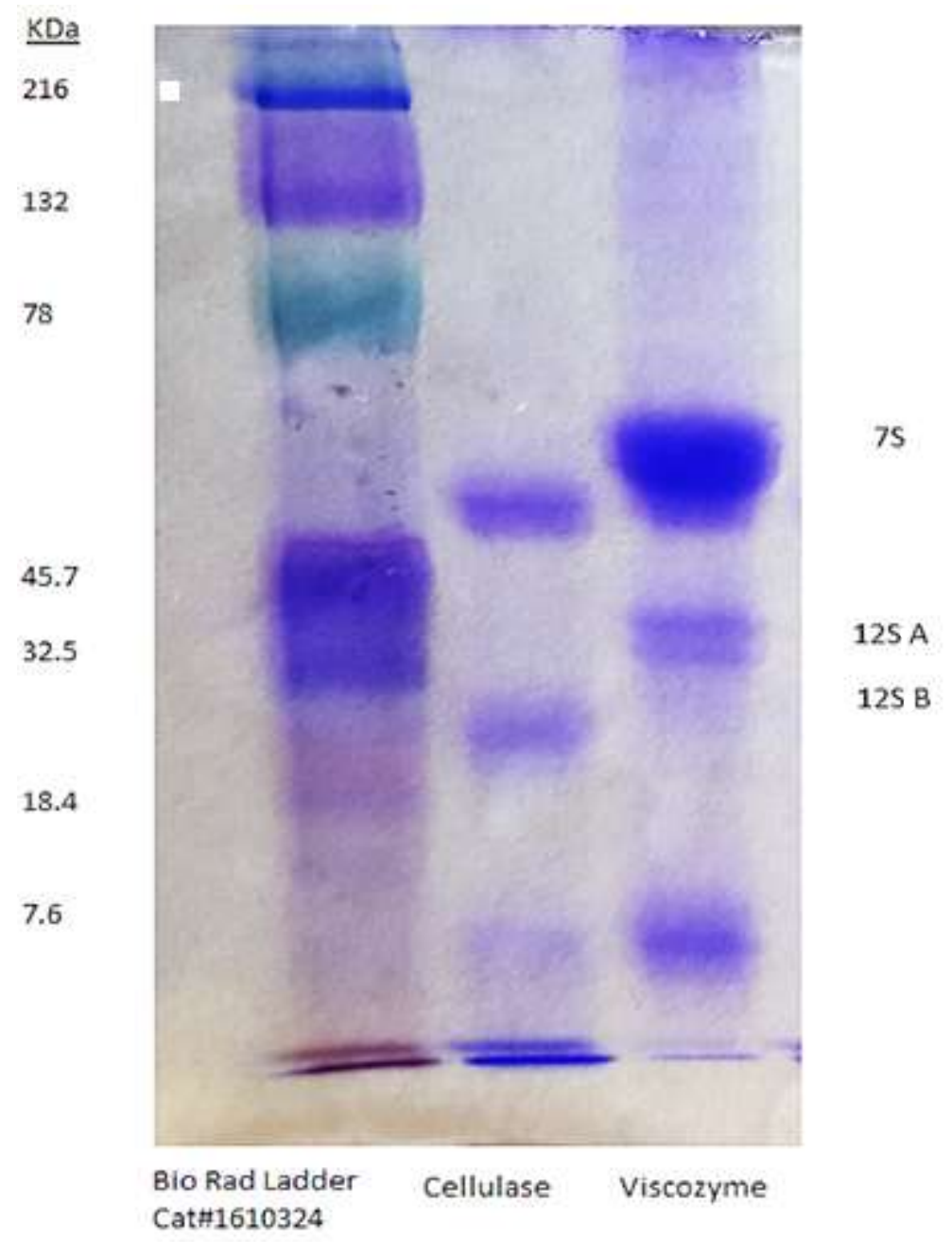

Figure 10. Gel electrophoresis of OBPI fractions.

In the SDS-PAGE gel electrophoresis, no visible bands appeared in OBPH samples, which was an indication of complete protein hydrolysis and formation of low molecular weight (LMW) peptides $(<7 \mathrm{kDa})$ too small for gel to trap the fractions inside gel network. Normally, protein hydrolysates have molecular weight smaller than $6 \mathrm{kDa}$ [101]. A similar result was also reported for maize 
protein hydrolysates and it was deduced that hydrolysates were possibly a mixture of extremely small peptides [193]. Protein hydrolysates can be fractionated to enhance their activity. Literature data suggest the use of size exclusion chromatography (SE-HPLC) for fractionations ranging between 7,000 and $100 \mathrm{Da}[194],[195]$.

\subsection{Antioxidant Properties}

Mechanisms by which antioxidants quenches free radicals are divided into two primary groups known as hydrogen atom transfer (HAT) and (single) electron transfer (ET or SET) [196],[197],[198]. ET mechanism is non-competitive and an antioxidant is capable of termination the oxidation reactions by transferring a single electron to a free radical. This phenomenon is easily measurable by the change in spectrophotometric absorbance to evaluate the reducing capacity of the antioxidant. In HAT-based assays, the quenching mechanism is based on competitive reactions of the oxidant/antioxidant with the substrate for the free radicals, in which the antioxidant donates hydrogen atom to neutralize the free radicals and makes it possible to monitor the change in probe oxidation [199],[200],[201]. It is suggested to use different methods of evaluation of the antioxidant capacity since each assay measures a specific properties of antioxidants or oxidation conditions [101],[196]. For the purpose of this thesis HAT (e.g. ORAC) and ET (e.g. ABTS) based assays were used to determine the activity of samples.

\subsubsection{Oxygen Radical Absorbance Capacity (ORAC)}

The two protein isolates (OBPI) and eight protein hydrolysates (OBPH) were analyzed by the oxygen radical absorbance capacity (ORAC) assay to measure their potential to scavenge peroxyl radicals. The values obtained from two concentrations were normalized to a known concentration of Trolox (a water-soluble vitamin $E$ analogue) equivalents per gram (TE/g) of freeze-dried samples. The assay protocol is based on measurable destructive effects of AAPHgenerated peroxyl radicals on fluorescein probe and reduction of fluorescent intensity [202]. The presence of antioxidants in samples prevent the damaging effects of peroxyl radicals, and the changes in fluorescence intensity can be evaluated using a fluorometer set to read excitation wavelength of $485 \pm 20 \mathrm{~nm}$ and an emission wavelength of $530 \pm 25 \mathrm{~nm}$ [201]. In ORAC assay, production of AAPH generated peroxyl radical is a thermodynamic reaction and there is a need 
for a built-in incubator to control temperature in the environment at $37^{\circ} \mathrm{C}[196]$. Peroxyl radical scavenging activities (ORAC values) were measured and shown in Figure 11. The higher value was an indication of better scavenging power.

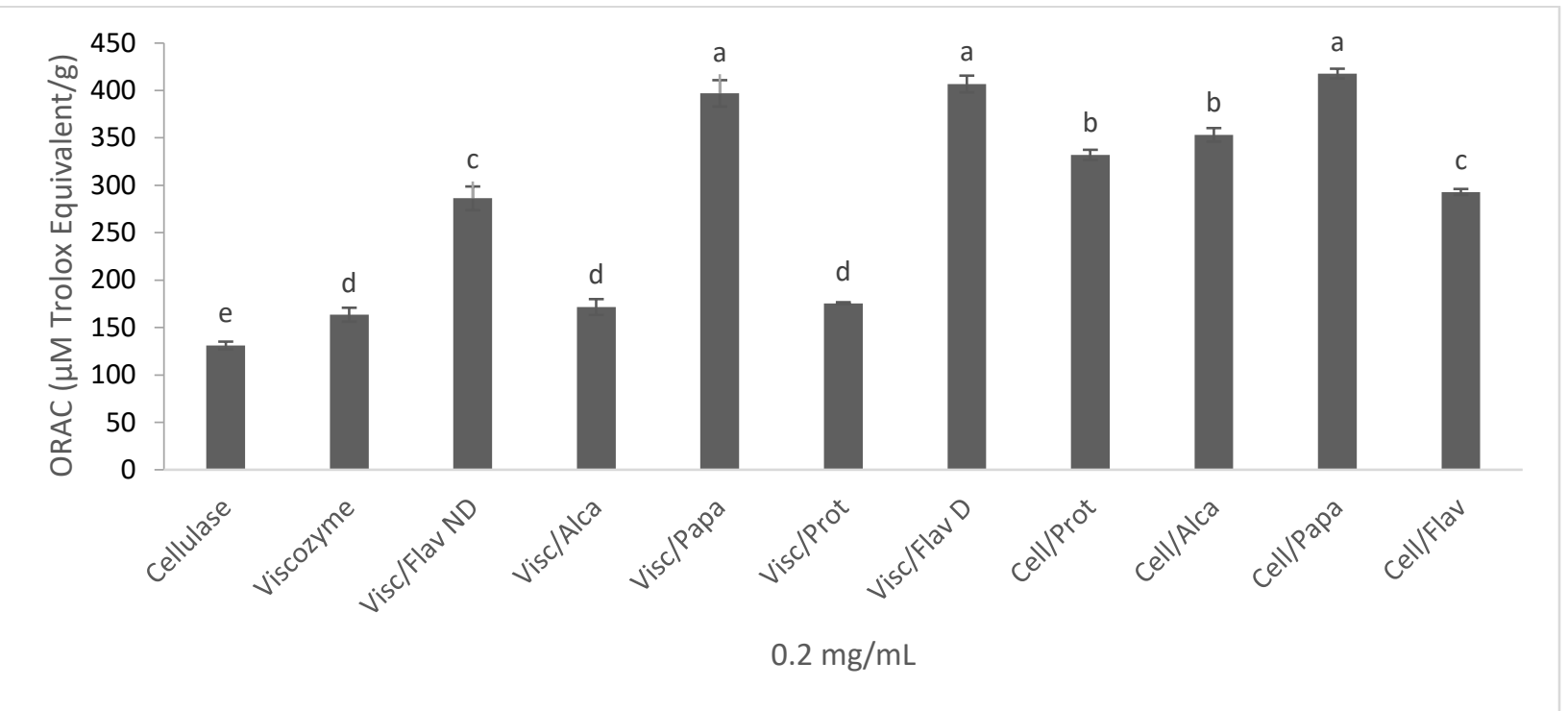

Figure 11. Oxygen radical absorbance capacity (ORAC) values based on $\mu M$ Trolox equivalent/g of freeze-dried protein hydrolysates (concentration: $0.2 \mathrm{mg} / \mathrm{mL}$ ). Cellulase (cell) and Viscozyme (Visc) were the primary carbohydrases used, and proteases were used as the second stage digestion enzymes. Alca: Alcalase, Flav: Flavourzyme, Papa: Papain, Prot: Protamex, ND: Non-Dialysis, and D: Dialysis. Different letters show significant difference between group means $(P<0.05)$. Data showed as means $\pm \operatorname{SEM}(n=3)$

The antioxidant capacity of protein hydrolysates was measured at $0.2 \mathrm{mg} / \mathrm{mL}$. It can be seen in Figure 11 that samples demonstrated different peroxyl radical (ROO') scavenging activities. Cell/Papa (417.85 $\pm 5.1 \mu \mathrm{M}$ TE/g), Visc/Flav D (406.87 $\pm 8.8 \mu \mathrm{M}$ TE/g) and Visc/Papa (396.97 \pm 13.9 $\mu \mathrm{M} \mathrm{TE} / \mathrm{g})$ had the highest activities followed by Cell/Prot $(332.10 \pm .5 .4)$ and Cell/Alca $(353.19 \pm 7.2)$. One of the samples - Visc/Flav - was randomly picked and a membrane dialysis procedure (Biotech CE Tubing, MWCO: 100 - 500 Da) was applied to evaluate if desalting, or elimination of compound with small molecular weight - between 100 to $500 \mathrm{Da}$ - could improve antioxidant ability of the hydrolysates. The sample with ND abbreviation was the original samples with no dialysis applied to it. Visc/Flav D treated samples showed a significantly higher antioxidant activity compare to the Visc/Flav ND samples (286.27 $\pm 12.5 \mu \mathrm{M} \mathrm{TE} / \mathrm{g})$. Apparently, dialysis helped to improve ORAC value in OPBH possibly by reducing salt and LMW peptides 
concentrations. Visc/Alca (171.60 $\pm 8.4 \mu \mathrm{M} \mathrm{TE} / \mathrm{g})$ and Visc/Prot (175.60 $\pm 1.1 \mu \mathrm{M} \mathrm{TE} / \mathrm{g})$ showed the lowest radical absorbance capacities.

The protein isolates from cellulase and Viscozyme treated oat brans also demonstrated peroxyl radical scavenging activity; however, the values were also low for cellulase treated samples at $131.08 \pm 4.1 \mu \mathrm{M} \mathrm{TE} / \mathrm{g}$ and Viscozyme at $163.5 \pm 7.3 \mu \mathrm{M} \mathrm{TE} / \mathrm{g}$. Other samples were valued in between the highest and the lowest value of $\mu \mathrm{M}$ TE/g. GSH, a known antioxidant peptide, had a value of $673.40 \pm 3.5 \mu \mathrm{M} \mathrm{TE} / \mathrm{g}$ (not shown here). All samples showed antioxidant activity at some extent. The two samples hydrolyzed with Papain as well as Visc/Flav-D had the highest ORAC values. Factors affecting radical scavenging activity of protein hydrolysates are size, hydrophobicity and amino acid composition of protein hydrolysates. For this study, the compositions of protein hydrolysates remained to be elucidated later, however, it was possible to foresee the possible composition of protein hydrolysate by knowing the preferred substrate and cleavage sites of each protease. In this study, four proteases were used and they were, Alcalase, Flavourzyme, Papain and Protamex. Papain has a broad range of preferred substrate. However, many studies showed this enzyme has a cleavage preference for sites containing amino acid Phenylalanine (aromatic and non-polar residue) followed by hydrophobic or basic residues such as Lysine, Valine and Alanine e.g. Phe-Ala sequence [120]. It is proven that increased hydrophobic residues in the protein hydrolysate may positively improve antioxidant activity of the protein hydrolysates [203],[204]. Overall, papain prefers the large hydrophobic amino acid residues such as Phenylalanine, Valine, and Leucine at the P2 position, which all seemed to be great contributors to increased antioxidative activity of protein hydrolysates [205],[206],[193].

Values obtained for OBPIs in this work are similar to those obtained in a previous study of oats 95 and $106 \mu \mathrm{M} \mathrm{TE} / \mathrm{g}$ for cellulase and viscozyme treated oats, respectively [167]. Most OBPHs had higher ORAC values than their OBPI, except for Visc/Alca and Visc/Prot treated samples, however, they were still in a good range compared to other food derived protein hydrolysates. For example, Alcalase soy hydrolysate ORAC value (peroxyl radical scavenging) was reported as to be $84 \mu \mathrm{M} \mathrm{TE} / \mathrm{g}$ while activities of hydrolysates $(1-3 \mathrm{kDa})$ were much higher [207]. Based on the observed results, it was deduced that the OBPIs and their Alcalase derive OBPHs values are in the same range as a previous study [167]. Data from this work are similar to those of quinoa 
proteins derived peptides (up to 11 amino acids) 501 - $514 \mu \mathrm{M} \mathrm{TE} / \mathrm{g}$ whose activities were attributed to the presence of hydrophobic tryptophan at the $\mathrm{N}$-terminus or a proline at position 2 of the peptide the sequence [208],[209]. Dialysis increased the activity of Visc/Flav from 286.27 \pm 12.5 to $406.87 \pm 8.8 \mu \mathrm{M} \mathrm{TE} / \mathrm{g}$ due to the removal of salts and potentially non-radical scavenging molecules less than $100 \mathrm{Da}$. It might be necessary in future studies to dialyze hydrolysate with 100 Da MWCO membrane to increase their peroxyl radical scavenging properties.

\subsubsection{ABTS Radical Scavenging Activity}

The ABTS (a cationic radical: $A B T S^{\bullet+}$ ) scavenging capacity assay measures the capacity of antioxidants that react directly with $\mathrm{ABTS}^{\bullet+}$ generated by a reaction between ABTS [2,2'-azinobis (3-ethylbenzothiazoline-6-sulphonic acid)] stock solution with potassium persulfate, the solution is blue in color and absorbs light at $734 \mathrm{~nm}$. Upon accepting an electron from an antioxidant compound, $\mathrm{ABTS}^{\bullet+}$ radicals are reduced and become colorless, and the scope of change in color is used to determine the antioxidant activity of molecules.

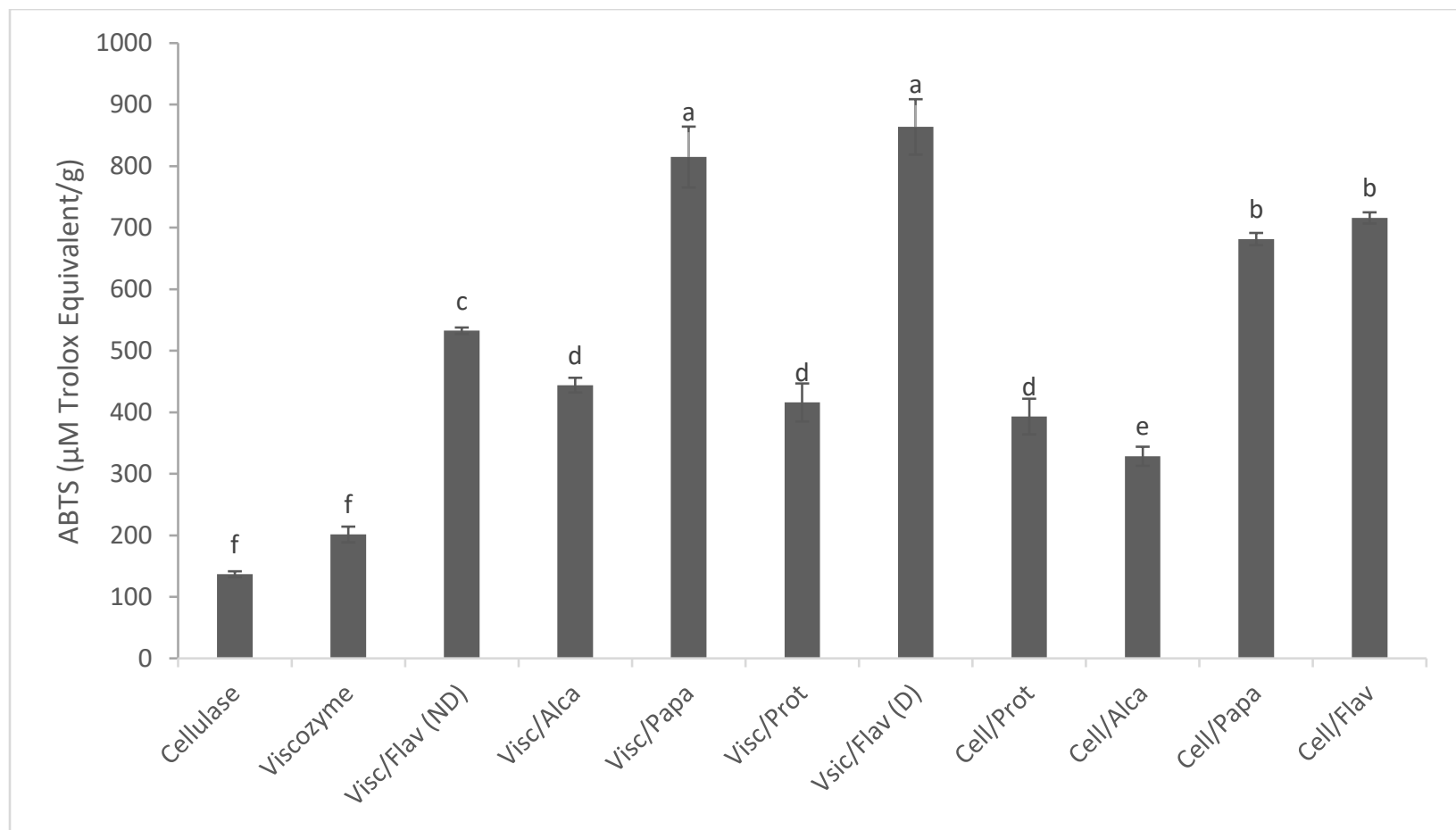

Figure 12. ABTS radical values based on $\mu M$ Trolox equivalent/g of freeze-dried protein hydrolysates $(0.2 \mathrm{mg} / \mathrm{mL})$. Cell: Cellulase, Visc: Viscozyme, Alca: Alcalase, Flav: Flavourzyme, Papa: Papain, Prot: Protamex, ND: Non-Dialysis, and D: Dialysis. Different letters show significant difference between group means $(P<0.05)$. Data shown as means $\pm \operatorname{SEM}(n=3)$ 
The ABTS radical scavenging activity of protein isolates and hydrolysates are summarized in Figure 12. The highest activities belong to Visc/Flav (D) and Visc/Papa (value at $863.8 \pm 20.3$ and $814.8 \pm 17.2 \mu \mathrm{M}$ TE/g respectively). Cell/Flav (715.88 $\pm 15.7 \mu \mathrm{M}$ TE/g) and Cell/Papa (681.51 \pm 17.2 $\mu \mathrm{M} \mathrm{TE} / \mathrm{g}$ ) also showed high scavenging activity. Non-digested samples (i.e. OBPI) cellulase $(136.72 \pm 4.8 \mu \mathrm{M} \mathrm{TE} / \mathrm{g})$, and Viscozyme $(201.30 \pm 12.8 \mu \mathrm{M} \mathrm{TE} / \mathrm{g})$ treated brans showed the lowest activities. One study suggests that abundance of globulins in plants including oats may contribute to antioxidant activity of protein hydrolysates. In oats, major storage proteins are globulins and prolamins and a study reported higher $\mathrm{ABTS}^{\bullet+}$ scavenging activity for both globulin and prolamin fractions [210]. In the present study, the highest $\mathrm{ABTS}^{\bullet+}$ scavenging activity of papain and viscozyme hydrolysate might be due to their preference for glubulin proteins.

Since both ORAC and ABTS methods used Trolox as a relative standard to express the results, it is possible to compare the results of both ORAC and ABTS although different mechanisms are involved.

By comparing both Figures 11 and 12 and the ability of protein hydrolysates to scavenge free radicals followed a similar pattern with ABTS assay showing much higher in calculated value; however, there was a strong positive relationship between the two assays and the correlation coefficient calculated to be at 0.75 . Although ABTS displayed higher values based on $\mu \mathrm{M} T E / g$ for most samples, it did not show the same increase in value for two samples Cell/Prot, and Cell/Alca. Antioxidant activities were more effective in the ABTS assay (values up to $863.80 \pm 20.3 \mu \mathrm{M} \mathrm{TE} / \mathrm{g}$ ), indicating the tendency of most protein hydrolysates to donate electron to neutralize ABTS ${ }^{\bullet+}$ radicals (i.e. proceed via ET-based mechanism). In the HAT-based ORAC assay, the highest value was $406.87 \pm 8.8 \mu \mathrm{M} \mathrm{TE} / \mathrm{g}$.

One of the sources of the variations among the two methods is the lipid-or water-solubility of hydrolysates in these the assays. ORAC evaluates antioxidant activity of hydrophilic samples, whereas ABTS determines the lipophilic ones [198]. This also can cause variation in the ORAC and $A B T S$ values to conclude that $\mathrm{OBPH}$ samples were more effective in lipophilic environment in general. Also, the lower antioxidant activity of Cell/Prot and Cell/Alca in ABTS assay - 
compared to other samples in the same assay - could be because the samples were less lipophilic. OBPHs produced by the activity of Visc/Papa and Visc/Flav (D) were the most effective in scavenging both peroxyl (ORAC) and $\mathrm{ABTS}^{\bullet+}$ radicals. LMW peptides can aggregate and form disulfide bonds and make the compounds to become less soluble, therefore their tendency to act as antioxidant might be reduced [211]. A study done by Popović, et al. (2013), suggested that a longer hydrolysis time often increase scavenging activities of protein hydrolysates because of the presence of higher amount of short chain peptides [212].

A study done by Klompong et al. (2007), showed that the type of enzyme used to produce protein hydrolysates can affect antioxidant activities, since different enzymes cleave proteins differently [182]. Enzymatic production of protein hydrolysates could also release other components that may remain in with the sample and affect the activity of hydrolysates.

There are advantages and disadvantages of any antioxidant activity assay. The disadvantage of ABTS assay is that generated radicals are not physiologically relevant and therefore may not be representative of in vivo activity. Whereas, AAPH produced peroxyl radicals are similar to what is present in a living systems.[213] The advantages of ABTS are that the $\mathrm{pH}$ is at 7.4, equal to biological system $\mathrm{pH}$ level, and the ABTS ${ }^{*+}$ assay can be used for both hydrophilic and lipophilic antioxidant compounds.[214] On top of AAPH-generated peroxyl radical (ROO•) which is a physiologically relevant free radical, $\mathrm{pH}$ and temperature are also controlled at 7.4 and $37^{\circ} \mathrm{C}$ (similar to physiological condition) in the ORAC assay.[214],[215] However, the disadvantage of ORAC method is the use of fluorescein - a water soluble probe with low solubility in nonpolar and organic solvents which is a cause of error in measuring the activity of antioxidants.[215] Also, there are reports of false positive activity of compounds in ORAC assay, when it is known that the mentioned compounds are not antioxidants. It is important to consider the interfering effects of solvents and other chemicals used in reaction solvents [216]. It is known that thermal processing of chemical compounds containing carbohydrates and amino acids result in Maillard reaction and formation a variety of compounds that affect the antioxidant capacity [217]. Formation of Maillard compounds such as pyrazines, pyrroles and furans, may affect the result by reaction between amino acids and carbohydrates [218]. This compounds are known to have antioxidant effect that may contribute to increased scavenging activity of the samples [7],[16],[219]. It will 
be interesting to specifically study if Maillard reaction products occur during hydrolysis of food proteins and the consequence on the activity of hydrolysates in the ORAC or the ABTS assay.

\subsubsection{Hydroxyl Radical Scavenging Assay}

Among the different oxygen containing free radicals, the hydroxyl radical $\left({ }^{\circ} \mathrm{OH}\right)$ is one of the most reactive species and can easily damage biomolecules such as DNA, lipid, and proteins, which can then lead to degenerative diseases in biological systems [3],[220],[221]. The principle of the assay is based on the production of hydroxyl radicals in a system containing Fe(II) and $\mathrm{H}_{2} \mathrm{O}_{2}$ (Fenton reaction) as summarized below [222]:

$\mathrm{H}_{2} \mathrm{O}_{2}+\mathrm{Fe}^{2+} \rightarrow \mathrm{Fe}^{3+}+{ }^{\cdot} \mathrm{OH}+\mathrm{OH}^{-}$

The activity of OBPI and OBPH was measured against blank, and stated as percentage inhibition of the formation of ${ }^{\circ} \mathrm{OH}$ radicals (Figure 13). Clearly, higher sample concentration increased the hydroxyl radical scavenging activity. Among the samples, OBPI showed the highest activity for both concentrations at $38.5 \pm 0.8 \%$ and $36.0 \pm 0.4 \%$ for both Cellulase and Viscozyme treated brans $(1.0 \mathrm{mg} / \mathrm{mL})$. For OBPHs $(1.0 \mathrm{mg} / \mathrm{mL})$ highest activity belonged to Cell/Alca $(21.5 \pm 0.4 \%)$, Visc/Prot $(17.9 \pm 0.8 \%)$ and Visc/Alca $(17.2 \pm 0.3 \%)$. Most OBPHs had relatively acceptable scavenging activity compared to GSH $(15.5 \pm 0.2 \%)$.

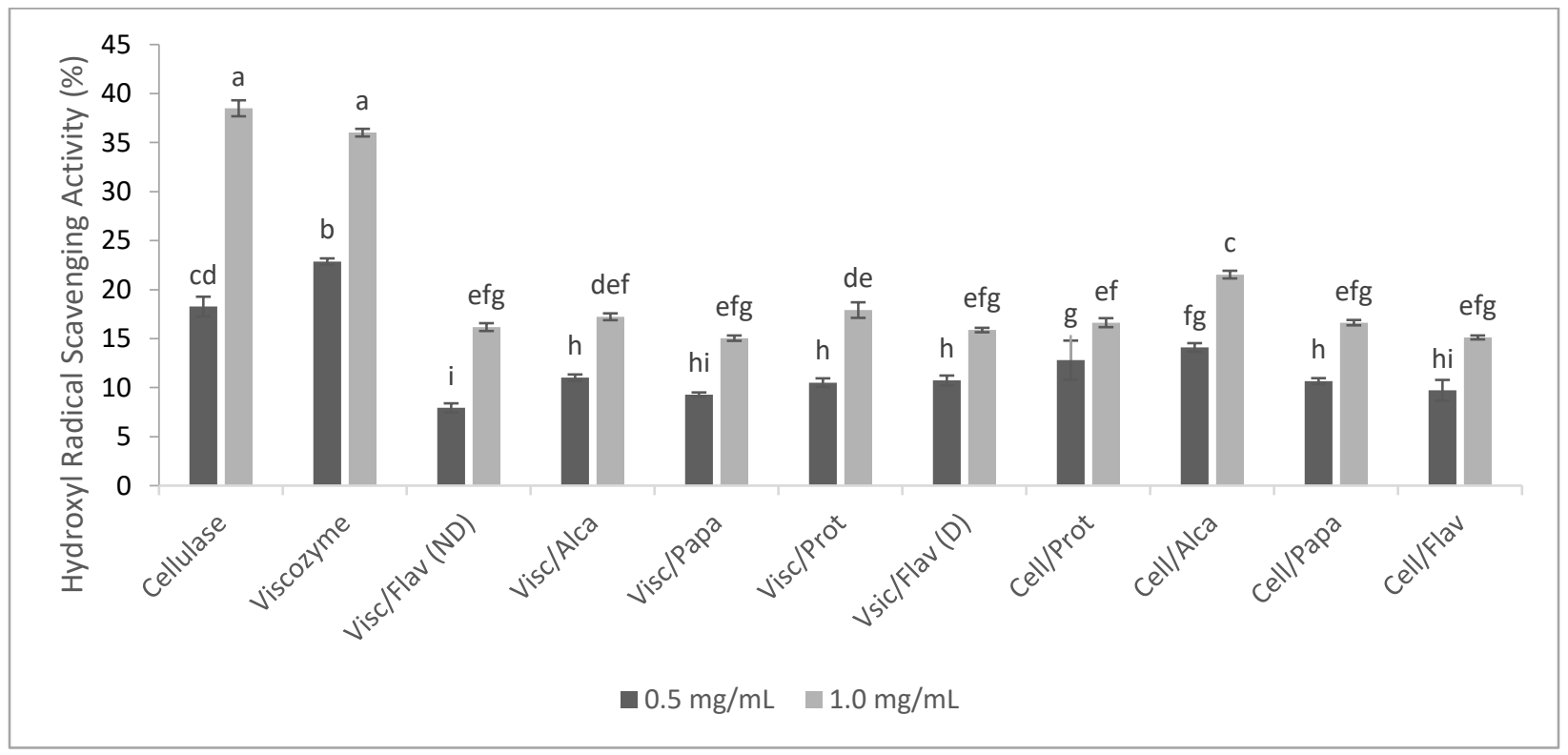

Figure 13. Hydroxyl radical scavenging activity of $O B P H$ and OBPI. Different letters show the significant difference between group means $(P<0.05)$. Data showed as means \pm SEM $(n=3)$ 
Cellulase and Viscozyme treated OBPIs had a significantly higher inhibition than hydrolysates. The mechanism reactions involve both iron chelating and direct ${ }^{\bullet} \mathrm{OH}$ scavenging. It is common for proteins to display higher inhibition values in this assay because their iron chelating properties outweigh their scavenging abilities, possibly due to concentrated antioxidant amino acid residues such as His [223]. Studies have shown that high molecular weight proteins isolated from food impose antioxidant activity in chemistry assays, yet, the underlying antioxidative mechanism remains to be elucidated [7],[224]. Hydroxyl scavenging activities of dietary compounds are associated with compounds containing carbonyl functional groups with the ability of chelating of metal ions such as iron [225]. Increased number of carbonyl functional groups may explain the higher activity of OBPIs compared to OBPHs for the same w/v sample concentrations. It is also observed that aromatic amino acid along with histidine [226], the proteins with higher molecular weight amino acids (specifically the ones with glycine and proline incorporated into them) [227],[228], and the polypeptide with hydrophobic residues [206] in the sequence, can show higher and more efficient hydroxyl radical scavenging activity. High molecular weight whey protein hydrolysates were also observed to increase hydroxyl radical scavenging capacity due to the presence of sulfhydryl groups in the whey protein [224]. The combination of all these properties in OBPI may contribute to providing higher $\mathrm{OH}$ radical scavenging in the samples, whereas in $\mathrm{OBPH}$, the hydrolysates may be limited in the number of affecting properties. Rice bran enzymatic hydrolysis with proteases such as Alcalase, Papain, and Flavourzyme produced peptides that had the same range of hydroxyl radical scavenging activity as the ones used for $\mathrm{OBPH}$. The activities of protein hydrolysates were mostly attributed to the hydrophobic amino acids with aliphatic and aromatic side chains such as Ala, lle Leu, Met, Val, Phe, Trp, and Tyr [229]. However, the same study used Neutrase ${ }^{\circledR}$ - a metalloprotease - and the hydroxyl scavenging activity was significantly higher than the samples treated with other proteases. Zhang, et. al. (2010) assumed that apart from aromatic amino acids, the metal chelating activity of acidic and basic amino acids may contribute to increased hydroxyl radical scavenging activity of rice protein hydrolysates [229]. They isolated two fractions Phe-Arg-Asp-Glu-His-Lys-Lys and Lys-His-Asp-ArgGly-Asp-Glu-Phe with MW of 900-1000 Da. There are many factors involved in antioxidant and hydroxyl scavenging activities of the specified protein hydrolysates such as the ability of these 
compound to donate hydrogen atoms, peroxyl radical scavenging and metal-chelating activity of histidine with imidazole group [230].

\subsubsection{Superoxide anion Scavenging Activity:}

Superoxide anion $\left(\mathrm{O}_{2}^{-\bullet}\right)$ radical is the first-line and most common free radical produced in biological systems. Even though superoxide radical is not highly reactive, it still can produce hydrogen peroxide and hydroxyl radicals by the activity of superoxide dismutase or by reacting with transition metals in the cells and causing damage to other biomolecules [231]. The assay targets the ability of hydrophilic antioxidants to react with superoxide directly. Superoxide radicals were generated using pyrogallol in an alkaline environment [232]. The generation and consumption of superoxide anion radicals $\left(\mathrm{O}_{2}^{-\bullet}\right)$ in the blank and antioxidant sample containing solution were monitored at $420 \mathrm{~nm}$ spectrophotometrically. The superoxide scavenging activity was evaluated and reported in percent increase in activity compared to the blank and results are shown in Figure 14. A GSH sample solution was also made, and superoxide scavenging assay was measured, and showing very high activity at $82.5 \pm 0.3 \%$ for $0.5 \mathrm{mg} / \mathrm{mL}$ and $91.5 \pm 0.3 \%$ for 1.0 $\mathrm{mg} / \mathrm{mL}$. The increases in superoxide scavenging assay are plausible since GSH is a powerful biological antioxidant and naturally hydrophilic. A similar result showing high superoxide activity of GSH was observed in previous studies [206],[233]. 


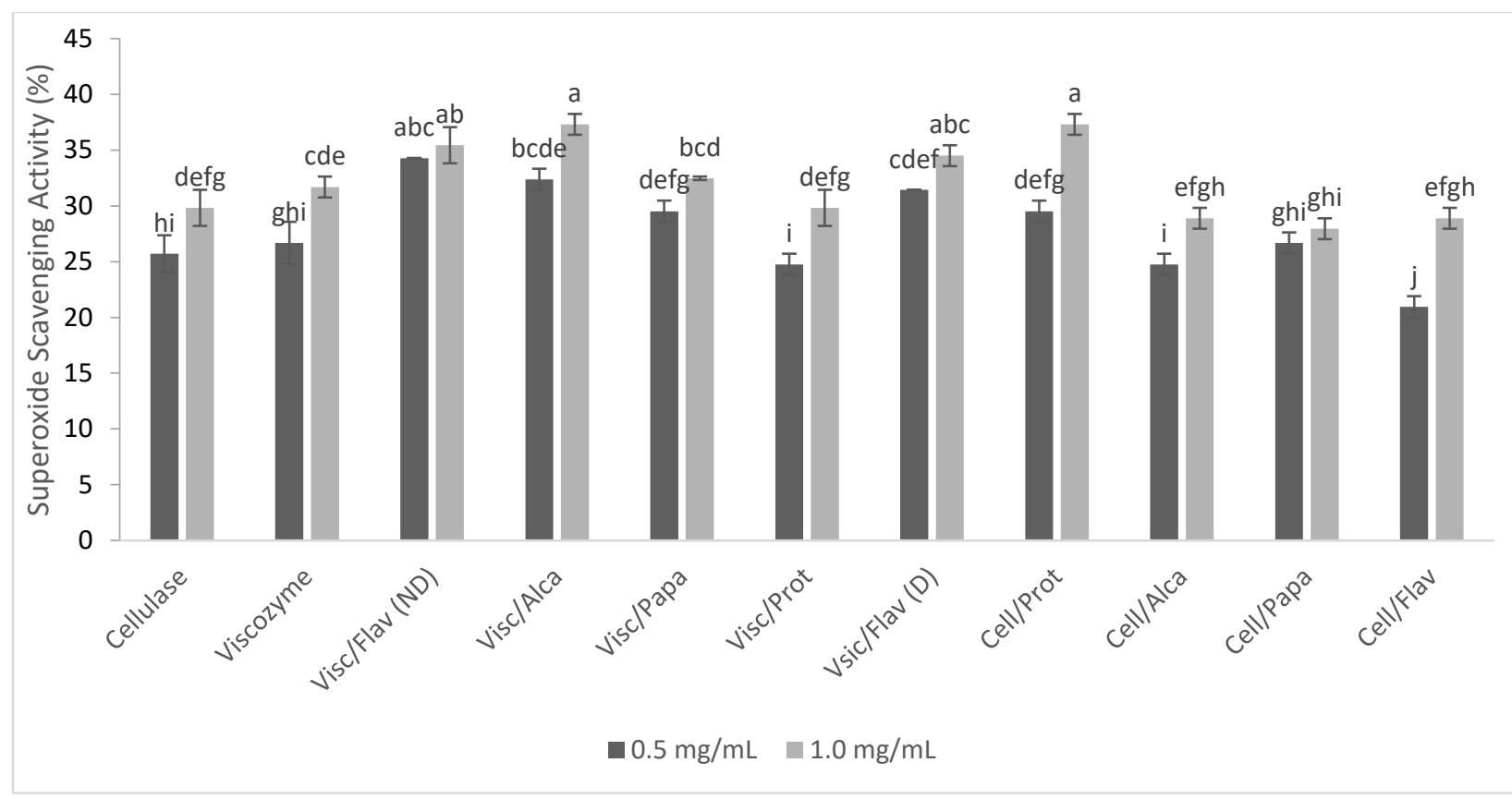

Figure 14. Superoxide radical scavenging activity of $\mathrm{OBPH}$ and $\mathrm{OBPI}$. Different letters indicate the significant difference between group means $(P<0.05)$. Data showed as means $\pm \operatorname{SEM}(n=3)$

All OBPI and $\mathrm{OBPH}$ samples demonstrated scavenging activity ranging from the minimum activity of $21.0 \pm 1 \%$ for Cell/Flav $(0.5 \mathrm{mg} / \mathrm{mL})$, up to maximum activity in Visc/Alca and Cell/Prot both at $37.3 \pm 0.9 \%(1.0 \mathrm{mg} / \mathrm{mL})$. Samples scavenged superoxide radicals in a dose dependent manner to some extent. Frequently, superoxide scavenging activity of hydrolysates is attributed to the presence of proline residue in peptide samples [206]. Vanvi and Tsopmo (2016) studied superoxide scavenging activity of oat bran hydrolysates hydrolyzed by pepsin, and the present results were similar to the scavenging activity of the same oat derived protein hydrolysates. It is suggested that in superoxide anion scavenging activity assays, the sequence of peptide chain was the determinant factor [155]. Since superoxide anion is a water-soluble molecule, increased solubility of protein hydrolysates can improve superoxide scavenging activity of hydrolysates. This effect was observed using Flavourzyme to produce protein hydrolysates from soy protein. The same study also correlated the superoxide scavenging activity to protein hydrolysates with MW lower than $30 \mathrm{kDa}$ [234].

Even though OBPIs and OBPHs showed superoxide scavenging activity, the activity was considerably less than the activity of GSH at the same concentration. The lower activity might be due to two reasons. First, the superoxide scavenging activity assay works better for the 
hydrophilic antioxidants, therefore, compare to GSH - a water-soluble antioxidant - OBPI and $\mathrm{OBPH}$ appeared to be less efficient as superoxide scavengers. Also, according to previous studies, it is possible to see decreased antioxidant activity due to extreme hydrolysis and bond cleavage [233],[235].

\subsubsection{Iron Chelating Activity}

There are transitional metals necessary for a living system to operate normally, and among those, iron (Fe) is one of the common elements with a significant functional role in different biological systems. It is an important part of Hemoglobin molecule responsible for oxygen transportation into and from human organs and tissues and commonly found in bound forms. It is found in heme-containing compounds, enzymes, transferrin, and ferritin [236],[237]. However, under oxidative stress, the presence of reduced iron $\left(\mathrm{Fe}^{3+}\right)$ is increased, and consequently, increases hydroxyl radicals through iron dependent Fenton or Haber-Weiss reactions and act as a prooxidant agent:[67],[68]

$\mathrm{H}_{2} \mathrm{O}_{2}+\mathrm{Fe}^{2+} \rightarrow \mathrm{Fe}^{3+}+\mathrm{OH}^{-}+\cdot \mathrm{OH} \quad$ (Fenton reaction)

$\mathrm{H}_{2} \mathrm{O}_{2}+\mathrm{O}_{2}^{-\bullet} \rightarrow \mathrm{OH}^{-}+\cdot \mathrm{OH}+\mathrm{O}_{2} \quad$ (Haber - Weiss reaction)

Iron has a significant role in oxidative damage to the mitochondrial and cellular components such as lipids, cell membrane, proteins and DNA resulting in the pathogenesis of many human diseases; hence, it is important to identify free iron in a system[238] .

In the iron (II) chelating assay, ferrozine can react with iron (II) and chelate it quantitatively to form a red colour complex, with the highest absorbance at $562 \mathrm{~nm}$ [239]. However, the absorbance is reduced in the presence of other chelators such as antioxidants by the formation of a compound with the iron ions and inhibit the oxidation.[191]

The results from iron (II) chelating assay showed improved chelating activities of all samples by increasing sample concentration in Figure 15. Most samples showed an increased jump in the concentrations 0.0625 to $0.125 \mathrm{mg} / \mathrm{mL}$. OBPHs - Visc/Papa, Visc/Alca, Cell/Alca, and Cell/Flav reaction rates plateaued at around $0.25 \mathrm{mg} / \mathrm{mL}$ sample concentrations, and they showed the highest activity among all samples, as well. This also means that these samples reached 
maximum activity at lower concentrations. However, the activity of OBPI Cellulase and Viscozyme treated samples did not plateau at the highest concentration of $2.0 \mathrm{mg} / \mathrm{mL}$, possibly due to continuing increase in activity at even higher concentrations. The lowest activity at 2.0 $\mathrm{mg} / \mathrm{mL}$ was found in samples treated with Visc/Prot at $40.4 \pm 0.2 \%$ and Cell/Prot at $42.5 \pm 0.8 \%$, and the highest activity was observed in samples treated with Visc/Papa at $77.5 \pm 0.8 \%$ and Viscozyme treated only at $75.7 \pm 0.2 \%$.

Many papers attributed the iron chelating activity to the peptides with carboxyl and amino group in the side chains of the acidic (Glu and Asp) and basic (Lys, His and Arg) amino acids; imidazole ring containing amino acid histidine (His) is also reported to have iron chelating activity [240]'[241]. Iron II chelating activity also was observed in Alcalase-treated protein hydrolysates from wheat germ with increased scavenging activity as high as $89 \%$, with the activity attributed to hydrolysates iron binding capacity [242]. Another study discussed that increased iron chelating activity could be due to increased amino acids His, Met, Cys, Tyr, and Phe, along with the hydrophobic amino acids [243]. It seems in the iron chelating activity of protein hydrolysate, sulfur containing amino acids have high impact and efficiency. As it has been studied, oats are an excellent source of amino acids, and rich mainly in Ala, Asn, Asp, Glu as well as Cys and Met which are more concentrated in the oat bran [244],[245]. It appeared that among the proteases used, Alcalase and Papain treated OBPHs had better outcome in the production of the protein hydrolysates efficient in iron (II) chelating activity. 


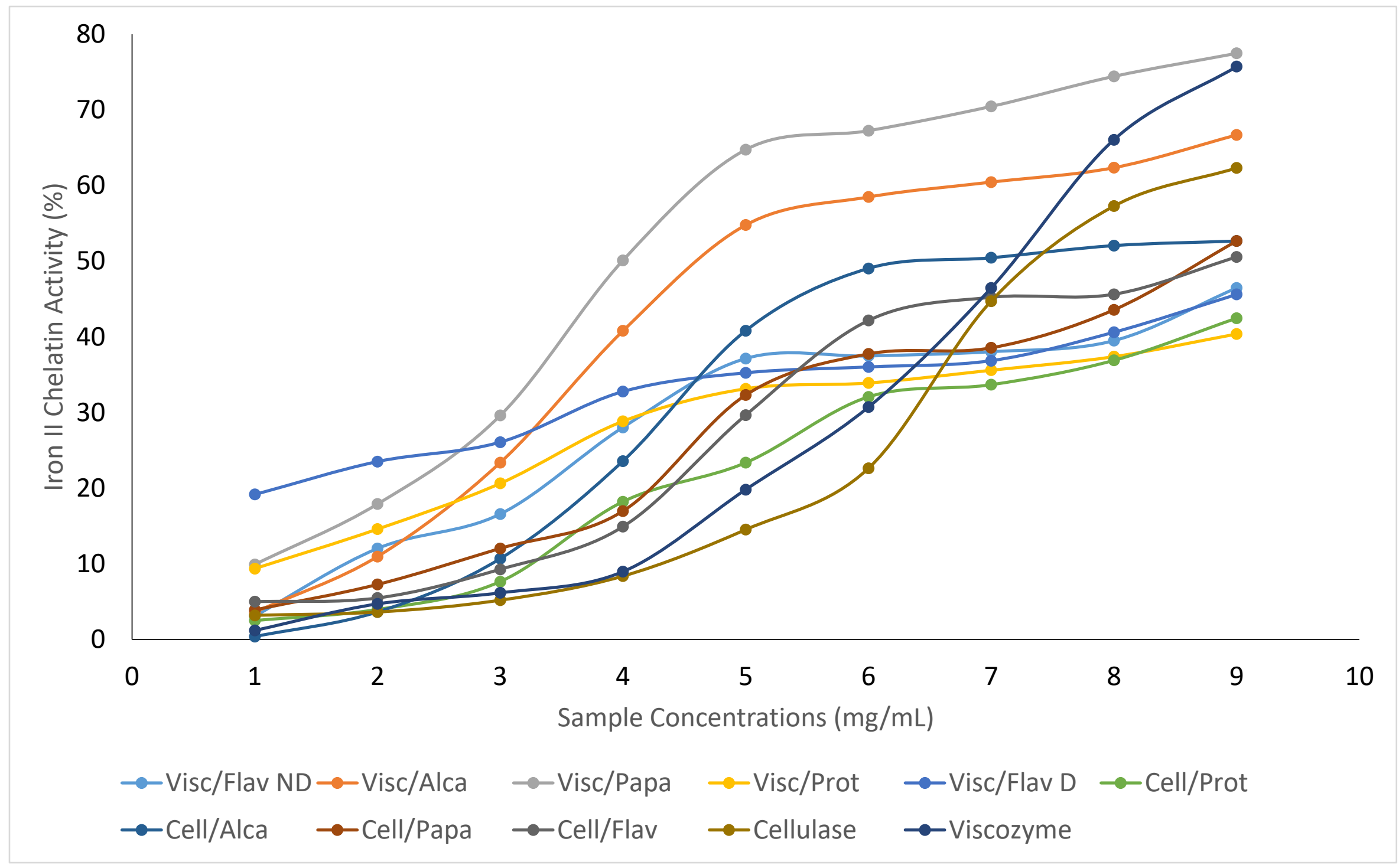

Figure 15. Iron chelating activity of $\mathrm{OBPH}$ and $\mathrm{OBPI}$. Two-fold serial dilutions were prepared from OBPI and OBPH ranging from 0.0078 to 2.0 mg/mL. $1: 0.0078,2: 0.0156,3: 0.0312,4$ : $0.0625,5: 0.125,6: 0.25,7: 0.50,8: 1.0,9: 2.0 \mathrm{mg} / \mathrm{mL}$ sample concentration. 
It is important to note that in vitro antioxidant activity measurements are not representative of their activity in vivo and the biological system. The activity, bioavailability, reactions, and processing of these antioxidants should be monitored and studied through living systems, such as cell culture, animal, and human studies. For this study, oxidative stress and antioxidant activity of OBPI and OBPH are evaluated in a HepG2 cell culture to assess and monitor the changes in antioxidant enzyme activities, total glutathione, generated ROS and programmed cell death or apoptosis.

\subsection{HepG2 Cell Culture Based Assay}

\subsubsection{MTT Cytotoxicity and Cytoprotective Activity of OBPI and OBPH}

Cytotoxicity: The cytotoxicity and cytoprotective effect of OBPIs and OBPHs on radical-mediated cellular injuries and death were investigated using human hepatoma HepG2 cells. HepG2 hepatocyte cell line is a well-differentiated human liver carcinoma cells that makes it an excellent model to study liver metabolism and toxicity effect of different compounds due to the production of the higher amount of antioxidant enzymes [125]. The initial measurement was performed using one sample (Visc/Flav ND) at $50-400 \mu \mathrm{g} / \mathrm{mL}$. No cytotoxicity was observed in MTT (3-(4,5Dimethylthiazol-2-yl)-2,5-Diphenyltetrazolium Bromide) assay. The two lowest concentrations 50 and $100 \mu \mathrm{g} / \mathrm{mL}$, were then used for all other measurements. The cytotoxicity of OBPI and OBPH samples were compared to a negative control (NEG) HepG2 cells cultured in media only. Most did not show cytotoxic or antiproliferative effect (Figure 16). Only the following hydrolysates Cell/Papa (50 and $100 \mu \mathrm{g} / \mathrm{mL})(76.5 \pm 1.4 \%$ and $78.2 \pm 1.3 \%$ respectively), Cell/Flav $(50 \mu \mathrm{g} / \mathrm{mL})$ $(79.9 \pm 4.4 \%)$ and Visc/Papa $(50 \mu \mathrm{g} / \mathrm{mL})(84.2 \pm 5.0 \%)$ appeared to be cytotoxic compared to NEG control. It has been observed that the antioxidant peptide may act as prooxidant due to presence of certain amino acids and their position in the peptide chain, as well as their concentration. High concentration of protein hydrolysates may result in more oxidation [246]. 


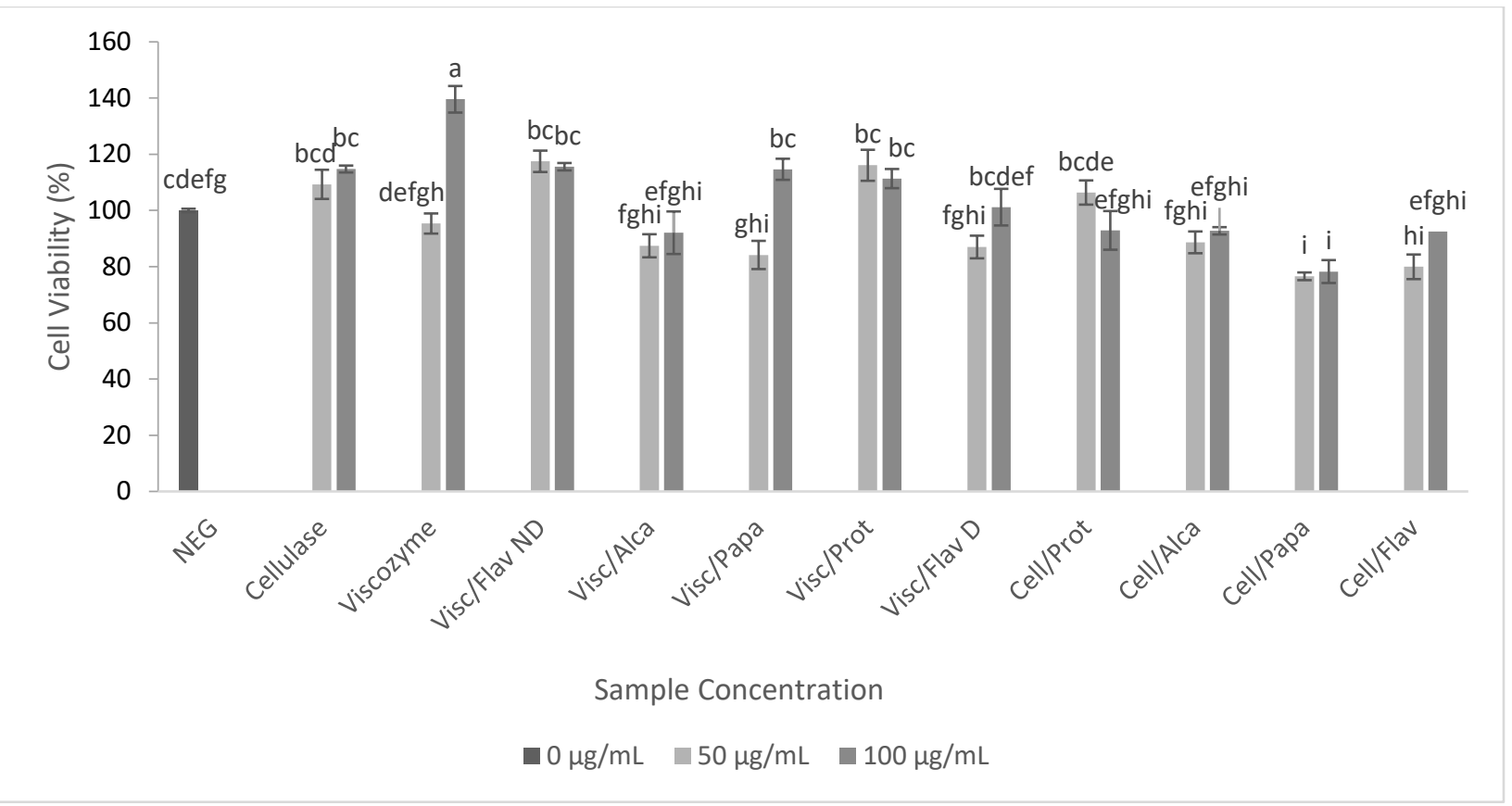

Figure 16. Cytotoxicity effect of OBPIs and OBPHs on HepG2 cells. HepG2 cells were cultured in DMEM mSedium with $10 \%$ FBS. HepG2 cells were treated with two peptide concentrations for 24 hours and viability were indicated as percent NEG untreated cells. Cell viability was determined by MTT assay ( $n=3)$. Data with different letters showed the significant difference $(p<0.05)$ in Duncan's multiple range test.

Figure 16 displays the effect of samples at 50 and $100 \mu \mathrm{g} / \mathrm{mL}$ compared to NEG. Oat bran hydrolysates affected the viability of HepG2 cell lines differently depending on the enzyme. The variation in cell viability is attributed to the fact that proteases have different specificities, and the production of different peptides may affect cell growth differently. HepG2 cell viability was not affected significantly using OBPIs and OBPHs except for Cell/papa sample where a decrease of $23 \%$ was noted $(p<0.05)$. A cell growth promotion $(p<0.05)$ was observed using Cellulase and Viscozyme treated OBPIs, Visc/Flav ND, Visc/Prot, and one concentration of Visc/Papa and Visc/Flav D (at $100 \mu \mathrm{g} / \mathrm{mL}$ ), as shown in Fig. 16. In this assay, dialysis of Visc/Flav sample did not affect cell viability. In a previous study, similar results were observed using purified oat peptides; however, the results were more uniformly distributed throughout the samples, possibly due to the purity of the samples [247]. The variation among OBPI and OBPH treated samples might be due to the existence of peptides fragments in hydrolysates and possibly the presence of small molecules like secondary metabolites, polysaccharides, and salts [248],[249],[250]. Higher concentration of small amino acids may act as prooxidants and affect cell growth patterns [45],[251]. Many authors have reported the protective effect of protein hydrolysates. For 
example, an enzymatically treated common bean protected Caco-2 cell lines against oxidative stress and the degree of protection was dependent on the amino acid composition of hydrolysates [252].

Cytoprotection: To study cytoprotection effect of protein hydrolysates, first, the amount of AAPH required was optimized to retain about 50 - 60\% HepG2 cell viability. Water soluble 2,2'Azobis(2-amidinopropane) dihydrochloride, also known as AAPH, is a free radical generator. Its thermal decomposition produces biologically relevant peroxyl radical that is used to induce oxidative stress in chemical and biological systems [253]. In this assay, HepG2 cells were exposed to different AAPH concentrations ranging from 5 to $40 \mathrm{mM}$ for $24 \mathrm{~h}$, and cell viability was determined using MTT assay. The results are shown in Figure 17. The concentration of AAPH selected was t $10 \mathrm{mM}$ because it produced $54.3 \%$ viable cells.

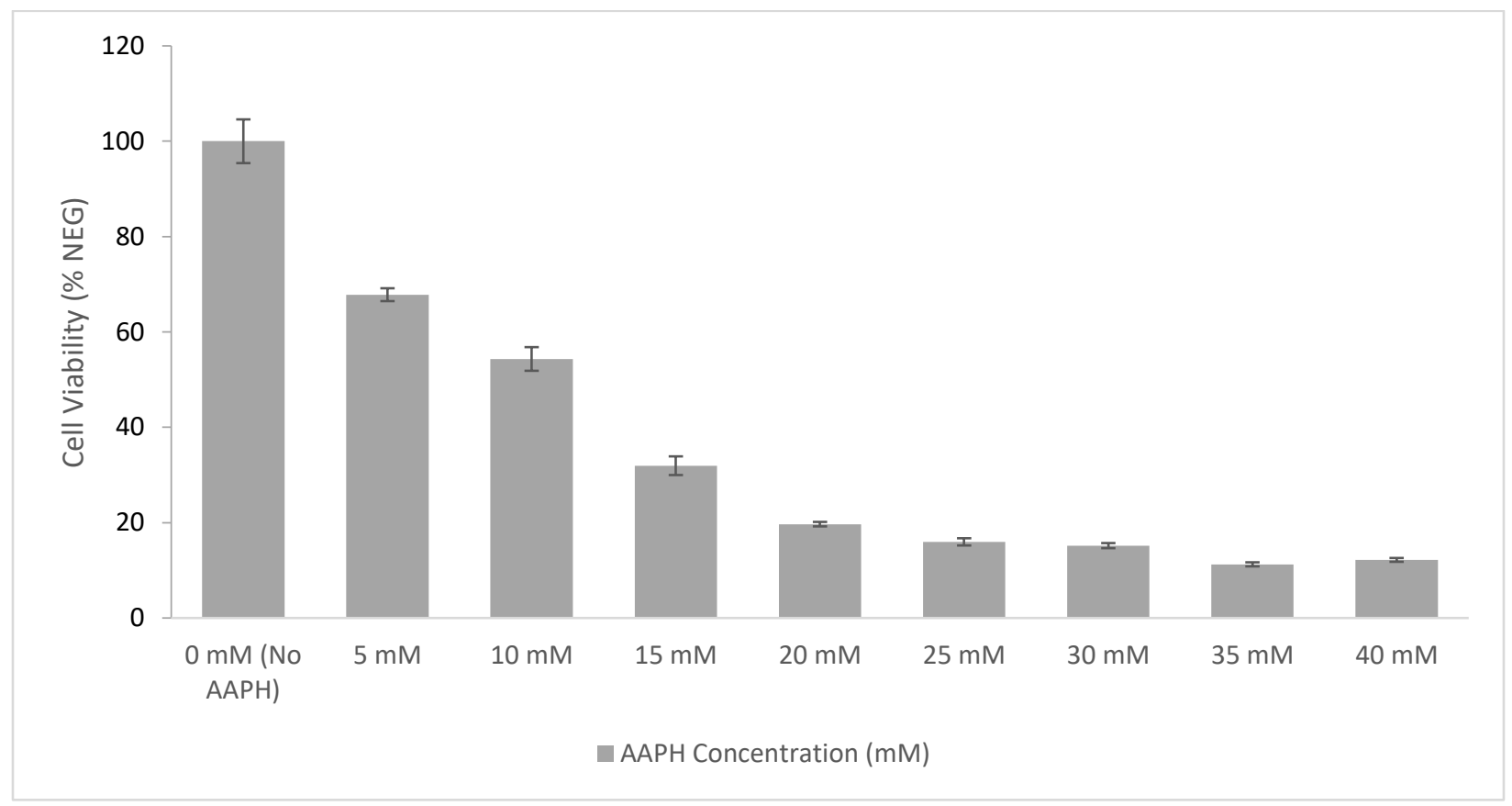

Figure 17. AAPH optimization to retain cell viability around $50-60 \%$ negative (no AAPH) control.

Cells were treated with two concentrations of OBPIs and OBPHs (50 and $100 \mu \mathrm{g} / \mathrm{mL}$ ) followed by oxidative stress with $10 \mathrm{mM} \mathrm{AAPH}$. Two controls were included; one negative (NEG) with no AAPH added to the media, and a positive (POS) with only $10 \mathrm{mM} \mathrm{AAPH}$ added to the media and no hydrolysate pre-treatment. The cytoprotective results are summarized in Figure 18. The viability of POS cells was reduced to $62.1 \pm 2.1 \%$. Among the samples, Cellulase and 
Cellulase/Peptidase treated oat bran samples failed to restore viability, and further induced cell death by $45-67 \%$. However, Viscozyme/peptidase samples had either no effect or restored cell viability back to the level of NEG control. Higher concentration of Visc/Papa (103.3 $\pm 14.2 \%)$, Visc/Prot $(93.3 \pm 6.3)$ and Visc/Flav D $(95.3 \pm 10.5 \%)$ restored viability back to normal. Dialysis improved the viability of Visc/Flav from 76.7 to $95.3 \%$ although no effect observed in the cytotoxicity assays.

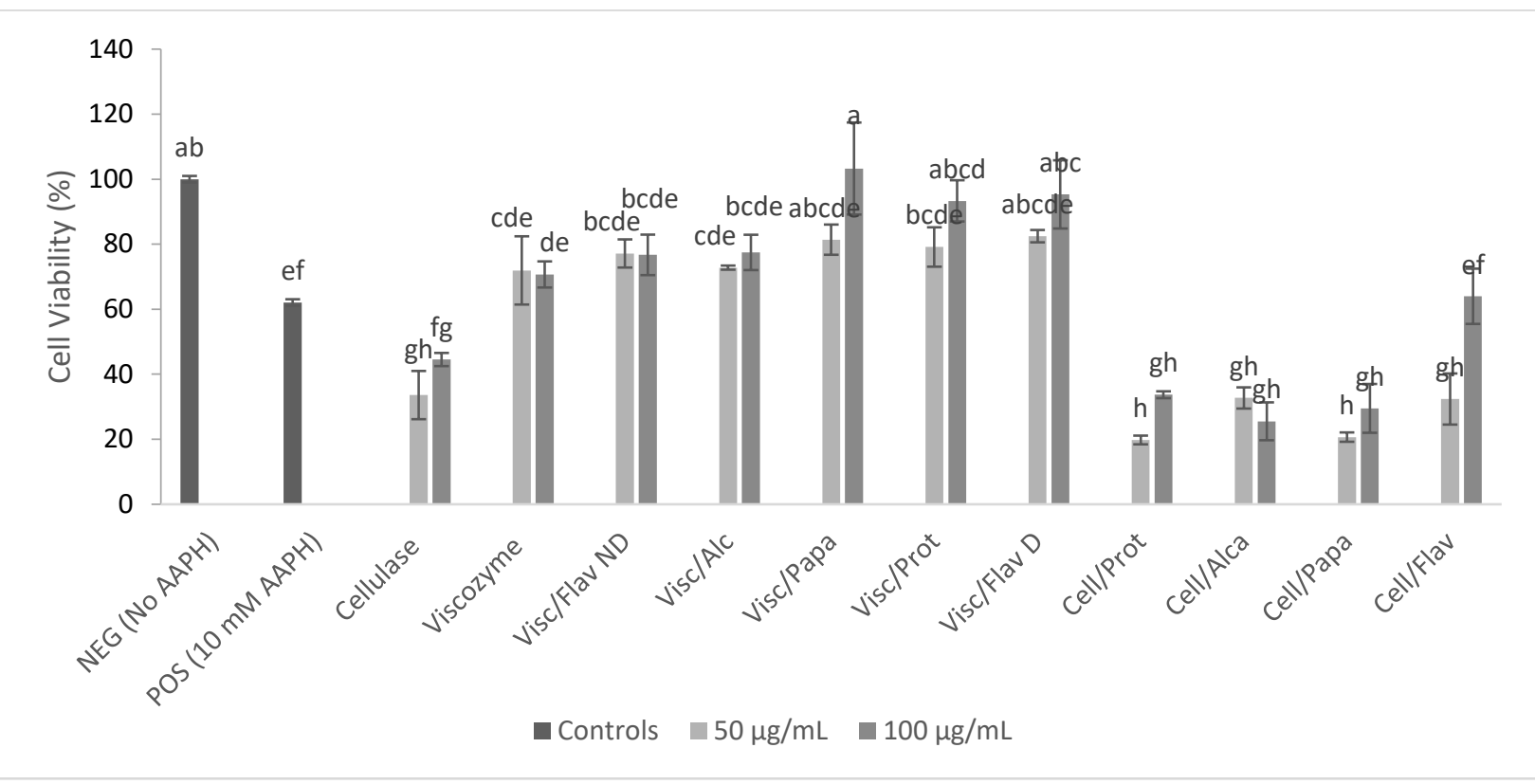

Figure 18. Cytoprotective effect of OBPIs and OBPHs on HepG2 cells. HepG2 cells were cultured in DMEM medium with $10 \%$ FBS. Cell viability was determined by MTT assay ( $n=3)$. HepG2 cells were treated with two peptide concentrations for 24 hours, followed by 24 incubation with AAPH. Viability was calculated as percent NEG untreated cells. Cell viability was determined by MTT assay $(n=3)$. Data with different letters showed the significant difference $(p<0.05)$ from Duncan's multiple range test.

Not all the samples affected cell viability in dose dependent manner. Cellulase and its protease treated samples caused lower cell viability meaning they acted synergistically along with AAPH either to lower HepG2 cell growth rate, or to induce more cell death.

Protein hydrolysates exert their antioxidant effect in many ways. They can scavenge free radicals, chelate metals, or act as reducing agents to inhibit peroxidation. Radical scavenging activity of protein hydrolysates is attributed to the presence of aromatic amino acids - such as Trp, Tyr, or Phe - or hydrophobic amino acids - such as Val, Leu, and Met [223]. The use of different enzymes to produce protein hydrolysates results in a broad range of different MW peptides and amino 
acids, since each enzyme have a preferred cleavage site. It is proven that low molecular weight peptides (less than $1 \mathrm{kDa}$ ) are more effective in antioxidant activity in cell culture assays but in this assay the entire hydrolysates were used and the weight distribution was much wider. Protein hydrolysates from flaxseed meal using papain demonstrated that LMW peptides in the range of 1-3 $\mathrm{kDa}$ exhibited better antioxidant activity in macrophages [254].

Based on the observed results and comparison with SDS-PAGE electrophoresis data, it is possible that presence of larger proteins resulted from Viscozyme pre-treatment of brans produced hydrolysates containing peptides that acted more efficiently in protecting HepG2 cells from $\mathrm{AAPH}$-induced oxidative stress. Factors such as $\mathrm{pH}$, temperature, preparation methods may affect the assay outcome [241],[255],[256].

There have been studies mentioning the adverse effects of protein hydrolysates and, for example, they can be prooxidant at high concentrations and not all of them can act in a dose dependent manner [257],[258],[259]. It is then important to determine peptide profile of protein hydrolysates to better explain their potential mechanisms.

\subsubsection{Antioxidant Enzymes}

The human body has developed both enzymatic and non-enzymatic defense mechanisms to maintain cellular redox balance. However, under disease conditions or in the presence of exogenous oxidants this balance is compromised. Cellular antioxidant enzymes such as catalase (CAT), glutathione peroxidase (GPx) and superoxide dismutase (SOD), are the primary line of defense reducing oxidative stress, by converting ROS into less reactive species [223]. For this part, OBPHs were selected based on their performance from chemistry based and MTT assays. They are Visc/Flav ND, Visc/Alca, Visc/Papa, Visc/Prot, Visc/Flav D, and Cell/Flav.

Activities of all primary antioxidant enzymes (CAT, GPx, SOD) were calculated based on the activity of normal HepG2, namely, NEG control. Results were reported as the percentage change in the activity per milligram protein content of the cell extract. As previously shown, treating HepG2 cells with oat protein hydrolysates can affect the activity of antioxidant enzymes [247]. In the CAT assay, the activity of the enzyme remained unchanged as displayed in Figure 19-A. As seen in Figure 19-B and 19-C, GPx and SOD activities of both enzymes were significantly lowered 
in the POS compared to the NEG control. However, treating HepG2 cells with OBPHs increased CAT activity to values between $175.5 \pm 5.1$ to $352.0 \pm 5.5 \mathrm{Unit} / \mathrm{mg}$ protein compared to NEG control. Treating HepG2 cells with OBPHs also altered the activity of GPx enzyme as well. The highest change of GPx was observed with cells treated with Visc/Flav ND (93.5 $\pm .5 \%)$, Visc/Alca $(92.3 \pm 0.5 \%)$, Visc/Papa $(89.5 \pm 1.4)$ and Visc/Flav $(89.5 \pm 3.6)$. But samples failed to restore GPx activity back to the normal NEG control level completely. SOD enzyme activity was affected by OBPHs pretreatments. All samples were able to restore the activity, partially or completely, from $55.2 \pm 1.1 \%$ (in POS) to $76.6 \pm 7.6 \%$ in Visc/Flav ND up to $176.4 \pm 8.7 \%$ in Visc/Flav D. In all enzymatic assays, no dose dependency pattern observed except for a few samples (Visc/Papa and Visc/Flav D). The biological redox state of a cell is highly regulated, and its balance is critical for cell viability and organ functions. Antioxidant systems in cells are profoundly integrated. Biotransformation of generated free radicals -AAPH generated peroxyl radicals to superoxide can induce, alter, and affect the activity of other antioxidant systems in the cells [2],[69],[260],[261]. An antioxidant network is essential for free radical quenching; for example, CAT activity is highly affected by GPx, and since both enzymes compete for hydrogen peroxide as their substrates, this may induce CAT activity even more[80]. Catalase (CAT) is a very active enzyme with high turnover rate and considered the most efficient antioxidant enzyme, and its reduced activity may result in tumor growth promotion [262]'[263]. As shown in Figure 19-A, catalase activity was reduced to $87.5 \pm 6.1 \%$, as an indication of reduced CAT activity in response to oxidative stress. Oxidative stress has a negative impact on intracellular antioxidant enzymes by decreasing the activity of catalase (CAT) and glutathione peroxide (GPX) and superoxide dismutase (SOD) [3]. By comparing CAT activity (Figure 19-A) with Cell viability patterns (Figure 18), it was apparent that the increased CAT activity resulted in promoting the cell viability. All the OBPH treated HepG2 cultures showed increased in CAT activity, with Visc/Papa (352\% increase) and Visc/Flav (307\% increase) being the most significant. Treatment with OPBH increased the activity of CAT in HepG2. Increased expression of CAT enzyme was observed using fish skin hydrolysates in RAW264.7 cells. The peptide fraction composed of Leu-Leu-Met-LeuAsp-Asn-Asp-Leu-Pro-Pro with LMW at $1.3 \mathrm{kDa}$, mostly made up of hydrophobic residues. These bioactive peptides also increase expression of SOD and GSH [264]. 

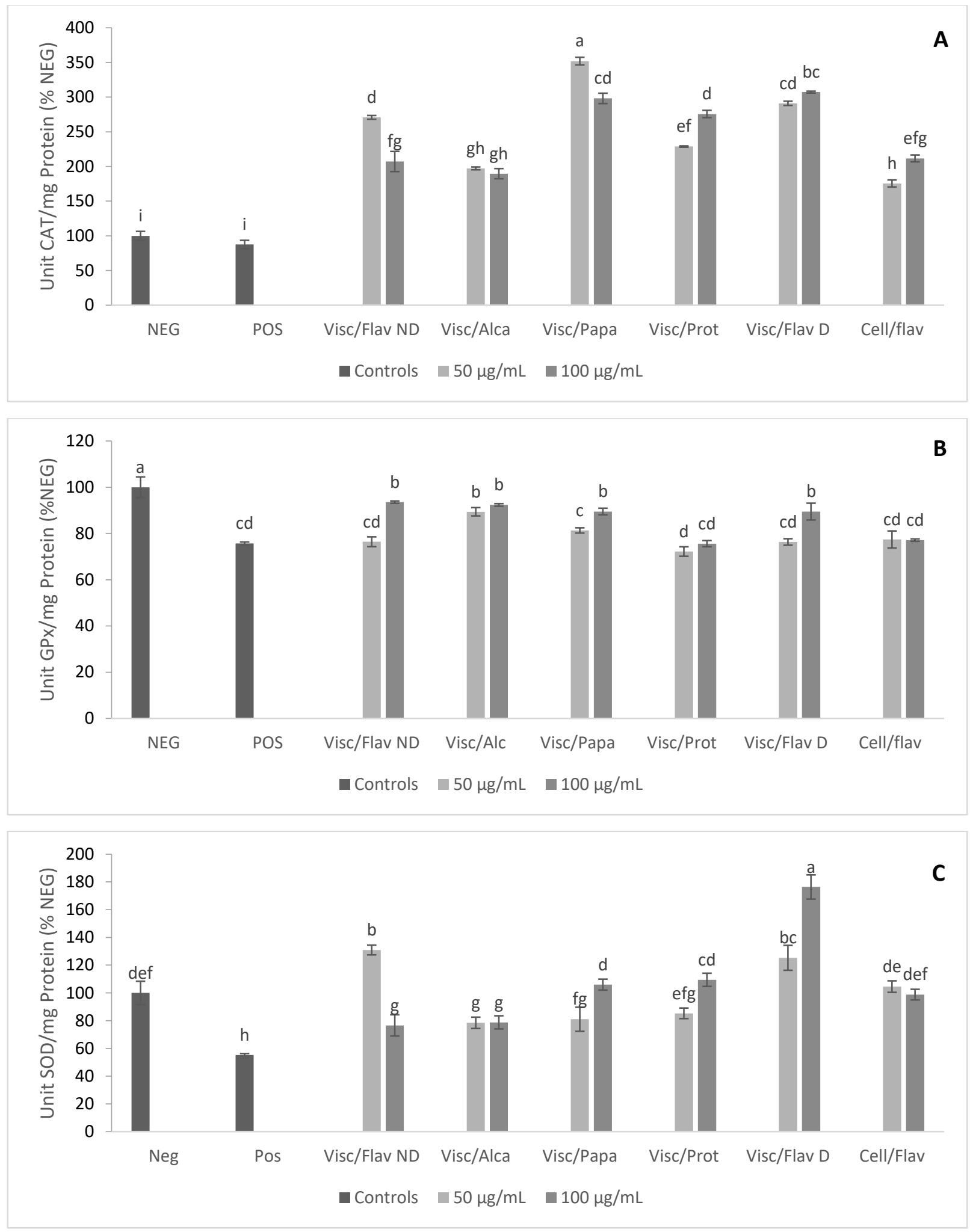

Figure 19. Changes in antioxidant enzyme activity in selected OBPHs treatment due to AAPH-induced oxidative stress. (A): CAT, (B): GPX, (C): SOD. HepG2 cells were treated with 50 and $100 \mu \mathrm{g} / \mathrm{mL} O B P H s$ and the changes in activity were compared with NEG (No treatment at all) and POS (AAPH treated Only), ( $n=3)$. Data with different letters showed the significant difference $(p<0.05)$ in Duncan's multiple range test. 
The primary action of GPx is to eliminate $\mathrm{H}_{2} \mathrm{O}_{2}$ as a substrate for the Fenton reactions. Its activity is dependent on the reduction of tripeptide glutathione (GSH) - intracellular and non-enzymatic antioxidant - to oxidized GSSG form [265]. Overproduction of ROS under AAPH-induced oxidative stress caused a significant decrease in detectable GPx level in HepG2 cells to $75.7 \pm$ 0.7\% (Figure 19-B). Treatment with OBPH also enhanced GPX activity, but not significantly higher than that of NEG control. In the previous study, some purified oat bran hydrolysates were able to increase GPx activity in HepG2 cells greater than that of NEG control [247]. The low activity of GPx in this study might be due to susceptibility to damage of GPx enzyme to hydrogen peroxide itself in presence of sample impurities [266]. Likewise, low level of GPx activity could be attributed to the GSH depletion due to oxidative stress burden on cell GSH supply [267]. The Viscozyme treated OBPHs worked more efficiently compared to the one derived from cellulase. Depending on the type of antioxidant used and the treatment time, activity level could increase variability, but generally, an increase in overall GPx activity is anticipated [268],[269].

Superoxide dismutase SOD is another antioxidant enzyme that catalyzes the conversion of superoxide $\left(\mathrm{O}_{2}{ }^{--}\right)$to $\mathrm{O}_{2}$ and $\mathrm{H}_{2} \mathrm{O}_{2}$, which is less reactive. The results of this study showed that use of AAPH to induce oxidative stress in cells had inhibitory activity on SOD enzyme in the POS HepG2 cells, and reduced the level to almost half the NEG control at $55.2 \pm 1.1 \%$ (Figure 19-C). By treating HepG2 cells, the activity level raised in all the samples significantly, specifically with Visc/Flav D (176.7 $\pm 8.7 \%)$ and Visc/Flav ND (130.9 $\pm 3.5 \%)$ treatments. Treating biological systems with protein hydrolysates showed improvement in the activity level of SOD, reducing the adverse effects of oxidative stress [270],[271]. All OBPHs could restore SOD activity in HepG2 cells more significantly compared to the previous study [247]. It is possible that production of a broad range of antioxidative peptides resulted in increased expression of SOD. Seaweed protein hydrolysates also were able to reproduce similar results in the induction of both SOD and CAT activity in Caco-2 cell cultures [272]. Overall the activity of antioxidative enzymes were all affected by $\mathrm{OBPH}$ treatment in HepG2 cells, and increased activity correlates with HepG2 cytoprotection. 


\subsubsection{Determination of ROS}

Intracellular formation of ROS was measured using $2^{\prime}, 7^{\prime}$-dichlorofluorescein diacetate $\left(\mathrm{DCFH}_{2}{ }^{-}\right.$ DA) as the fluorescent substrate. Treating cells with AAPH-induced free radicals turned nonfluorescent $\mathrm{DCFH}_{2}$-DA into DCF fluorescence compound, and the changes were quantified using a fluorescence microplate reader at an excitation wavelength of $485 \mathrm{~nm}$ and an emission wavelength of $528 \mathrm{~nm}$ over time. For this step, proper AAPH concentration was re-evaluated again. In general, increased intracellular ROS resulted in higher fluorescent intensity and scavenging more ROS reduced the fluorescent intensity.

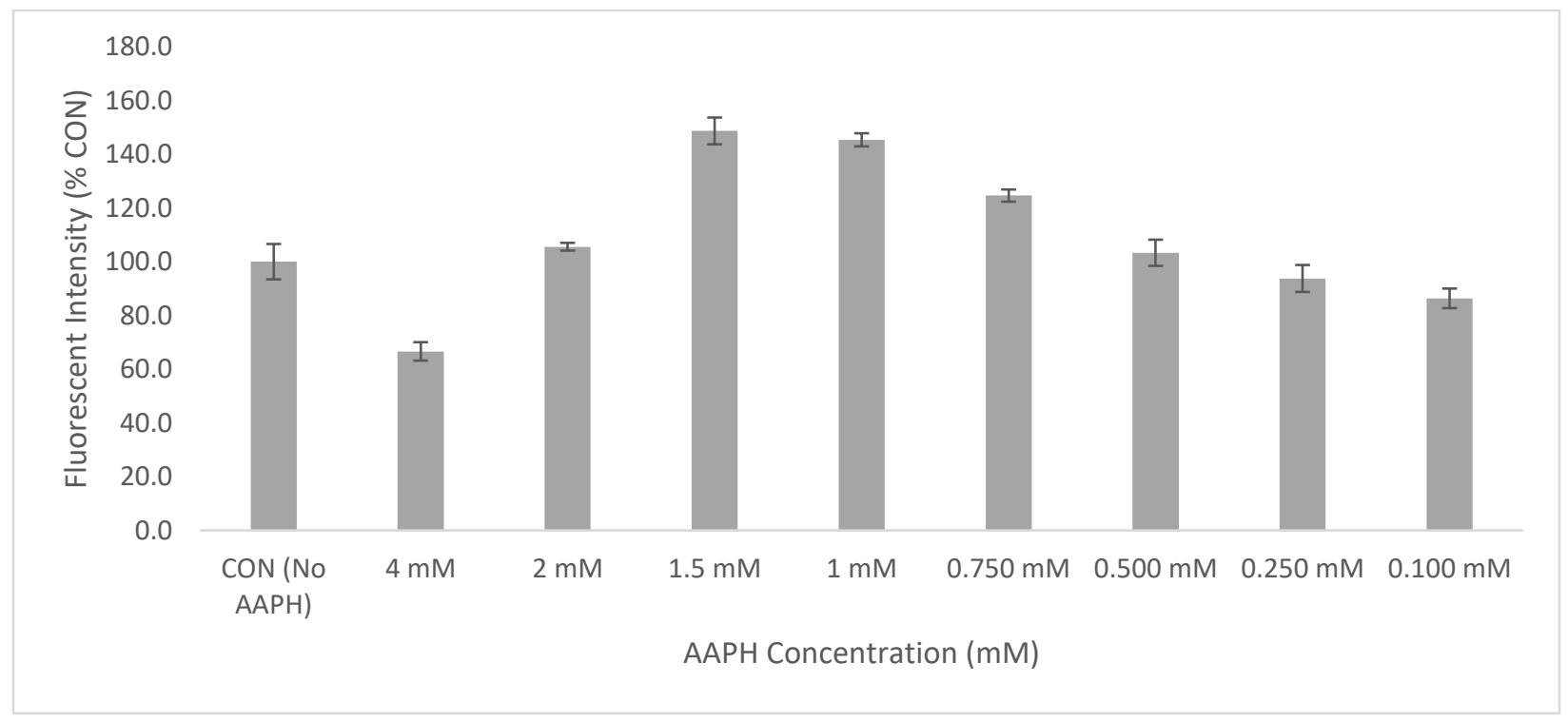

Figure 20. AAPH optimization to evaluate maximum ROS production.

The suitable AAPH concentration for this assay measured to be $1.5 \mathrm{mM}$ to produce a maximum level of ROS without affecting the cell viability (Figure 20). OBPIs and OBPHs were expected to reduce the ROS level in POS control back to the level of NEG un-induced HepG2 control cells. As it was expected, treating cells with AAPH increased the ROS level to $170.4 \pm 3.2 \%$ in POS HepG2 cells compared to the NEG control. Treating cells with all OBPI and OBPHs reduced the ROS level significantly. This decrease was the most substantial in Viscozyme treated OBPHs ranging from $71.6 \pm 6.3 \%$ in Visc/Flav ND $(50 \mu \mathrm{g} / \mathrm{mL})$ to $104.1 \pm 6.0$ in Visc/Papa $(100 \mu \mathrm{g} / \mathrm{mL})$. Cellulase treated OBPHs also reduced ROS level, but compared to Viscozyme derived OBPHs, the change in ROS level was less significant. The most ROS inhibition among cellulase derived OBPH was observed in Cell/Prot, as low as $107.0 \pm 4.8 \%$. Among OBPIs, cellulase OBPI reduced ROS level more 
significantly than Viscozyme OBPIs. As it was observed in other HepG2 cell assays, there was no dose dependency pattern observed amongst different sample. Results are shown in Figure 21.

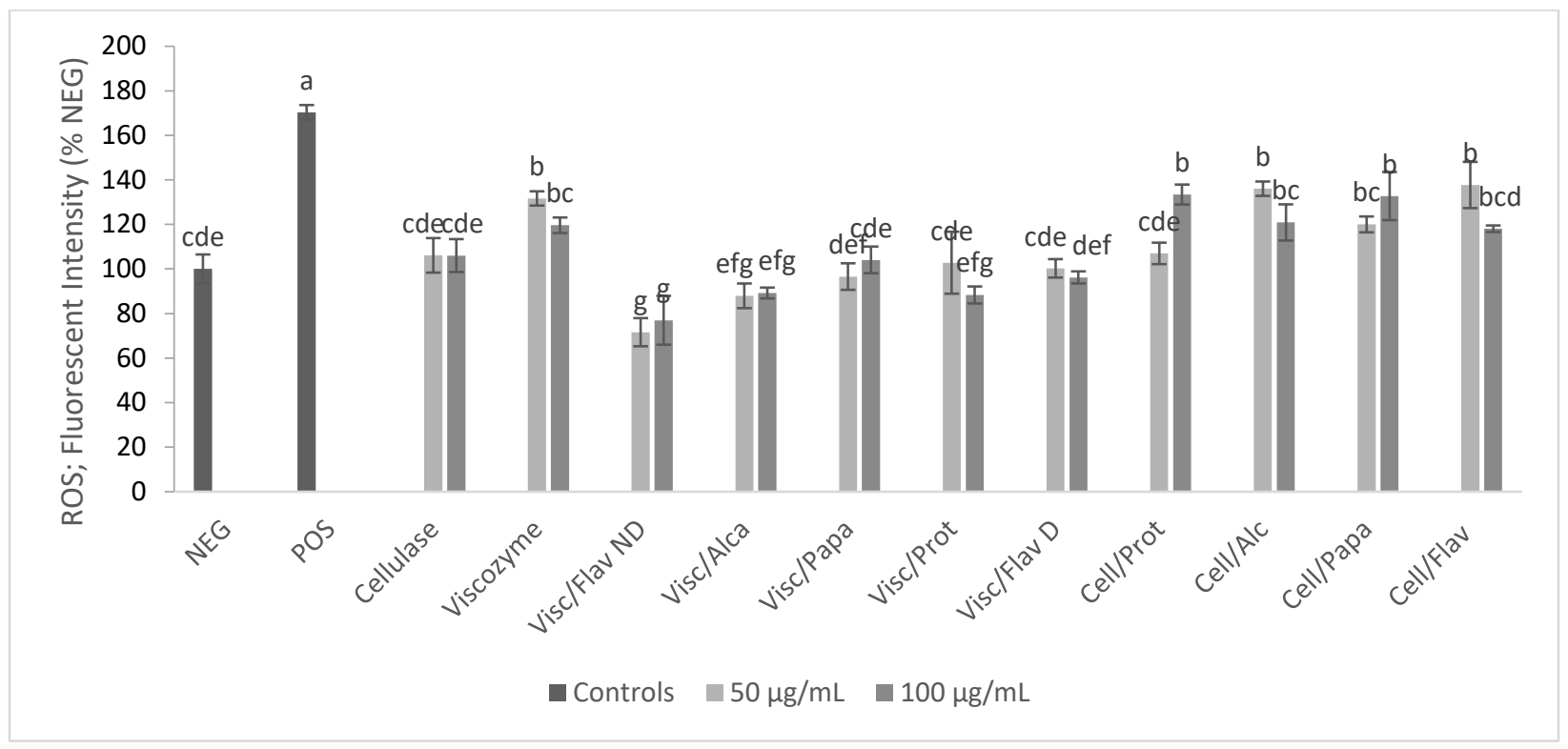

Figure 21. Determination of ROS measured by the changes in fluorescent Intensity (\% NEG) in selected OBPHs treatment due to AAPH-induced oxidative stress. HepG2 cells were treated with 50 and $100 \mu \mathrm{g} / \mathrm{mL} O B P H s$ and the changes in activity were compared with NEG (No treatment at all) and POS (AAPH treated only), ( $n=3)$. Data with different letters showed significant difference $(p<0.05)$ in Duncan's multiple range test

There were no visible protein bands formed running OBPHs in SDS-PAGE electrophoresis since the OBPHs were too small to be trapped in the gel. However, the results from SDS-PAGE combined with the observations from other assays showed better ROS scavenging activity for Cellulase OBPIs compared with Viscozyme OBPIs. This meant slightly smaller isolates were more efficient antioxidants than the bigger isolates. However, it seemed that Viscozyme derived OBPHs had better efficiency in scavenging ROS. Normally, the size of protein hydrolysates is one of the determinative factors in the antioxidative effect of protein hydrolysates [273]. Protein hydrolysates with too high or too low MW diminishes the scavenging efficiency of these proteins or peptides. Typically, for an effective antioxidative activity, protein hydrolysates should be composed of 6-20 amino acid in particular molecular weight range [101],[274]. Himaya, et al. (2012) also reported that fish protein hydrolysates with the molecular weight ranging between 500-1,500 Da were stronger ROS scavengers, compared to the ones less than 500 or above 1,500 $\mathrm{Da}$ [264]. It is possible that Viscozyme-derived OBPH produced peptides in the same MW range that scavenged ROS more efficiently in HepG2 cells, compared to Cellulase-derived OBPH. 
Peptides with specific amino acids residues may increase ROS scavenging in cell models; for example, chickpea protein hydrolysates produced amino acids with antioxidative residues such as hydrophobic, acidic and basic properties [275]. Using Alcalase and Papain also produced fish protein hydrolysates that provided ROS scavenging activity in AAPH induced stress in HepG2 cells in another study. Again the molecular weight ranged between 1,000-5,000 Da [276].

\subsubsection{Total Glutathione}

Glutathione (GSH) - a linear LMW tripeptide of L-glutamine, L-cysteine, glycine - is the most abundant antioxidant existing in cells. Under normal physiological function, glutathione exists in reduced form (GSH) 10-fold more than the concentration of oxidized glutathione or GSSG.[93]

Cancerous cells have higher GSH level due to higher level of oxidative stress. The challenge in cancer studies is to overcome the protective mechanism of antioxidative GSH that promotes the proliferative activity of cancer cells. This protective mechanism of cancer cells should be suppressed for the drug to destroy cancerous cells [277]. Oxidative stress was induced in HepG2 cells using $10 \mathrm{mM}$ AAPH in media, and the effects of OBPIs and OBPHs on GSH level were evaluated. All samples showed elevated intracellular levels of total GSH, yet, the increase was not dose dependent as shown in Figure 22. Treating cells with AAPH for 24 hours increased total GSH level 3-fold in POS compared to NEG HepG2 cells, possibly due to the protective mechanism of cells in response to the stress. However, treating HepG2 cells with OBPIs and OBPHs increased the level of total GSH as well, and in some cases, the increase was very significant. For example, using OBPIs increased total GSH 4-fold in Cellulase treated samples and up to 6-fold in Viscozyme treated samples compared to the NEG control. OBPHs also caused an increase in total GSH with the highest in Visc/Papa $(50 \mu \mathrm{g} / \mathrm{mL})$ and Cell/Papa $(100 \mu \mathrm{g} / \mathrm{mL})$ more than 5 -fold. It seemed that use of Papain - a plant protease - released peptides at selective concentration, increased GSH level more than the microbial proteases. In a study done by Kang, et al., 2012, two fractions isolated from algae using papain, increased GSH level in ethanol induced HepG2 [278]. It is possible to hypothesize that using Papain in the production of OBPHs could result in separating functional peptide sequences with the ability to induce production of GSH inside the cells by providing cell culture with a pool of desired amino acids for GSH synthesis. 


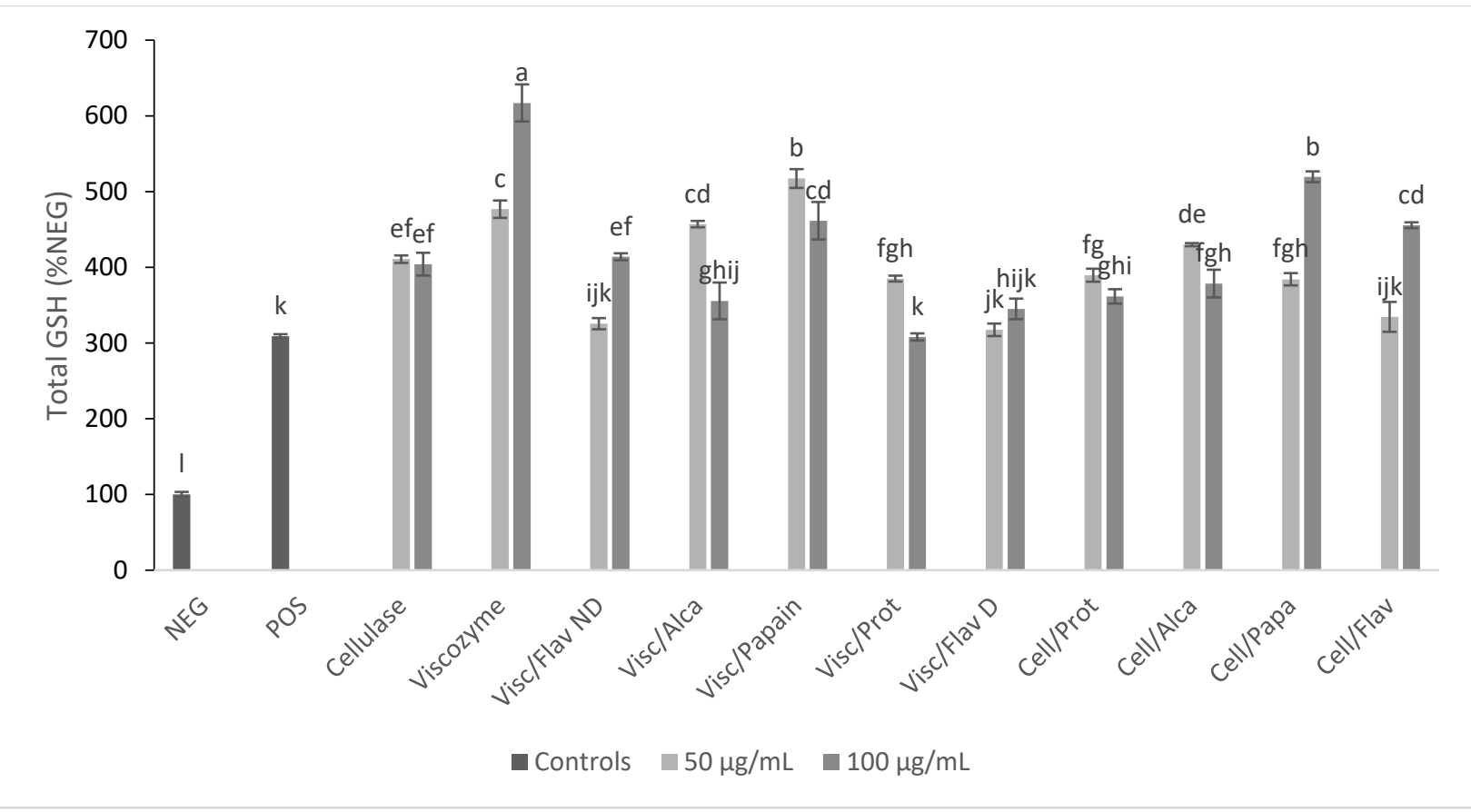

Figure 22. Total Glutathione change responses due to AAPH-induced oxidative stress in HepG2 cells. HepG2 cells were treated with 50 and $100 \mu \mathrm{g} / \mathrm{mL} O B P H s$, and the changes in activity were compared with NEG (No treatment at all) and POS (AAPH treated only), $(n=3)$. Data with different letters showed the significant difference $(p<0.05)$ in Duncan's multiple range test.

In this assay, a higher level of total GSH is not an indication of cytoprotection. It is common to see increased level of GSH in cancerous cells such as HepG2 [277]. It is suggested to consider the ratio of GSH/GSSH in oxidative stress induced cells, since GSH/GSSG ratio is a good indication of glutathione depletion in oxidative stress in cells or changes in intracellular redox state [25].

In Figure 23, most samples showed a variable fluctuation in the ratio. It is evident that using the higher concentration of OBPI and OBPHs induced more GSH depletion in HepG2 cells. All samples showed differences in GSH/GSSH ratio, and treating HepG2 cells with a lower concentration of samples showed lower GSH to GSSH turnover ratio except for Visc/Flav ND. According to Rahman et.al. (2007) it is rather challenging to measure GSSG levels in biological systems due to its high rate of turnover and GSH oxidation [162].

There are, as well, many factors affecting the process of recycling GSSG and GSH. Some of those factors include gene expressed in cells and the activity of the enzymes - GPx and glutathione reductase (GR) - involving in the recycling process. These factors affect the GSH/GSSG ratio, since GSH have a multifunctional role of as an antioxidant and as a regulatory compound [267]. 
The activity and the rate of the reaction these enzymes are affected by the protein hydrolysates treatments.

Also, the importance of phase II enzyme - glutathione-S-transferase (GST) - should be noted here. This enzyme uses GSH to conjugate xenobiotics to GSH for biotransformation and elimination of the compounds from biological systems [279]. It is possible that glutathione is involved in any of these reactions, thus, it is not available to be evaluated in the assay. Also, low ratio of most treatments might be an indication of more oxidative stress induced by treating cells at $100 \mu \mathrm{g} / \mathrm{mL}$ compared to using $50 \mu \mathrm{g} / \mathrm{mL}$.

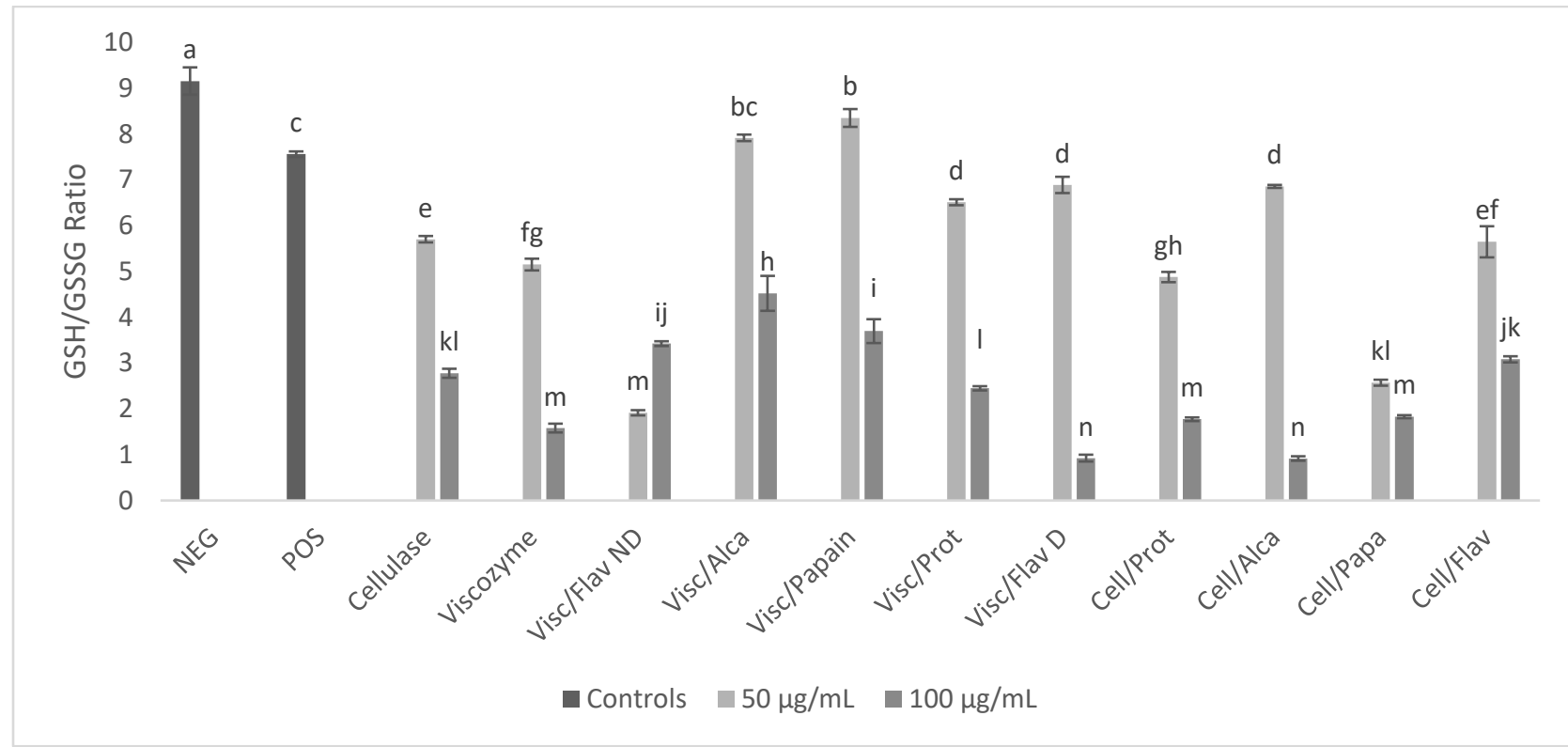

Figure 23. GSH/GSSG ratio. Indicated GSH to GSSG turnover in HepG2 cells. Cells were treated with 50 and $100 \mu \mathrm{g} / \mathrm{mL}$ OBPIs and OBPHs and the changes in activity were compared with NEG (No treatment at all) and POS (AAPH treated only), $(n=3)$. Data with different letters showed significant difference $(p<0.05)$ Duncan's multiple range test

The role of glutathione is very critical in biological reactions, not only as an intracellular free radical scavenger and antioxidant, but also for the regulation of other biological pathways such as apoptotic pathways [94]. An increase in GSH level was reported in HepG2 cells using salmon protein hydrolysates. Protein hydrolysate MW was in 1,000-2,000 Da range, with specific peptide sequences composed of hydrophobic - either aliphatic or aromatic - basic and imidazole containing amino acid residues [280]. Even though GSH depletion was observed in AAPHstressed HepG2, total GSH was representative of cell viability. However, the GSH/GSSG ratio can 
be studied more in regards to the expression of glutathione reductase (GR), an enzyme responsible for the recovery of reduced GSH, and analyzed to see if AAPH-generated peroxyl radical can affect $\mathrm{GR}$.

\subsubsection{Caspase-3 Determination and Cell Apoptosis}

Caspase-3 belongs to a family of proteases that initiate apoptosis in AAPH-induced oxidative stress in HepG2 cells. In this assay, caspase can recognize labeled substrate polypeptide sequence DEVD-pNA and cleave pNA (p-nitroaniline) - a chromophore compound - after this sequence. Upon cleavage, pNA emits light that can be quantified spectrophotometrically at 405 $\mathrm{nm}$ wavelength. Higher emitted light intensity indicates more apoptosis and the intensity of emitted light by samples was compared to an untreated NEG control.

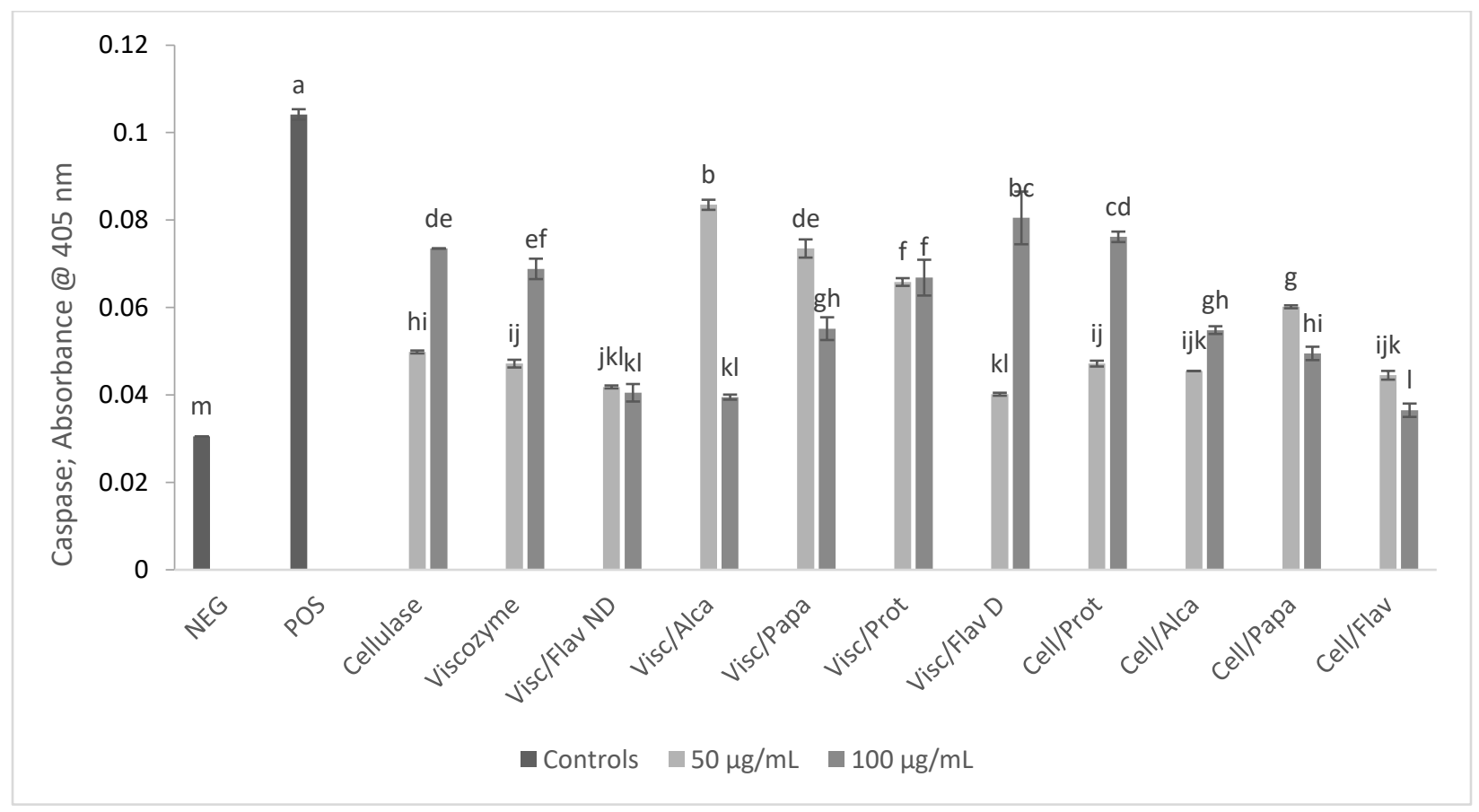

Figure 24. Caspase-3 determination. Changes in absorbance measured at $405 \mathrm{~nm}$. HepG2 cells were treated with 50 and $100 \mu \mathrm{g} / \mathrm{mL}$ OBPIs and OBPHs for 24 hours. Oxidative stress was induced in HepG2 cells using $10 \mathrm{mM}$ AAPH for 24 hours. The changes in activity were compared to NEG (untreated HepG2 cells). Results are sample means \pm S.E.M. $(n=3)$

As shown in Figure 24, AAPH-induced oxidative stress increased the absorbance as high as 0.104 in POS control, whereas, in NEG control HepG2 cells absorbance is at 0.030 , which was more than 3-fold increase in the Caspase-3 generation POS control. All samples were capable of reduction of caspase at a significant level but in a disorganized pattern. Among those that attenuate activity 
of Caspase-3 were Cell/Flav $(100 \mu \mathrm{g} / \mathrm{mL})$, Visc/Flav D $(50 \mu \mathrm{g} / \mathrm{mL})$, Visc/Flav ND (50 and 100 $\mu \mathrm{g} / \mathrm{mL})$, and Visc/Alca $(100 \mu \mathrm{g} / \mathrm{mL})$.

Generally, in apoptotic cells, there are other cell death signaling compounds formed due to either intrinsic or extrinsic pathways [281]. The intrinsic pathway is activated due to response to the internal damage such as damage to DNA, hypoxia, or to increased oxidative stress. Internal damages initiate a series of mitochondrial signaling cascades that cause changes to mitochondrial permeability releasing inner-mitochondrial components such as cytochrome $\mathrm{C}$, which results in activation of Caspase-9 - also known as initiator caspase [281],[282]. In extrinsic pathways, cell death is initiated by bounding a ligand and its corresponding death receptors, that trigger formation of bigger compounds known as cytoplasmic adapter proteins, consequently the formation of entities known as DISC (death-inducing signaling complex). Formation of DISC compounds is a signaling pathway for activation of Caspase-8. Both intrinsic and extrinsic pathways initiate activation of Caspase-3 for cellular DNA fragmentation and eventually cell death [281],[282],[283]. Even though OBPI and OBPH didn't display dose dependent pattern, all samples were able to reduce Caspase-3 level significantly with Visc/Flav ND and Cell/Flav, more efficiently compared to other OBPH and OBPI. A pentapeptide isolated from egg white showed significant antioxidant and antiapoptotic effect in hydrogen peroxide stress induced HEK-293 cell cultures. Treatment with this peptide fraction interrupted the apoptotic effect of Caspase-3 by up-regulation Bcl-2 protein and reduced the level of caspase-3 [284]. In another study, two protein hydrolysates from tuna cooking juice showed to have antiapoptotic properties. Both fractions were rich in hydrophobic amino acid, with $\mathrm{MW}$ around $2.5 \mathrm{kDa}$. The fractions also downregulated the expression of proteins involved in apoptosis induced by oxidative stress in MCF-7 breast cancer cells [146]. All data and findings suggested that treating HepG2 cells with $\mathrm{OBPH}$ have antioxidative and antiapoptotic effect in AAPH induced oxidative stress. 


\section{Conclusion}

In conclusion, the OBPI and OBPH fractions were able to affect redox state in biological cells, as they influence chemistry based antioxidant activity. In chemistry based assays all samples seemed to be free radical scavengers of hydroxyl radical, superoxide anion, peroxyl and ABTS ${ }^{\bullet+}$ radicals. They also showed acceptable iron (II) chelating activity. In most cases, protein hydrolysates appeared to exert their activity in a dose dependent manner in chemistry based assays. In HepG2 cell culture assays, they showed no cytotoxicity using Visc/Flav at different sample concentration as high as $400 \mu \mathrm{g} / \mathrm{mL}$. In MTT cytoprotection, the OBPHs derived from Viscozyme appeared to be more cytoprotective. In the same cytoprotection assay, cellulase and all its protease OBPHs derivatives showed lower cell viability at a significant level. Only Cell/Flav OBPH (at $100 \mu \mathrm{g} / \mathrm{mL}$ ) did not reduce cell viability beyond POS control. All the samples affected the enzymatic activity of catalase, glutathione peroxidase, and superoxide dismutase. In both catalase and superoxide dismutase, there were increases observed in enzymatic activity using OBPHs compared to their activity in POS control. In $\mathrm{DCFH}_{2}$-DA or ROS determination, all samples reduced generated ROS significantly compared to the POS control. However, in both total GSH determination assay and the caspase-3 assay, OBPIs and OBPHs activities were variable considerably. Still, all samples affected GSH production and Caspase-3 level. The reason depends on the nature of the GSH molecule and its connection in different pathways, and the involvement of other cell death pathways in apoptosis process. All samples, overall, were able to affect the antioxidant activity in both chemistry and cell culture assays to increase overall antioxidant capacity in both chemistry and cell culture assays. Among the samples, Viscozyme derived peptide - Visc/Flav and Visc/Papa worked better. It is possible to evaluated the amino acid composition, molecular weight and overall hydrophobicity of the effective peptides using analytical techniques and more cell culture assay. Although use of dialysis technique improved antioxidant activities in chemistry based assay, it did not improve the antioxidant activity in cell culture based assay. 


\section{Future Work}

The current study proved different antioxidative activity of protein hydrolysates prepared from oat bran using two carbohydrases - Cellulase and Viscozyme - and four proteases - Alcalase, Flavourzyme, Papain, and Protamex. However, their mechanisms of action, molecular weight and other chemical properties, such as hydrophilic or hydrophobic properties, should be evaluated. Also, these compounds should be tested for the presence of other chemical such as Maillard-driven compound with the ability to affect the study outcome. There are procedures available to purify and isolate protein hydrolysates for further studying the bioactive peptides. Methods such as mass-spectrometry, or SE-HPLC could be used to determine protein sequence and molecular weight of the compounds. For this study, it is useful to apply purification methods to eliminate impurities and interfering compounds. Prevention of cellular death and adjusting AAPH concentration to produce maximum free radicals without cell death, so the basal activity evaluated for the same level of cells. Reduced cell survival makes calculation and assumption less precise. Also, evaluation of their bioavailability through absorption using different cell lines such as Caco-2 can be measured as well. 


\section{References:}

[1] B. Halliwell, The antioxidant paradox: less paradoxical now, Br. J. Clin. Pharmacol. 75 (2013) 637-644.

[2] M. Valko, D. Leibfritz, J. Moncol, M.T. Cronin, M. Mazur, J. Telser, Free radicals and antioxidants in normal physiological functions and human disease, Int.J Biochem Cell Biol. 39 (2007) 44-84.

[3] S. Sen, R. Chakraborty, C. Sridhar, Y.S.R. Reddy, B. De, Free radicals, antioxidants, diseases and phytomedicines: current status and future prospect, Int. J. Pharm. Sci. Rev. Res. 3 (2010) 91-100.

[4] C.C. Udenigwe, R.E. Aluko, Food protein-derived bioactive peptides: production, processing, and potential health benefits, J. Food Sci. 77 (2012).

[5] G. Wu, Dietary protein intake and human health, Food Funct. 7 (2016) 1251-1265.

[6] J.E. Kinsella, Functional properties of soy proteins, J. Am. Oil Chem. Soc. 56 (1979) 242258.

[7] R.J. Elias, S.S. Kellerby, E.A. Decker, Antioxidant activity of proteins and peptides., Crit. Rev. Food Sci. Nutr. 48 (2008) 430-41.

[8] P.M. Kris-Etherton, M. Lefevre, G.R. Beecher, M.D. Gross, C.L. Keen, T.D. Etherton, Bioactive compounds in nutrition and health-research methodologies for establishing biological function: the antioxidant and anti-inflammatory effects of flavonoids on atherosclerosis, Annu. Rev. Nutr. 24 (2004) 511-538.

[9] P.A. Harnedy, R.J. FitzGerald, In vitro assessment of the cardioprotective, anti-diabetic and antioxidant potential of Palmaria palmata protein hydrolysates, J. Appl. Phycol. 25 (2013) 1793-1803.

[10] X. Wang, H. Chen, S. Li, J. Zhou, J. Xu, Physico-chemical properties, antioxidant activities and antihypertensive effects of walnut protein and its hydrolysate, J. Sci. Food Agric. 96 (2016) 2579-2587. 
[11] A.L. McCarthy, Y.C. O'Callaghan, A. Connolly, C.O. Piggott, R.J. FitzGerald, N.M. O’Brien, In vitro antioxidant and anti-inflammatory effects of brewers' spent grain protein rich isolate and its associated hydrolysates, Food Res. Int. 50 (2013) 205-212.

[12] B. Poljsak, D. Šuput, I. Milisav, Achieving the balance between ROS and antioxidants: when to use the synthetic antioxidants, Oxid. Med. Cell. Longev. 2013 (2013).

[13] A. Rahal, A. Kumar, V. Singh, B. Yadav, R. Tiwari, S. Chakraborty, K. Dhama, Oxidative stress, prooxidants, and antioxidants: the interplay, Biomed Res. Int. 2014 (2014).

[14] A. McCarthy, Y. O'Callaghan, N. O'Brien, Protein hydrolysates from agricultural cropsbioactivity and potential for functional food development, Agriculture. 3 (2013) 112-130.

[15] A. Clemente, A. Clemente, Enzymatic protein hydrolysates in human nutrition, 2244 (2000) 254-262.

[16] A.G.B. Wouters, I. Rombouts, E. Fierens, K. Brijs, J.A. Delcour, Relevance of the functional properties of enzymatic plant protein hydrolysates in food systems, Compr. Rev. Food Sci. Food Saf. 15 (2016) 786-800.

[17] H. van den Broeck, D. Londono, R. Timmer, M. Smulders, L. Gilissen, I. van der Meer, Profiling of nutritional and health-related compounds in oat varieties, Foods. 5 (2015) 2.

[18] B. Leff, N. Ramankutty, J.A. Foley, Geographic distribution of major crops across the world, Global Biogeochem. Cycles. 18 (2004) n/a-n/a.

[19] R.H. Liu, Health benefits of whole grain phytochemicals, Food Eng. Ingredients. 35 (2010) $18-22$.

[20] P.R. Shewry, V. Piironen, A.M. Lampi, L. Nyström, L. Li, M. Rakszegi, A. Fraś, D. Boros, K. Gebruers, C.M. Courtin, J.A. Delcour, A.A.M. Andersson, L. Dimberg, Z. Bedo, J.L. Ward, Phytochemical and fiber components in oat varieties in the health grain diversity screen, J. Agric. Food Chem. 56 (2008) 9777-9784.

[21] R. Singh, S. De, A. Belkheir, Avena sativa (Oat), A Potential Neutraceutical and Therapeutic Agent: An Overview, Crit. Rev. Food Sci. Nutr. 53 (2013) 126-144. 
[22] S. Bryngelsson, L.H. Dimberg, A. Kamal-Eldin, Effects of commercial processing on levels of antioxidants in oats (Avena sativa L.), J. Agric. Food Chem. 50 (2002) 1890-1896.

[23] C.L. Emmons, D.M. Peterson, G.L. Paul, Antioxidant capacity of oat (Avena sativa L.) extracts. 2. In vitro antioxidant activity and contents of phenolic and tocol antioxidants, J. Agric. Food Chem. 47 (1999) 4894-4898.

[24] C.S. Yang, S. Sang, J.D. Lambert, M.J. Lee, Bioavailability issues in studying the health effects of plant polyphenolic compounds, Mol. Nutr. Food Res. 52 (2008) 139-151.

[25] T. Bohn, Dietary factors affecting polyphenol bioavailability, Nutr. Rev. 72 (2014) 429452.

[26] K.H. van Het Hof, C.E. West, J. a Weststrate, J.G. Hautvast, Dietary factors that affect the bioavailability of carotenoids., J. Nutr. 130 (2000) 503-506.

[27] E.A. Decker, D.J. Rose, D. Stewart, Processing of oats and the impact of processing operations on nutrition and health benefits, Br. J. Nutr. 112 (2014) S58-S64.

[28] J. Slavin, Why whole grains are protective: biological mechanisms., Proc. Nutr. Soc. 62 (2003) 129-34.

[29] A. Gani, W. SM, M. FA, Whole-grain cereal bioactive compounds and their health benefits: a review, J. Food Process. Technol. 3 (2012).

[30] P.M. Kris-Etherton, K.D. Hecker, A. Bonanome, S.M. Coval, A.E. Binkoski, K.F. Hilpert, A.E. Griel, T.D. Etherton, Bioactive compounds in foods: their role in the prevention of cardiovascular disease and cancer, Am. J. Med. 113 Suppl (2002) 71S-88S.

[31] S. Nobili, D. Lippi, E. Witort, M. Donnini, L. Bausi, E. Mini, S. Capaccioli, Natural compounds for cancer treatment and prevention, Pharmacol. Res. 59 (2009) 365-378.

[32] R. Sur, A. Nigam, D. Grote, F. Liebel, M.D. Southall, Avenanthramides, polyphenols from oats, exhibit anti-inflammatory and anti-itch activity, Arch. Dermatol. Res. 300 (2008) 569-574. 
[33] P. Vitaglione, A. Napolitano, V. Fogliano, Cereal dietary fibre: a natural functional ingredient to deliver phenolic compounds into the gut, Trends Food Sci. Technol. 19 (2008) 451-463.

[34] R. Rodríguez, A. Jiménez, J. Fernández-Bolaños, R. Guillén, A. Heredia, Dietary fibre from vegetable products as source of functional ingredients, Trends Food Sci. Technol. 17 (2006) 3-15.

[35] N.P. Möller, K.E. Scholz-Ahrens, N. Roos, J. Schrezenmeir, Bioactive peptides and proteins from foods: ilndication for health effects, Eur. J. Nutr. 47 (2008) 171-182.

[36] G.M. Pauletti, S. Gangwar, G.T. Knipp, M.M. Nerurkar, F.W. Okumu, K. Tamura, T.J. Siahaan, R.T. Borchardt, Structural requirements for intestinal absorption of peptide drugs, J. Control. Release. 41 (1996).

[37] V.I. Lushchak, Free radicals, reactive oxygen species, oxidative stress and its classification, Chem. Biol. Interact. 224 (2014) 164-175.

[38] R.R. Jenkins, Exercise and oxidative stress methodology: a critique, in: Am. J. Clin. Nutr., 2000.

[39] K.J. Davies, Oxidative stress, antioxidant defenses, and damage removal, repair, and replacement systems., IUBMB Life. 50 (2000) 279-89.

[40] K. Apel, H. Hirt, Reactive oxygen species: metabolism, oxidative stress, and signal transduction, Annu. Rev. Plant Biol. 55 (2004) 373-399.

[41] M. Valko, C.J. Rhodes, J. Moncol, M. Izakovic, M. Mazur, Free radicals, metals and antioxidants in oxidative stress-induced cancer, 160 (2006) 1-40.

[42] D.P. Jones, Radical-free biology of oxidative stress., Am. J. Physiol. Cell Physiol. 295 (2008) C849-68.

[43] A. Phaniendra, D.B. Jestadi, L. Periyasamy, Free radicals: properties, sources, targets, and their implication in various diseases, Indian J. Clin. Biochem. 30 (2015) 11-26. 
[44] T. Finkel, N.J. Holbrook, Oxidants, oxidative stress and the biology of ageing., Nature. 408 (2000) 239-247.

[45] M. Carocho, I.C.F.R. Ferreira, A review on antioxidants, prooxidants and related controversy: natural and synthetic compounds, screening and analysis methodologies and future perspectives, Food Chem. Toxicol. 51 (2013) 15-25.

[46] L.A. Pham-Huy, H. He, C. Pham-Huy, Free radicals, antioxidants in disease and health., Int. J. Biomed. Sci. 4 (2008) 89-96.

[47] I. Rahman, I.M. Adcock, Oxidative stress and redox regulation of lung inflammation in COPD, Eur. Respir. J. 28 (2006) 219-242.

[48] O. Altindag, M. Karakoc, A. Kocyigit, H. Celik, N. Soran, Increased DNA damage and oxidative stress in patients with rheumatoid arthritis, Clin. Biochem. 40 (2007) 167-171.

[49] M.A. Ansari, S.W. Scheff, Oxidative stress in the progression of alzheimer disease in the frontal cortex, J. Neuropathol. Exp. Neurol. 69 (2010) 155-167.

[50] M. Maes, M. Kubera, E. Obuchowiczwa, L. Goehler, J. Brzeszcz, Depression's multiple comorbidities explained by (neuro)inflammatory and oxidative \& nitrosative stress pathways, Neuroendocrinol. Lett. 32 (2011) 7-24.

[51] J.A. Vinson, Oxidative stress in cataracts, Pathophysiology. 13 (2006) 151-162.

[52] N.R. Madamanchi, A. Vendrov, M.S. Runge, Oxidative stress and vascular disease, Arterioscler. Thromb. Vasc. Biol. 25 (2005) 29-38.

[53] S. Reuter, S.C. Gupta, M.M. Chaturvedi, B.B. Aggarwal, Oxidative stress, inflammation, and cancer: How are they linked?, Free Radic. Biol. Med. 49 (2010) 1603-1616.

[54] D. W., Role of peroxisomes in ROS/RNS-metabolism: Implications for human disease, Biochim, Physiol Rev. 82 (2002) 47-95.

[55] V.J. Thannickal, B.L. Fanburg, Activation of an $\mathrm{H}_{2} \mathrm{O}_{2}$-generating $\mathrm{NADH}$ oxidase in human lung fibroblasts by transforming growth factor beta 1, J.Biol.Chem. 270 (1995) 30334- 
30338.

[56] C.H. Huang, M.L. Yang, C.H. Tsai, Y.C. Li, Y.J. Lin, Y.H. Kuan, Ginkgo biloba leaves extract (EGb 761) attenuates lipopolysaccharide-induced acute lung injury via inhibition of oxidative stress and NF-KB-dependent matrix metalloproteinase-9 pathway, Phytomedicine. 20 (2013) 303-309.

[57] D.A. Daels-Rakotoarison, B. Gressier, F. Trotin, C. Brunet, M. Luyckx, T. Dine, F. Bailleul, M. Cazin, J.C. Cazin, Effects of Rosa canina fruit extract on neutrophil respiratory burst, Phyther. Res. 16 (2002) 157-161.

[58] M. Fransen, M. Nordgren, B. Wang, O. Apanasets, Role of peroxisomes in ROS/RNSmetabolism: implications for human disease, Biochim. Biophys. Acta - Mol. Basis Dis. 1822 (2012) 1363-1373.

[59] M. Nordgren, M. Fransen, Peroxisomal metabolism and oxidative stress, Biochimie. 98 (2014) 56-62.

[60] B. Halliwell, Reactive species and antioxidants. Redox biology is a fundamental theme of aerobic life., Plant Physiol. 141 (2006) 312-322.

[61] A. Boueiz, P.M. Hassoun, Regulation of endothelial barrier function by reactive oxygen and nitrogen species, Microvasc. Res. 77 (2009) 26-34.

[62] J.L. Zweier, M.A.H. Talukder, The role of oxidants and free radicals in reperfusion injury, Cardiovasc. Res. 70 (2006) 181-190.

[63] R.O. Poyton, K.A. Ball, P.R. Castello, Mitochondrial generation of free radicals and hypoxic signaling, Trends Endocrinol. Metab. 20 (2009) 332-340.

[64] M.Y.B. Çimen, Free radical metabolism in human erythrocytes, Clin. Chim. Acta. 390 (2008) 1-11.

[65] B. Halliwell, Free radicals and antioxidants: Updating a personal view, Nutr. Rev. 70 (2012) 257-265. 
[66] U. Förstermann, W.C. Sessa, Nitric oxide synthases: regulation and function, Eur. Heart J. 33 (2012) 829-837.

[67] R. Kohen, A. Nyska, Toxicologic pathology, Toxicol. Pathol. 30 (2002) 620-650.

[68] S.I. Liochev, I. Fridovich, The Haber-Weiss cycle-70 years later: an alternative view, Redox Rep. 7 (2002) 55-57.

[69] Y.-Z. Fang, S. Yang, G. Wu, Free radicals, antioxidants, and nutrition., Nutrition. 18 (2002) $872-879$.

[70] D.A. Pratt, K.A. Tallman, N.A. Porter, Free radical oxidation of polyunsaturated lipids: new mechanistic insights and the development of peroxyl radical clocks, Acc. Chem. Res. 44 (2011) 458-467.

[71] C. Schneider, N.A. Porter, A.R. Brash, Routes to 4-hydroxynonenal: fundamental issues in the mechanisms of lipid peroxidation, J. Biol. Chem. 283 (2008) 15539-15543.

[72] M.G. Bonini, O. Augusto, Carbon dioxide stimulates the production of thiyl, sulfinyl, and disulfide radical anion from thiol oxidation by peroxynitrite, J. Biol. Chem. 276 (2001) 9749-9754.

[73] A. Höhn, J. König, T. Grune, Protein oxidation in aging and the removal of oxidized proteins, J. Proteomics. 92 (2013) 132-159.

[74] E. Cadenas, K.J.A. Davies, Mitochondrial free radical generation, oxidative stress, and aging, Free Radic. Biol. Med. 29 (2000) 220-230.

[75] S.J. Ralph, S. Rodríguez-Enríquez, J. Neuzil, E. Saavedra, R. Moreno-Sánchez, The causes of cancer revisited: "mitochondrial malignancy" and ROS-induced oncogenic transformation - Why mitochondria are targets for cancer therapy, Mol. Aspects Med. 31 (2010) 145-170.

[76] B. Halliwell, Oxidative stress and cancer: have we moved forward?, Biochem. J. 401 (2007) 1-11. 
[77] A. Azqueta, S. Shaposhnikov, A.R. Collins, DNA oxidation: investigating its key role in environmental mutagenesis with the comet assay, Mutat. Res. - Genet. Toxicol. Environ. Mutagen. 674 (2009) 101-108.

[78] K. Kino, H. Sugiyama, Possible cause of G??C???C??G transversion mutation by guanine oxidation product, imidazolone, Chem. Biol. 8 (2001) 369-378.

[79] B. Halliwell, Letters to the editors: the definition and measurement of antioxidants in biological systems, Free Radic. Biol. Med. 18 (1995) 125-126.

[80] K. Rahman, Studies on free radicals, antioxidants, and co-factors., Clin. Interv. Aging. 2 (2007) 219-236.

[81] D. Koracevic, G. Koracevic, V. Djordjevic, S. Andrejevic, V. Cosic, Method for the measurement of antioxidant activity in human fluids., J. Clin. Pathol. 54 (2001) 356-61.

[82] H. Sies, Oxidative stress: oxidants and antioxidants, Exp. Physiol. 82 (1997) 291-295.

[83] P. Chelikani, I. Fita, P.C. Loewen, Diversity of structures and properties among catalases, Cell. Mol. Life Sci. 61 (2004) 192-208.

[84] M.E. Inal, G. Kanbak, E. Sunal, Antioxidant enzyme activities and malondialdehyde levels related to aging, Clin. Chim. Acta. 305 (2001) 75-80.

[85] M. Marí, A.I. Cederbaum, Induction of catalase, alpha, and microsomal glutathione Stransferase in CYP2E1 overexpressing HepG2 cells and protection against short-term oxidative stress, Hepatology. 33 (2001) 652-661.

[86] P. Doyen, A. Bigot, P. Vasseur, F. Rodius, Molecular cloning and expression study of piclass glutathione S-transferase (pi-GST) and selenium-dependent glutathione peroxidase (Se-GPx) transcripts in the freshwater bivalve Dreissena polymorpha, Comp. Biochem. Physiol. - C Toxicol. Pharmacol. 147 (2008) 69-77.

[87] R. Mittler, Oxidative stress, antioxidants and stress tolerance, Trends Plant Sci. 7 (2002) 405-410. 
[88] M. Alía, S. Ramos, R. Mateos, A.B. Granado-Serrano, L. Bravo, L. Goya, Quercetin protects human hepatoma HepG2 against oxidative stress induced by tert-butyl hydroperoxide, Toxicol. Appl. Pharmacol. 212 (2006) 110-118.

[89] I.N. Zelko, T.J. Mariani, R.J. Folz, Superoxide dismutase multigene family: a comparison of the CuZn-SOD (SOD1), Mn-SOD (SOD2), and EC-SOD (SOD3) gene structures, evolution, and expression, Free Radic. Biol. Med. 33 (2002) 337-349.

[90] A.C. Maritim, R.A. Sanders, J.B. Watkins, Diabetes, oxidative stress, and antioxidants: a review, J. Biochem. Mol. Toxicol. 17 (2003) 24-38.

[91] H.Y. Yoo, M.S. Chang, H.M. Rho, The activation of the rat copper/zinc superoxide dismutase gene by hydrogen peroxide through the hydrogen peroxide-responsive element and by paraquat and heat shock through the same heat shock element, J. Biol. Chem. 274 (1999) 23887-23892.

[92] S.C. Lu, Regulation of glutathione synthesis, Mol. Aspects Med. 30 (2009) 42-59.

[93] H.J. Forman, H. Zhang, A. Rinna, Glutathione: Overview of its protective roles, measurement, and biosynthesis, Mol. Aspects Med. 30 (2009) 1-12.

[94] G. Wu, Y. Fang, S. Yang, J.R. Lupton, N.D. Turner, Recent advances in nutritional sciences glutathione metabolism and its implications for health, Environ. Heal. 134 (2004) 489492. http://www.ncbi.nlm.nih.gov/pubmed/14988435.

[95] P.C. Bickford, T. Gould, L. Briederick, K. Chadman, A. Pollock, D. Young, B. Shukitt-Hale, J. Joseph, Antioxidant-rich diets improve cerebellar physiology and motor learning in aged rats, Brain Res. 866 (2000) 211-217.

[96] K.B. Pandey, S.I. Rizvi, Plant polyphenols as dietary antioxidants in human health and disease., Oxid. Med. Cell. Longev. 2 (2009) 270-8.

[97] B. Halliwell, J. Rafter, A. Jenner, Health promotion by flavonoids, tocopherols, tocotrienols, and other phenols: direct or indirect effects? Antioxidant or not?, Am. J. Clin. Nutr. 81 (2005) 268-276. 
[98] S. Martins, S.I. Mussatto, G. Martínez-Avila, J. Montañez-Saenz, C.N. Aguilar, J.A. Teixeira, Bioactive phenolic compounds: production and extraction by solid-state fermentation. A review, Biotechnol. Adv. 29 (2011) 365-373.

[99] R. Di Bernardini, P. Harnedy, D. Bolton, J. Kerry, E. O\&apos;Neill, A.M. Mullen, M. Hayes, Antioxidant and antimicrobial peptidic hydrolysates from muscle protein sources and byproducts, Food Chem. 124 (2011) 1296-1307.

[100] A. Pihlanto, Antioxidative peptides derived from milk proteins, Int. Dairy J. 16 (2006) 1306-1314.

[101] B.H. Sarmadi, A. Ismail, Antioxidative peptides from food proteins: a review, Peptides. 31 (2010) 1949-1956.

[102] R. Hartmann, H. Meisel, Food-derived peptides with biological activity: from research to food applications, Curr. Opin. Biotechnol. 18 (2007) 163-169.

[103] H. Korhonen, Milk-derived bioactive peptides: from science to applications, J. Funct. Foods. 1 (2009) 177-187.

[104] A. Bougatef, M. Hajji, R. Balti, I. Lassoued, Y. Triki-Ellouz, M. Nasri, Antioxidant and free radical-scavenging activities of smooth hound (Mustelus mustelus) muscle protein hydrolysates obtained by gastrointestinal proteases, Food Chem. 114 (2009) 1198-1205.

[105] Y. Lv, Q. Liu, X. Bao, W. Tang, B. Yang, S. Guo, Identification and characteristics of ironchelating peptides from soybean protein hydrolysates using IMAC-Fe3+, J. Agric. Food Chem. 57 (2009) 4593-4597.

[106] K. Erdmann, N. Grosser, K. Schipporeit, H. Schroder, The ACE inhibitory dipeptide MetTyr diminishes free radical formation in human endothelial cells via induction of heme oxygenase-1 and ferritin, J. Nutr. 136 (2006) 2148-2152. http://jn.nutrition.org/content/136/8/2148.abstract.

[107] F. Franek, O. Hohenwarter, H. Katinger, Plant protein hydrolysates: preparation of defined peptide fractions promoting growth and production in animal cells cultures, 
Biotechnol. Prog. 16 (2000) 688-692.

[108] P. m. Nielsen, D. Petersen, C. Dambmann, Improved method for determining food protein degree of hydrolysis, J. Food Sci. 66 (2001) 642-646.

[109] R.C. Kuhad, R. Gupta, A. Singh, Microbial cellulases and their industrial applications, Enzyme Res. 2011 (2011) 1-10.

[110] M.K. Bhat, Cellulases and related enzymes in biotechnology, Biotechnol. Adv. 18 (2000) 355-383.

[111] S.D. Sheet, Viscozyme ${ }^{\circledR}$ L, (2015) 1-8.

[112] M. Merz, T. Eisele, P. Berends, D. Appel, S. Rabe, I. Blank, T. Stressler, L. Fischer, Flavourzyme, an enzyme preparation with industrial relevance: automated nine-step purification and partial characterization of eight enzymes, J. Agric. Food Chem. 63 (2015) 5682-5693.

[113] T.V. Nieto-Nieto, Y.X. Wang, L. Ozimek, L. Chen, Effects of partial hydrolysis on structure and gelling properties of oat globular proteins, Food Res. Int. 55 (2014) 418-425.

[114] J.I. Boye, S. Roufik, N. Pesta, C. Barbana, Angiotensin I-converting enzyme inhibitory properties and SDS-PAGE of red lentil protein hydrolysates, LWT - Food Sci. Technol. 43 (2010) 987-991.

[115] L. Hedstrom, Serine protease mechanism and specificity, Chem. Rev. 102 (2002) 45014523.

[116] K. Jellouli, O. Ghorbel-Bellaaj, H. Ben Ayed, L. Manni, R. Agrebi, M. Nasri, Alkalineprotease from Bacillus licheniformis MP1: Purification, characterization and potential application as a detergent additive and for shrimp waste deproteinization, Process Biochem. 46 (2011) 1248-1256.

[117] B.J.H. Kuipers, A.C. Alting, H. Gruppen, Comparison of the aggregation behavior of soy and bovine whey protein hydrolysates, Biotechnol. Adv. 25 (2007) 606-610. 
[118] D. Doucet, D.E. Otter, S.F. Gauthier, E.A. Foegeding, Enzyme-induced gelation of extensively hydrolyzed whey proteins by alcalase: peptide identification and determination of enzyme specificity, J. Agric. Food Chem. 51 (2003) 6300-6308.

[119] C.N. Larsen, J.S. Price, K.D. Wilkinson, Substrate binding and catalysis by ubiquitin Cterminal hydrolases: identification of two active site residues., Biochemistry. 35 (1996) 6735-6744.

[120] I. Schechter, A. Berger, Mapping the active site of papain; specific peptide inhibitors of papain., Biochem. Biophys. Res. Commun. 32 (1968) 898-902.

[121] S. Huang, L. Zhao, X. Cai, S. Wang, Y. Huang, J. Hong, P. Rao, Purification and characterisation of a glutamic acid-containing peptide with calcium-binding capacity from whey protein hydrolysate, J. Dairy Res. 82 (2015) 29-35.

[122] C.F. Chi, F.Y. Hu, B. Wang, Z.R. Li, H.Y. Luo, Influence of amino acid compositions and peptide profiles on antioxidant capacities of two protein hydrolysates from skipjack tuna (Katsuwonus pelamis) dark muscle, Mar. Drugs. 13 (2015) 2580-2601.

[123] Z. Xie, J. Huang, X. Xu, Z. Jin, Antioxidant activity of peptides isolated from alfalfa leaf protein hydrolysate, Food Chem. 111 (2008) 370-376.

[124] R. Zhu, Y. Wang, L. Zhang, Q. Guo, Oxidative stress and liver disease, Hepatol. Res. 42 (2012) 741-749.

[125] V. Mersch-Sundermann, S. Knasmüller, X.J. Wu, F. Darroudi, F. Kassie, Use of a humanderived liver cell line for the detection of cytoprotective, antigenotoxic and cogenotoxic agents, Toxicology. 198 (2004) 329-340.

[126] S. Zunec, V. Kasuba, I. Pavicic, A.M. Marjanoviic, B. Tariba, M. Milic, N. Kopjar, A. Pizent, A.L. Vrdoljak, R. Rozgaj, D. Zeljeic, Assessment of oxidative stress responses and the cytotoxic and genotoxic potential of the herbicide tembotrione in HepG2 cells, Food Chem. Toxicol. 94 (2016) 64-74.

[127] R.H. Liu, J. Finley, Potential cell culture models for antioxidant research, J. Agric. Food 
Chem. 53 (2005) 4311-4314.

[128] M. Alía, S. Ramos, R. Mateos, L. Bravo, L. Goya, Response of the antioxidant defense system to tert-butyl hydroperoxide and hydrogen peroxide in a human hepatoma cell line (HepG2), J. Biochem. Mol. Toxicol. 19 (2005) 119-128.

[129] W. Liao, Z. Ning, L. Chen, Q. Wei, E. Yuan, J. Yang, J. Ren, Intracellular antioxidant detoxifying effects of diosmetin on 2,2-azobis(2-amidinopropane) dihydrochloride (AAPH)-induced oxidative stress through inhibition of reactive oxygen species generation, J. Agric. Food Chem. 62 (2014) 8648-8654.

[130] R.L. Prior, H. Hoang, L. Gu, X. Wu, M. Bacchiocca, M. Hampsch-woodill, D. Huang, B. Ou, R. Jacob, Assays for hydrophilic and lipophilic antioxidant capacity ( oxygen radical absorbance capacity ( ORAC )) of plasma and other biological and food samples assays for hydrophilic and lipophilic antioxidant capacity ( oxygen radical absorbance capacity ( ORA, J. Agric. Food Chem. 51 (2003) 3273-3279.

[131] A. Karadag, B. Ozcelik, S. Saner, Review of methods to determine antioxidant capacities, (2009) 41-60.

[132] P. Meier, A. Finch, G. Evan, Apoptosis in development., Nature. 407 (2000) 796-801.

[133] Y. Fuchs, H. Steller, Programmed cell death in animal development and disease, Cell. 147 (2011) 742-758.

[134] S. Fulda, A.M. Gorman, O. Hori, A. Samali, Cellular stress responses: cell survival and cell death, Int. J. Cell Biol. 2010 (2010).

[135] M.L. Circu, T.Y. Aw, Glutathione and modulation of cell apoptosis, Biochim. Biophys. Acta - Mol. Cell Res. 1823 (2012) 1767-1777.

[136] M.L. Circu, T.Y. Aw, Reactive oxygen species, cellular redox systems, and apoptosis, Free Radic. Biol. Med. 48 (2010) 749-762.

[137] S. Arandjelovic, K.S. Ravichandran, C. Biology, Phagocytosis of apoptotic cells in homeostasis, Nat. Immunol. 16 (2016) 907-917. 
[138] J.C. Martinou, R.J. Youle, Mitochondria in apoptosis: Bcl-2 family members and mitochondrial dynamics, Dev. Cell. 21 (2011) 92-101.

[139] M.O. Hengartner, The biochemistry of apoptosis., Nature. 407 (2000) 770-6.

[140] S.J. Riedl, G.S. Salvesen, The apoptosome: signalling platform of cell death, Nat. Rev. Mol. Cell Biol. 8 (2007) 405-413.

[141] K.M. Boatright, G.S. Salvesen, Mechanisms of caspase activation, Curr. Opin. Cell Biol. 15 (2003) 725-731.

[142] M. Brentnall, L. Rodriguez-Menocal, R. De Guevara, E. Cepero, L.H. Boise, Caspase-9, caspase- 3 and caspase-7 have distinct roles during intrinsic apoptosis, BMC Cell Biol. 14 (2013) 32.

[143] L.S. Dickens, I.R. Powley, M.A. Hughes, M. MacFarlane, The "complexities" of life and death: death receptor signalling platforms, Exp. Cell Res. 318 (2012) 1269-1277.

[144] C. Kantari, H. Walczak, Caspase-8 and Bid: Caught in the act between death receptors and mitochondria, Biochim. Biophys. Acta - Mol. Cell Res. 1813 (2011) 558-563.

[145] D.M. Hockenbery, Z.N. Oltvai, X.M. Yin, C.L. Milliman, S.J. Korsmeyer, Bcl-2 functions in an antioxidant pathway to prevent apoptosis, Cell. 75 (1993) 241-251.

[146] C. Hung, Y. Yang, P. Kuo, K.-C. Hsu, Protein hydrolysates from tuna cooking juice inhibit cell growth and induce apoptosis of human breast cancer cell line MCF-7, J. Funct. Foods. 11 (2014) 563-570.

[147] J.I. Yang, J.Y. Tang, Y.S. Liu, H.R. Wang, S.Y. Lee, C.Y. Yen, H.W. Chang, Roe protein hydrolysates of giant grouper (Epinephelus lanceolatus) inhibit cell proliferation of oral cancer cells involving apoptosis and oxidative stress, Biomed Res. Int. 2016 (2016).

[148] T. Sae-leaw, Y.C. O'Callaghan, S. Benjakul, N.M. O’Brien, Antioxidant, immunomodulatory and antiproliferative effects of gelatin hydrolysates from seabass (Lates calcarifer) skins, Int. J. Food Sci. Technol. 51 (2016) 1545-1551. 
[149] M.-M. Jin, L. Zhang, H.-X. Yu, J. Meng, Z. Sun, R.-R. Lu, Protective effect of whey protein hydrolysates on $\mathrm{H}_{2} \mathrm{O}_{2}$-induced PC12 cells oxidative stress via a mitochondria-mediated pathway, Food Chem. 141 (2013) 847-852.

[150] T. Yang, Y. Li, M. Ma, Q. Lin, S. Sun, B. Zhang, X. Feng, J. Liu, Protective effect of soluble eggshell membrane protein hydrolysate on cardiac ischemia/reperfusion injury, 1 (2016) $1-5$.

[151] Y. Shi, P. Rupa, B. Jiang, Y. Mine, Hydrolysate from eggshell membrane ameliorates intestinal inflammation in mice, Int. J. Mol. Sci. 15 (2014) 22728-22742.

[152] Z. Ma, T. Hou, W. Shi, W. Liu, H. He, Inhibition of hepatocyte apoptosis: an important mechanism of corn peptides attenuating liver injury induced by ethanol, Int. J. Mol. Sci. 16 (2015) 22062-22080.

[153] W. Li, F.S. Hosseinian, A. Tsopmo, J.K. Friel, T. Beta, Evaluation of antioxidant capacity and aroma quality of breast milk, Nutrition. 25 (2009) 105-114.

[154] R. Re, N. Pellegrini, A. Proteggente, A. Pannala, M. Yang, C. Rice-Evans, Antioxidant activity applying an improved abts radical cation decolorization assay, Free Radic. Biol. Med. 26 (1999) 1231-1237.

[155] A. Vanvi, A. Tsopmo, Pepsin digested oat bran proteins: separation, antioxidant activity, and identification of new peptides, J. Chem. 2016 (2016).

[156] L.L.S. Canabady-Rochelle, C. Harscoat-Schiavo, V. Kessler, A. Aymes, F. Fournier, J.M. Girardet, Determination of reducing power and metal chelating ability of antioxidant peptides: revisited methods, Food Chem. 183 (2015) 129-135.

[157] A. Jang, M. Lee, Purification and identification of angiotensin converting enzyme inhibitory peptides from beef hydrolysates, Meat Sci. 69 (2005) 653-661.

[158] Y. Liu, M.G. Nair, An efficient and economical MTT assay for determining the antioxidant activity of plant, J. Nat. Prod. 73 (2010) 1193-1195.

[159] R.F. Beers, I.W. Sizer, A spectrophotometric method for measuring the breakdown of 
hydrogen peroxide by catalase, J. Biol. Chem. 195 (1951) 133-140.

[160] R.A. Lawrence, R.F. Burk, Glutathione peroxidase activity in selenium-deficient rat liver, Biochem. Biophys. Res. Commun. 71 (1976) 952-958.

[161] D.R. Spitz, L.W. Oberley, An assay for superoxide dismutase activity in mammalian tissue homogenates, Anal. Biochem. 179 (1989) 8-18.

[162] I. Rahman, A. Kode, S.K. Biswas, Assay for quantitative determination of glutathione and glutathione disulfide levels using enzymatic recycling method, Nat. Protoc. 1 (2007) 3159-3165.

[163] L. Rui Hai, K.L. Wolfe, Cellular antioxidant activity assay for assessing antioxidants, foods , and dietary supplements, J. Agric. Food Chem. 55 (2007) 8896-8907.

[164] M.A.K. Markwell, S.M. Haas, L.L. Bieber, N.E. Tolbert, A modification of the Lowry procedure to simplify protein determination in membrane and lipoprotein samples, Anal. Biochem. 87 (1978) 206-210.

[165] X. Guan, H. Yao, Optimization of Viscozyme L-assisted extraction of oat bran protein using response surface methodology, Food Chem. 106 (2008) 345-351.

[166] J.M. Gasparotto, L.B. Werle, E.L. Foletto, R.C. Kuhn, S.L. Jahn, M.A. Mazutti, Production of cellulolytic enzymes and application of crude enzymatic extract for saccharification of lignocellulosic biomass, Appl. Biochem. Biotechnol. 175 (2015) 560-572.

[167] S. Jodayree, J.C. Smith, A. Tsopmo, Use of carbohydrase to enhance protein extraction efficiency and antioxidative properties of oat bran protein hydrolysates, Food Res. Int. 46 (2012) 69-75.

[168] M. Dashtban, H. Schraft, W. Qin, Fungal bioconversion of lignocellulosic residues; Opportunities \& perspectives, Int. J. Biol. Sci. 5 (2009) 578-595.

[169] C. Baschien, G. Rode, U. Böckelmann, P. Götz, U. Szewzyk, Interactions between hyphosphere-associated bacteria and the fungus cladosporium herbarum on aquatic leaf litter, Microb. Ecol. 58 (2009) 642-650. 
[170] L. Homolka, Laboratory protocols in fungal biology, Lab. Protoc. Fungal Biol. Curent Methods Fungal Biol. (2013) 9-17.

[171] N. Thieme, V.W. Wu, A. Dietschmann, A.A. Salamov, M. Wang, J. Johnson, V.R. Singan, I. V Grigoriev, N.L. Glass, C.R. Somerville, J.P. Benz, The transcription factor PDR-1 is a multi-functional regulator and key component of pectin deconstruction and catabolism in Neurospora crassa., Biotechnol. Biofuels. 10 (2017) 149.

[172] N. Aldred, I.Y. Phang, S.L. Conlan, A.S. Clare, G.J. Vancso, The effects of a serine protease, Alcalase, on the adhesives of barnacle cyprids (Balanus amphitrite)., Biofouling. 24 (2008) 97-107.

[173] A. Sumantha, C. Larroche, A. Pandey, Microbiology and industrial biotechnology of food grade proteases : a perspective, Food Technol. Biotechnol. 44 (2006) 211-220.

[174] J.S. Hamada, Characterization and functional properties of rice bran proteins modified by commercial exoproteases and endoproteases, J. Food Sci. 65 (2000) 305-310.

[175] A. Waglay, S. Karboune, Enzymatic generation of peptides from potato proteins by selected proteases and characterization of their structural properties, Biotechnol. Prog. 32 (2016) 420-429.

[176] M. Mirzapour, K. Rezaei, M.A. Sentandreu, A.A. Moosavi-Movahedi, In vitro antioxidant activities of hydrolysates obtained from Iranian wild almond (Amygdalus scoparia) protein by several enzymes, Int. J. Food Sci. Technol. 51 (2016) 609-616.

[177] O.L. Tavano, Protein hydrolysis using proteases: an important tool for food biotechnolog, J. Mol. Catal. B Enzym. 90 (2013) 1-11.

[178] I.P. Claver, H. Zhou, Enzymatic hydrolysis of defatted wheat germ by proteases and the effect on the functional properties of resulting protein hydrolysates, J. Food Biochem. 29 (2005) 13-26.

[179] R. Gupta, P. Ramnani, Microbial keratinases and their prospective applications: an overview, Appl. Microbiol. Biotechnol. 70 (2006) 21-33. 
[180] V.K. Dubey, M. Pande, B.K. Singh, M. V Jagannadham, Papain-like proteases : applications of their inhibitors, African J. Biotechnol. 6 (2007) 1077-1086.

[181] D. Vivares, P. Arnoux, D. Pignol, A papain-like enzyme at work: native and acyl-enzyme intermediate structures in phytochelatin synthesis., Proc. Natl. Acad. Sci. U. S. A. 102 (2005) 18848-18853.

[182] V. Klompong, S. Benjakul, D. Kantachote, F. Shahidi, Antioxidative activity and functional properties of protein hydrolysate of yellow stripe trevally (Selaroides leptolepis) as influenced by the degree of hydrolysis and enzyme type, Food Chem. 102 (2007) 13171327.

[183] P.K. Smith, R.I. Krohn, G.T. Hermanson, A.K. Mallia, F.H. Gartner, M.D. Provenzano, E.K. Fujimoto, N.M. Goeke, B.J. Olson, D.C. Klenk, Measurement of protein using bicinchoninic acid, Anal. Biochem. 150 (1985) 76-85.

[184] M.M. Bradford, A rapid and sensitive method for the quantitation of microgram quantities of protein utilizing the principle of protein-dye binding, Anal. Biochem. 72 (1976) 248-254.

[185] K. Inouye, K. Nagai, T. Takita, Coagulation of soy protein isolates induced by subtilisin Carlsberg, J. Agric. Food Chem. 50 (2002) 1237-1242.

[186] F. Zhong, Z. Wang, S.Y. Xu, C.F. Shoemaker, The evaluation of proteases as coagulants for soy protein dispersions, Food Chem. 100 (2007) 1371-1376.

[187] J.L. Harris, B.J. Backes, F. Leonetti, S. Mahrus, J. a Ellman, C.S. Craik, Rapid and general profiling of protease specificity by using combinatorial fluorogenic substrate libraries., Proc. Natl. Acad. Sci. U. S. A. 97 (2000) 7754-7759.

[188] M. Grudkowska, B. Zagdańska, Multifunctional role of plant cysteine proteinases, Acta Biochim. Pol. 51 (2004) 609-624.

[189] S.H. Tang, N.S. Hettiarachchy, T.H. Shellhammer, Protein extraction from heat stabilized defatted rice bran. Physical processing and enzyme treatments, J. Agric. Food Chem. 50 
(2002) 7444-7448.

[190] L.M. Humiski, R.E. Aluko, Physicochemical and bitterness properties of enzymatic pea protein hydrolysates, J. Food Sci. 72 (2007).

[191] J. Carrasco-Castilla, A.J. Hernández-Álvarez, C. Jiménez-Martínez, C. Jacinto-Hernández, M. Alaiz, J. Girón-Calle, J. Vioque, G. Dávila-Ortiz, Antioxidant and metal chelating activities of peptide fractions from phaseolin and bean protein hydrolysates, Food Chem. 135 (2012) 1789-1795.

[192] A.L. Tan-Wilson, K.A. Wilson, Mobilization of seed protein reserves, Physiol. Plant. 145 (2012) 140-153.

[193] B. Kong, Y.L. Xiong, Antioxidant activity of zein hydrolysates in a liposome system and the possible mode of action, J. Agric. Food Chem. 54 (2006) 6059-6068.

[194] J. Carrasco-Castilla, A.J. Hernández-Álvarez, C. Jiménez-Martínez, C. Jacinto-Hernández, M. Alaiz, J. Girón-Calle, J. Vioque, G. Dávila-Ortiz, Antioxidant and metal chelating activities of peptide fractions from phaseolin and bean protein hydrolysates, Food Chem. 135 (2012) 1789-1795.

[195] P. Hong, S. Koza, E.S.P. Bouvier, Size-exclusion chromatography for the analysis of protein biotherapeutics and their aggregates, J. Liq. Chromatogr. Relat. Technol. 35 (2012) 29232950.

[196] R.L. Prior, X. Wu, K. Schaich, Standarized methods for the dDetermination of antioxidant capacity and phenolics in foods and dietary supplements, J. Agric. Food Chem. 53 (2005) 4290-4302.

[197] E. Niki, Assessment of antioxidant capacity in vitro and in vivo, Free Radic. Biol. Med. 49 (2010) 503-515.

[198] J. Pérez-Jiménez, S. Arranz, M. Tabernero, M.E. Díaz- Rubio, J. Serrano, I. Goñi, F. SauraCalixto, Updated methodology to determine antioxidant capacity in plant foods, oils and beverages: extraction, measurement and expression of results, Food Res. Int. 41 (2008) 
$274-285$.

[199] R. Pamplona, D. Costantini, Molecular and structural antioxidant defenses against oxidative stress in animals, Am J Physiol Regul Integr Comp Physiol Am. J. Physiol. Regulatory, Integr. Comp. Physiol. 301 (2011) 843-863.

[200] M. Ozgen, R.N. Reese, A.Z. Tulio, J.C. Scheerens, A.R. Miller, Modified 2,2-azino-bis-3ethylbenzothiazoline-6-sulfonic acid (ABTS) method to measure antioxidant capacity of selected small fruits and comparison to ferric reducing antioxidant power (FRAP) and 2,2'-diphenyl-1-picrylhydrazyl (DPPH) methods, J. Agric. Food Chem. 54 (2006) 11511157.

[201] S. Dudonne, X. Vitrac, P. Coutiere, M. Woillez, J.-M. Merillon, Comparative study of antioxidant properties and total phenolic content of 30 plant extracts of industrial interest using DPPH , ABTS , FRAP, J. Agric. Food Chem. 57 (2009) 1768-1774.

[202] B. Ou, M. Hampsch-woodill, R.L. Prior, Development and validation of an improved oxygen radical absorbance capacity assay using fluorescein as the fluorescent probe, $\mathrm{J}$. Agric. Food Chem. 49 (2001) 4619-4626.

[203] Y. Ren, H. Wu, X. Li, F. Lai, G. Zhao, X. Xiao, A two-step, one-pot enzymatic method for preparation of duck egg white protein hydrolysates with high antioxidant activity, Appl. Biochem. Biotechnol. 172 (2014) 1227-1240.

[204] S. Yahia, S. Yahia, S. Benomar, S. Benomar, F. Dehiba, M.J. Rodriguez-Yoldi, Hypocholesterolaemic and antioxidant efficiency of chickpea (Cicer arietinum) protein hydrolysates depend on its degree of hydrolysis in cholesterol-fed rat, Nutr. Food Sci. 47 (2017) 254-269.

[205] J. Drenth, J. Jansonius, R. Koekoek, J. Marrink, J. Munnik, B. Wolthers, The crystal structure of papain. Two-dimensional fourier syntheses, J. Mol. Biol. 5 (1962) 398-407.

[206] T.L. Pownall, C.C. Udenigwe, R.E. Aluko, Amino acid composition and antioxidant properties of pea seed (Pisum sativum L.) Enzymatic protein hydrolysate fractions, J. 
Agric. Food Chem. 58 (2010) 4712-4718.

[207] L. Zhang, J. Li, K. Zhou, Chelating and radical scavenging activities of soy protein hydrolysates prepared from microbial proteases and their effect on meat lipid peroxidation, Bioresour. Technol. 101 (2010) 2084-2089.

[208] A.B. Nongonierma, S. Le Maux, C. Dubrulle, C. Barre, R.J. FitzGerald, Quinoa (Chenopodium quinoa Willd.) protein hydrolysates with in vitro dipeptidyl peptidase IV (DPP-IV) inhibitory and antioxidant properties, J. Cereal Sci. 65 (2015) 112-118.

[209] A.B. Nongonierma, R.J. FitzGerald, Investigation of the potential of hemp, pea, rice and soy protein hydrolysates as a source of dipeptidyl peptidase IV (DPP-IV) inhibitory peptides, Food Dig. Res. Curr. Opin. 6 (2015) 19-29.

[210] D. Orona-Tamayo, M.E. Valverde, B. Nieto-Rendón, O. Paredes-López, Inhibitory activity of chia (Salvia hispanica L.) protein fractions against angiotensin I-converting enzyme and antioxidant capacity, LWT - Food Sci. Technol. 64 (2015) 236-242.

[211] C. Fabian, Y.-H. Ju, A Review on Rice Bran Protein: its Properties and Extraction Methods, Crit. Rev. Food Sci. Nutr. 51 (2011) 816-827.

[212] L. Popović, D. Peričin, Ž. Vaštag, S. Popović, V. Krimer, A. Torbica, Antioxidative and functional properties of pumpkin oil cake globulin hydrolysates, JAOCS, J. Am. Oil Chem. Soc. 90 (2013) 1157-1165.

[213] S. Raghavan, H.G. Kristinsson, C. Leeuwenburgh, Radical scavenging and reducing ability of tilapia (Oreochromis niloticus) protein hydrolysates, J. Agric. Food Chem. 56 (2008) 10359-10367.

[214] A. Zulueta, M.J. Esteve, A. Frígola, ORAC and TEAC assays comparison to measure the antioxidant capacity of food products, Food Chem. 114 (2009) 310-316.

[215] D. Huang, B. Ou, R.L. Prior, The chemistry behind antioxidant capacity assays, J. Agric. Food Chem. 53 (2005) 1841-1856.

[216] J. Pérez-Jiménez, F. Saura-Calixto, Effect of solvent and certain food constituents on 
different antioxidant capacity assays, Food Res. Int. 39 (2006) 791-800.

[217] I. Fridovich, N. Carolina, Oxidative Stress, Encycl. Life Sci. (2001) 1-5.

[218] D. Ryan, M. Kendall, K. Robards, Bioactivity of oats as it relates to cardiovascular disease., Nutr. Res. Rev. 20 (2007) 147-162.

[219] A. Scalbert, G. Williamson, Chocolate: modern science investigates an ancient medicine, J. Med. Food. 3 (2000) 121-125.

[220] Y. Xue, Q. Luan, D. Yang, X. Yao, K. Zhou, Direct evidence for hydroxyl radical scavenging activity of cerium oxide nanoparticles, J. Phys. Chem. C. 115 (2011) 4433-4438.

[221] D. Bar-Or, R. Bar-Or, L.T. Rael, E.N. Brody, Oxidative stress in severe acute illness, Redox Biol. 4 (2015) 340-345.

[222] T. Maezono, M. Tokumura, M. Sekine, Y. Kawase, Hydroxyl radical concentration profile in photo-Fenton oxidation process: generation and consumption of hydroxyl radicals during the discoloration of azo-dye Orange II, Chemosphere. 82 (2011) 1422-1430.

[223] O. Power, P. Jakeman, R.J. Fitzgerald, Antioxidative peptides: enzymatic production, in vitro and in vivo antioxidant activity and potential applications of milk-derived antioxidative peptides, Amino Acids. 44 (2013) 797-820.

[224] L.M. Tong, S. Sasaki, D.J. McClements, E.A. Decker, Mechanisms of the antioxidant activity of a high molecular weight fraction of whey, J. Agric. Food Chem. 48 (2000) 1473-1478.

[225] T. Ak, I. Gülçin, Antioxidant and radical scavenging properties of curcumin, Chem. Biol. Interact. 174 (2008) 27-37.

[226] H. Chen, K. Muramoto, F. Yamauchi, K. Fujimoto, K. Nokihara, Antioxidative properties of histidine-Containing peptides designed from peptide fragments found in the digests of a soybean protein., J. Agric. Food Chem. 46 (1998) 49-53.

[227] Y. Yoshimura, T. lijima, T. Watanabe, H. Nakazawa, Antioxidative effect of maillard 
reaction products using glucose-glycine model system, J. Agric. Food Chem. 45 (1997) 4106-4109.

[228] A. Meda, C.E. Lamien, M. Romito, J. Millogo, O.G. Nacoulma, Determination of the total phenolic, flavonoid and proline contents in Burkina Fasan honey, as well as their radical scavenging activity, Food Chem. 91 (2005) 571-577.

[229] J. Zhang, H. Zhang, L. Wang, X. Guo, X. Wang, H. Yao, Isolation and identification of antioxidative peptides from rice endosperm protein enzymatic hydrolysate by consecutive chromatography and MALDI-TOF/TOF MS/MS, Food Chem. 119 (2010) 226234.

[230] J.Y. Je, P.J. Park, S.K. Kim, Antioxidant activity of a peptide isolated from Alaska pollack (Theragra chalcogramma) frame protein hydrolysate, Food Res. Int. 38 (2005) 45-50.

[231] C. López-Alarcón, A. Denicola, Evaluating the antioxidant capacity of natural products: a review on chemical and cellular-based assays, Anal. Chim. Acta. 763 (2013) 1-10.

[232] X. Li, Improved pyrogallol autoxidation method: a reliable and cheap superoxidescavenging assay suitable for all antioxidants, J. Agric. Food Chem. 60 (2012) 6418-6424.

[233] M. Zhang, T.H. Mu, Y.B. Wang, M.J. Sun, Evaluation of free radical-scavenging activities of sweet potato protein and its hydrolysates as affected by single and combination of enzyme systems, Int. J. Food Sci. Technol. 47 (2012) 696-702.

[234] A. Moure, H. Domínguez, J.C. Parajó, Antioxidant properties of ultrafiltration-recovered soy protein fractions from industrial effluents and their hydrolysates, Process Biochem. 41 (2006) 447-456.

[235] H. Wu, H. Chen, C. Shiau, Free amino acids and peptides as related to antioxidant properties in protein hydrolysates of mackerel (Scomber austriasicus), Food Res. Int. 36 (2003) 949-957.

[236] R. Hurrell, I. Egli, Iron bioavailability and dietary reference values., Am. J. Clin. Nutr. 91 (2010) 1461S-1467S. 
[237] E.C. Theil, Iron homeostasis and nutritional iron deficiency, J. Nutr. 141 (2011) 724S$728 S$.

[238] S. Puntarulo, Iron, oxidative stress and human health, Mol. Aspects Med. 26 (2005) 299312.

[239] J. Riemer, H.H. Hoepken, H. Czerwinska, S.R. Robinson, R. Dringen, Colorimetric ferrozine-based assay for the quantitation of iron in cultured cells, Anal. Biochem. 331 (2004) 370-375.

[240] K.A. Nam, S.G. You, S.M. Kim, Molecular and physical characteristics of squid (Todarodes pacificus) skin collagens and biological properties of their enzymatic hydrolysates, J. Food Sci. 73 (2008) 249-255.

[241] A. Saiga, S. Tanabe, T. Nishimura, Antioxidant activity of peptides obtained from porcine myofibrillar proteins by protease treatment, J. Agric. Food Chem. 51 (2003) 3661-3667.

[242] K. Zhu, H. Zhou, H. Qian, Antioxidant and free radical-scavenging activities of wheat germ protein hydrolysates (WGPH) prepared with alcalase, Process Biochem. 41 (2006) 12961302.

[243] M.Z.T. Mu, M. Sun, Original article Sweet potato protein hydrolysates : antioxidant activity and protective effects on oxidative DNA damage, Int. J. Food Sci. Technol. 47 (2012) 2304-2310.

[244] A. Mustafa, P. ??man, R. Andersson, A. Kamal-Eldin, Analysis of free amino acids in cereal products, Food Chem. 105 (2007) 317-324.

[245] W. Biel, K. Bobko, R. Maciorowski, Chemical composition and nutritive value of husked and naked oats grain, J. Cereal Sci. 49 (2009) 413-418.

[246] E.A. Peña-Ramos, Y.L. Xiong, Antioxidative activity of whey protein hydrolysates in a liposomal system, J. Dairy Sci. 84 (2001) 2577-2583.

[247] Y. Du, R. Esfandi, W.G. Willmore, A. Tsopmo, Antioxidant activity of oat proteins derived peptides in stressed hepatic HepG2 cells, Antioxidants. 5 (2016) 39. 
[248] W. Wang, M. Scali, R. Vignani, A. Spadafora, E. Sensi, S. Mazzuca, M. Cresti, Protein extraction for two-dimensional electrophoresis from olive leaf, a plant tissue containing high levels of interfering compounds, Electrophoresis. 24 (2003) 2369-2375.

[249] W. Wang, F. Tai, S. Chen, Optimizing protein extraction from plant tissues for enhanced proteomics analysis, J. Sep. Sci. 31 (2008) 2032-2039.

[250] D. Martínez-Maqueda, B. Hernández-Ledesma, L. Amigo, B. Miralles, J.Á. Gómez-Ruiz, Proteomics in Foods, in: F. Toldrá, L.M. Nollet (Eds.), Proteomics Foods Princ. Appl., Springer Science \& Business Media, 2013: pp. 181-203.

[251] E.A. Peñta-Ramos, Y.L. Xiong, Antioxidant activity of soy protein hydrolysates in a liposomal system, J. Food Sci. 67 (2002) 2952-2956.

[252] J. Carrasco-Castilla, A.J. Hernández-Álvarez, C. Jiménez-Martínez, C. Jacinto-Hernández, M. Alaiz, J. Girón-Calle, J. Vioque, G. Dávila-Ortiz, Antioxidant and metal chelating activities of Phaseolus vulgaris L. var. Jamapa protein isolates, phaseolin and lectin hydrolysates, Food Chem. 131 (2012) 1157-1164.

[253] P.A.C. McPherson, A. Bole, K.A. Cruz, I.S. Young, J. McEneny, A curvilinear approach to the kinetic analysis of linoleate peroxidation in aqueous liposomes by 2,2' azobis(2amidoinopropane) dihydrochloride, Chem. Phys. Lipids. 165 (2012) 682-688.

[254] C.C. Udenigwe, Y.L. Lu, C.H. Han, W.C. Hou, R.E. Aluko, Flaxseed protein-derived peptide fractions: antioxidant properties and inhibition of lipopolysaccharide-induced nitric oxide production in murine macrophages, Food Chem. 116 (2009) 277-284.

[255] H.G. Kristinsson, B.A. Rasco, Fish protein hydrolysates: production, biochemical, and functional properties, 2000.

[256] S.J. Hur, S.Y. Lee, Y.C. Kim, I. Choi, G.B. Kim, Effect of fermentation on the antioxidant activity in plant-based foods, Food Chem. 160 (2014) 346-356.

[257] M.Y. Jung, S.K. Kim, S.Y. Kim, Riboflavin-sensitized photooxidation of ascorbic acid: kinetics and amino acid effects, Food Chem. 53 (1995) 397-403. 
[258] B. Hernández-Ledesma, A. Dávalos, B. Bartolomé, L. Amigo, Preparation of antioxidant enzymatic hydrolysates from alpha-lactalbumin and beta-lactoglobulin. Identification of active peptides by HPLC-MS/MS., J. Agric. Food Chem. 53 (2005) 588-593.

[259] S.J. Heo, E.J. Park, K.W. Lee, Y.J. Jeon, Antioxidant activities of enzymatic extracts from brown seaweeds, Bioresour. Technol. 96 (2005) 1613-1623.

[260] B.H. Bielski, J.M. Gebicki, Study of peroxidase mechanisms by pulse radiolysis: III. The rate of reaction of $\mathrm{O} 2-$ and $\mathrm{HO} 2$ radicals with horse-radish peroxidase compound I, Biochim. Biophys. Acta (BBA)-Enzymology. 364 (1974) 233-235.

[261] M. Altarawneh, B.Z. Dlugogorski, Reactions of HO2 with n-propylbenzene and its phenylpropyl radicals, Combust. Flame. 162 (2015) 1406-1416.

[262] R. Singh, B. Wiseman, T. Deemagarn, V. Jha, J. Switala, P.C. Loewen, Comparative study of catalase-peroxidases (KatGs), Arch. Biochem. Biophys. 471 (2008) 207-214.

[263] M. Nishikawa, Reactive oxygen species in tumor metastasis, Cancer Lett. 266 (2008) 5359.

[264] S.W.A. Himaya, D.H. Ngo, B. Ryu, S.K. Kim, An active peptide purified from gastrointestinal enzyme hydrolysate of Pacific cod skin gelatin attenuates angiotensin-1 converting enzyme (ACE) activity and cellular oxidative stress, Food Chem. 132 (2012) 1872-1882.

[265] >J.M. Matés, Effects of antioxidant enzymes in the molecular control of reactive oxygen species toxicology, Toxicology. 153 (2000) 83-104.

[266] S.J. Tsai, M.C. Yin, Antioxidative and anti-inflammatory protection of oleanolic acid and ursolic acid in PC12 cells, J. Food Sci. 73 (2008) 174-178.

[267] J. Redón, M.R. Oliva, C. Tormos, V. Giner, J. Chaves, A. Iradi, G.T. Sáez, Antioxidant activities and oxidative stress byproducts in human hypertension, Hypertension. 41 (2003) 1096-1101.

[268] E. Mendis, N. Rajapakse, S.K. Kim, Antioxidant properties of a radical-scavenging peptide 
purified from enzymatically prepared fish skin gelatin hydrolysate, J. Agric. Food Chem. 53 (2005) 581-587.

[269] J.F. Ding, Y.Y. Li, J.J. Xu, X.R. Su, X. Gao, F.P. Yue, Study on effect of jellyfish collagen hydrolysate on anti-fatigue and anti-oxidation, Food Hydrocoll. 25 (2011) 1350-1353.

[270] L. You, M. Zhao, R.H. Liu, J.M. Regenstein, Antioxidant and antiproliferative activities of loach (Misgurnus anguillicaudatus) peptides prepared by papain digestion, J. Agric. Food Chem. 59 (2011) 7948-7953.

[271] M. Phelan, S.A. Aherne-Bruce, D. O’Sullivan, R.J. FitzGerald, N.M. O’Brien, Potential bioactive effects of casein hydrolysates on human cultured cells, Int. Dairy J. 19 (2009) 279-285.

[272] A.M. O’Sullivan, Y.C. O’Callaghan, M.N. O’Grady, B. Queguineur, D. Hanniffy, D.J. Troy, J.P. Kerry, N.M. O’Brien, In vitro and cellular antioxidant activities of seaweed extracts prepared from five brown seaweeds harvested in spring from the west coast of Ireland, Food Chem. 126 (2011) 1064-1070.

[273] K.N. Kim, S.J. Heo, C.B. Song, J. Lee, M.S. Heo, I.K. Yeo, K.A. Kang, J.W. Hyun, Y.J. Jeon, Protective effect of Ecklonia cava enzymatic extracts on hydrogen peroxide-induced cell damage, Process Biochem. 41 (2006) 2393-2401.

[274] P.J. Park, W.K. Jung, K.S. Nam, F. Shahidi, S.K. Kim, Purification and characterization of antioxidative peptides from protein hydrolysate of lecithin-free egg yolk, JAOCS, J. Am. Oil Chem. Soc. 78 (2001) 651-656.

[275] C. Torres-Fuentes, M.D.M. Contreras, I. Recio, M. Alaiz, J. Vioque, Identification and characterization of antioxidant peptides from chickpea protein hydrolysates, Food Chem. 180 (2015) 194-202.

[276] S. Yarnpakdee, S. Benjakul, H.G. Kristinsson, H.E. Bakken, Preventive effect of Nile tilapia hydrolysate against oxidative damage of $\mathrm{HepG} 2$ cells and DNA mediated by $\mathrm{H}_{2} \mathrm{O}_{2}$ and AAPH, J. Food Sci. Technol. 52 (2015) 6194-6205. 
[277] J.I. Chuang, T.Y. Chang, H.S. Liu, Glutathione depletion-induced apoptosis of Ha-rastransformed NIH3T3 cells can be prevented by melatonin., Oncogene. 22 (2003) 134957.

[278] K.H. Kang, Z.J. Qian, B. Ryu, F. Karadeniz, D. Kim, S.K. Kim, Antioxidant peptides from protein hydrolysate of microalgae navicula incerta and their protective effects in Hepg2/CYP2E1 cells induced by ethanol, Phyther. Res. 26 (2012) 1555-1563.

[279] G. Structure, C.B. Pickett, C. Hr, A.Y.H. Lu, Glutathione s-transferases: gene structure, regulation, and biological function, (2000).

[280] C.B. Ahn, J.Y. Je, Y.S. Cho, Antioxidant and anti-inflammatory peptide fraction from salmon byproduct protein hydrolysates by peptic hydrolysis, Food Res. Int. 49 (2012) 9298.

[281] L. Ouyang, Z. Shi, S. Zhao, F.T. Wang, T.T. Zhou, B. Liu, J.K. Bao, Programmed cell death pathways in cancer: A review of apoptosis, autophagy and programmed necrosis, Cell Prolif. 45 (2012) 487-498.

[282] S. Elmore, Apoptosis: a review of programmed cell death., Toxicol. Pathol. 35 (2007) 495-516.

[283] P.H. Krammer, the immune system B cells, 407 (2000) 789-795.

[284] J. Liu, Z. Chen, J. He, Y. Zhang, T. Zhang, Y. Jiang, Anti-oxidative and anti-apoptosis effects of egg white peptide, Trp-Asn-Trp-Ala-Asp, against $\mathrm{H}_{2} \mathrm{O}_{2}$-induced oxidative stress in human embryonic kidney 293 cells, Food Funct. 5 (2014) 3179-3188. 